NBER WORKING PAPER SERIES

\title{
THE DEPRESSING EFFECT OF AGRICULTURAL INSTITUTIONS ON THE PREWAR JAPANESE ECONOMY
}

\author{
Fumio Hayashi \\ Edward C. Prescott \\ Working Paper 12081 \\ http://www.nber.org/papers/w12081 \\ NATIONAL BUREAU OF ECONOMIC RESEARCH \\ 1050 Massachusetts Avenue \\ Cambridge, MA 02138 \\ March 2006
}

Earlier versions of the paper were presented on various occasions, including the 2003 Australasian Econometric Society Meeting in Sydney, a Seoul National University macro conference, the 2004 NBER Japan program meeting in Tokyo, the 2004 Taipei Conference on Macroeconomics and Development, and workshops at Arizona State University and University of Pennsylvania. We thank Serguey Braguinsky, Toni Braun, Steve Davis, John Fernald, Richard Rogerson, and David Weinstein for comments on earlier versions of the paper. Shuhei Aoki provided competent research assistance. Gratefully acknowledged is research support from Grants-in-Aid for Scientific Research No. 12124202 administered by the Ministry of Education, Culture, Sports, Science and Technology of the Japanese government and the National Science Foundation SES 0422539. The views expressed herein are those of the author(s) and do not necessarily reflect the views of the National Bureau of Economic Research.

(C2006 by Fumio Hayashi and Edward C. Prescott. All rights reserved. Short sections of text, not to exceed two paragraphs, may be quoted without explicit permission provided that full credit, including $\odot$ notice, is given to the source. 
The Depressing Effect of Agricultural Institutions on the Prewar Japanese Economy

Fumio Hayashi and Edward C. Prescott

NBER Working Paper No. 12081

March 2006

JEL No. E1, O1, O4, N3, N5

\begin{abstract}
The question we address in this paper is why the Japanese miracle didn't take place until after World War II. For much of the pre-WWII period, Japan's real GNP per worker was not much more than a third of that of the U.S., with falling capital intensity. We argue that its major cause is a barrier that kept agricultural employment constant at about 14 million throughout the prewar period. In our twosector neoclassical growth model, the barrier-induced sectoral mis-allocation of labor and a resulting disincentive for capital accumulation account well for the depressed output level. Were it not for the barrier, Japan's prewar GNP per worker would have been close to a half of the U.S. The labor barrier existed because, we argue, the prewar patriarchy, armed with paternalistic clauses in the prewar Civil Code, forced the son designated as heir to stay in agriculture.
\end{abstract}

\author{
Fumio Hayashi \\ Department of Economics \\ University of Tokyo \\ Tokyo 113-0033, Japan \\ and NBER \\ fumio.hayashi@gmail.com \\ Edward C. Prescott \\ Department of Economics \\ W. P. Carey School of Business \\ Arizona State University \\ Tempe, AZ 85287-3806 \\ edward.prescott@asu.edu
}




\section{Introduction}

The Japanese miracle, which lifted the Japanese economy from the ashes of the World War II destruction to the present-day prosperity, and the "lost decade" of the 1990s, during which the economy ceased to grow, are well known. Much less so is the decades-long stagnation before World War II: for much of the prewar period of 1885-1940, Japan's real GNP per worker remained a third of that of the U.S. This paper addresses the question of why the Japanese miracle didn't occur before the war.

An amazing fact about agricultural employment in prewar Japan is that it was virtually constant at 14 million persons (about $64 \%$ of total employment in 1885) throughout the entire prewar period, despite a very large urban-rural income disparity. There was a persistent and significant rural-to-urban emigration, but its size was never large enough to diminish rural population. The constancy strongly suggests that there was a powerful non-economic force that prevented people from moving out of agriculture and that the 14 million was a binding lower bound for agricultural employment.

This leads us to ask whether a possible sectoral mis-allocation of labor due to this barrier to labor mobility had a quantitatively important effect on the economic development of prewar Japan. We do so by a two-sector neoclassical growth model with agriculture. Our two-sector model builds on the long tradition of modeling the "dual economy" starting with Jorgenson (1961). ${ }^{1}$ Its most recent renditions are Echeverria (1997), Robertson (1999), Laitner (2000), Gollin, Parente, and Rogerson (2002), and others. They examine the interaction of Engel's Law and the dynamics of capital accumulation, which also is a focus of our paper.

Our paper is also related to the recent development accounting literature on international income differences, although our focus is exclusively on Japan in relation to the U.S. ${ }^{2}$ Vollrath (2005) finds for a number of countries that the sectoral allocation of labor and capital is inefficient because their marginal products are not equated across sectors. He finds that the factor market inefficiency accounts 90 to $100 \%$ of international differences in the overall (economy-wide) TFP. Restuccia, Yang, and Zhu (2004) show that sectoral distortions in the use of intermediate inputs and labor generate large international differences in the overall TFP. Our paper is similar to these papers in that we find a large effect on the overall TFP of a sectoral distortion (due, in our case, to the labor barrier) for prewar Japan. Unlike these

\footnotetext{
${ }^{1}$ Thus, contrary to the Lewisian tradition of development economics, we that agricultural workers are paid their marginal, not their average, product.

${ }^{2}$ See Caselli (2004) for a survey of the recent burgeoning literature on development accounting.
} 
papers, however, our analysis is dynamic in that we also examine the effect of the distortion on capital accumulation.

We show that our simple two-sector growth model, when the labor barrier is superimposed on it, can account for the prewar Japanese stagnation. We then lift the labor barrier to predict what would have happened to the prewar Japanese economy. This counter-factual simulation shows that prewar GNP per worker would have been higher by about $33 \%$, which would have placed Japan at close to a half, not a third, of the U.S. in terms of per-worker output. This substantial output gain comes about despite a tight grip of Engel's law. In our model, minimum food consumption is set at a very high fraction, $90 \%$, of food consumption in 1885. Given the state of technology for food and non-food production, however, the country did not need $64 \%$ of total employment in agriculture to feed its population in 1885 and after. The labor force released from agriculture upon the removal of the labor barrier would have been put to better use outside agriculture and the increased overall production efficiency would have sparked an investment boom.

The plan of the paper is as follows. The next section, Section 2, describes facts about Japan's economic development in more detail. Section 3 advances our sectoral mis-allocation hypothesis and summarizes our main results. This is followed by four sections of elaboration: a presentation of the two-sector growth model in Section 4, asymptotic properties of the model in Section 5, a calibration of the model in Section 6 , and simulation results in Section 7 . The issue of why there existed the barrier in the first place will be taken up in Section 8. Section 9 briefly states conclusions and an agenda for future research.

\section{Accounting for Japan's Economic Development Since 1885}

\section{The Postwar Miracle and Prewar Stagnation}

We start out with a look at aggregate output since 1885. The basic data source for prewar macro variables for Japan (Japan proper, excluding former colonies) is the Long Term Economic Statistics (hereafter LTES), a consistent system of national income accounts compiled by a group of Japanese academics. The reader is referred to Appendix 1 for how real GNP and other variables are constructed from the LTES and other sources. Figure 1 shows output per worker (real GNP divided by working-age population) for Japan 
and the U.S for 1885-2000, with Japan assumed to be about $71 \%$ of the U.S. for $1990 .^{3}$ The scale is in logs with a base of 2 , so a difference of 1.0 in the log scale represents a $100 \%$ difference in levels. The $\log$ difference for 1885 is 1.75 , which means U.S. per-worker GNP was about $3.4\left(=2^{1.75}\right)$ times Japan's (or Japan was about $30 \%$ of the U.S.) in 1885.

Figure 1: GNP Per Worker, 1885-2000

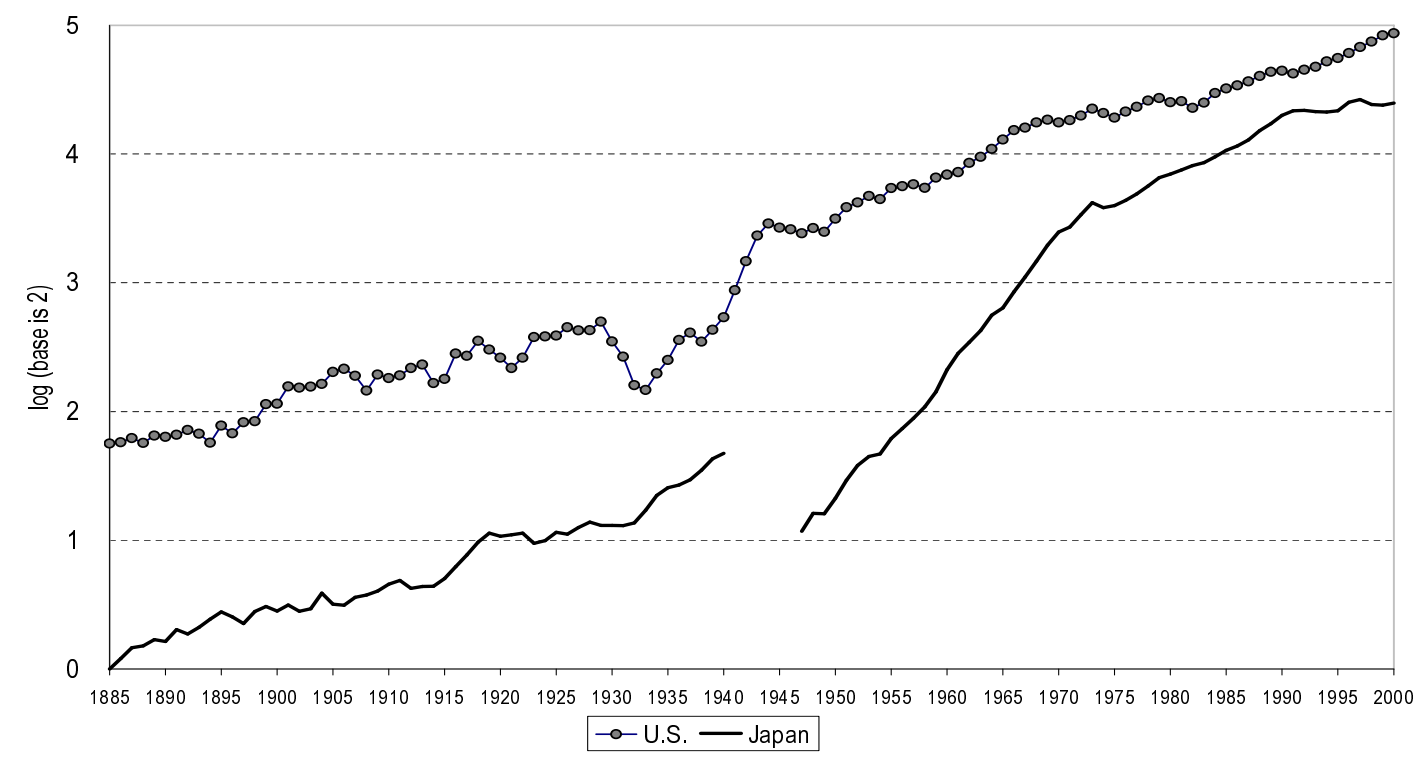

There are three features that would catch anyone's eye. The first is the fabulous growth in the postWorld War II era, known as the Japanese miracle. There was a five-fold increase in Japan's GNP per worker in 25 years since 1947. The second is the prewar stagnation of several decades: between 1885 and 1940, Japan's GNP per worker remained 30\% to 50\% of the U.S. GNP per worker. The average of the Japan-U.S. ratio of per-worker output is $36 \%$. The third feature is the stagnation in the 1990s. We have dealt with Japan's 1990s elsewhere (Hayashi and Prescott (2002)). The question we address in this paper is why the Japanese miracle didn't take place until after World War II.

\footnotetext{
${ }^{3}$ U.S. real GNP since 1929 is the chained real GNP from the U.S. NIPA (National Income and Product Accounts). Real GNP before 1929 is from Balke and Gordon (1989). The working-age population is the population 16 years or older for the U.S. and 15 or older for Japan until 1945 and 21 years or older for the U.S. and 20 or older for Japan after 1945. We assume that the ratio of Japan's per-worker GNP to that of the U.S. is $71.2 \%$ in 1998 . This ratio is implied by Maddison's (2001) estimate of GDP levels in 1990 international PPP dollars, placing Japan's GDP at 31.9\% of U.S. GDP for 1990. See his Tables A1-b and A-j.
} 


\section{Growth Accounting}

A very standard way to account for a country's growth is to define the (overall or macro) TFP (total factor productivity) as

$$
\operatorname{TFP}_{t} \equiv \frac{Y_{t}}{K_{t}^{\theta}\left(h_{t} E_{t}\right)^{1-\theta}}
$$

where $Y_{t}$ is aggregate output in period $t, K_{t}$ is aggregate capital stock, $E_{t}$ is employment, $h_{t}$ is average hours worked per employed person (so $h_{t} E_{t}$ equals total hours worked), and $\theta$ is capital's share of aggregate income. In the growth accounting calculations below, we set $\theta$ to the customary value of $1 / 3$. An easy algebra on this definition yields that GNP per worker can be decomposed into four factors:

$$
\frac{Y_{t}}{N_{t}}=\operatorname{TFP}_{t}^{\frac{1}{1-\theta}} \times\left(\frac{K_{t}}{Y_{t}}\right)^{\frac{\theta}{1-\theta}} \times\left(\frac{E_{t}}{N_{t}}\right) \times h_{t}
$$

where $N_{t}$ is working-age population. This formula shows that, in the long run where the capital intensity (i.e., the capital-output ratio, $\left.\frac{K_{t}}{Y_{t}}\right)$, the employment rate $\left(\frac{E_{t}}{N_{t}}\right)$, and hours worked per employed person $\left(h_{t}\right)$ are constant, the trend in GNP per worker $\left(\frac{Y_{t}}{N_{t}}\right)$ is given by the TFP factor TFP $P_{t}^{\frac{1}{1-\theta}}$. The power $\frac{1}{1-\theta}$ represents the magnification effect of TFP that an increase in TFP generates a proportionate increase in the capital stock, so the capital intensity factor $\left(\frac{K_{t}}{Y_{t}} \frac{\theta}{1-\theta}\right)$ represents only the part of capital accumulation not induced by TFP growth. ${ }^{4}$ The left-side, GNP per worker, has been graphed in Figure 1.

Table 1 reports the average annual growth rate of per-worker GNP and its four factors shown in (2.2) for prewar and postwar Japan. ${ }^{5}$ For the high-growth era of 1960-73, despite a decline in both the average hours worked per worker and the employment rate, a high per-worker GNP growth rate of $7.2 \%$ is brought about by a very high TFP growth and, less importantly, by a slight increase in capital intensity (a $0.8 \%$ growth in $\left(\frac{K_{t}}{Y_{t}}\right)^{\frac{\theta}{1-\theta}}$ ). For the prewar period, there was no increase in capital intensity: between 1885 and 1940, the capital-output ratio declined. The much lower TFP growth before the war than after means that the prewar TFP level was very low. This is described by the graph of the TFP factor $T F P_{t}^{\frac{1}{1-\theta}}$ in Figure 2 (for now, ignore the line labeled "without barrier"). Postwar TFP factor lies far above the dotted trend line extrapolated from the prewar period.

\footnotetext{
${ }^{4}$ This formula has been adopted by King and Levine (1994), Hayashi and Prescott (2002) and others. Klenow and Rodriguez-Clare (1997) has a discussion of the advantages and disadvantages of this form of growth accounting against the more standard form of decomposing output growth into TFP, capital growth, and labor growth.

${ }^{5}$ We use the deflator for non-agricultural goods to convert nominal capital stock into real capital stock in calculating $K$. This is to be consistent with the assumption of the paper's model that agricultural goods cannot be used as an investment good. See Appendix 1 for more details on how we defined real output $Y$ and the real capital stock K. Employment and hours worked are not adjusted for quality. The initial year for the postwar period is taken to be 1960 because the capital stock data in the Japanese national accounts for the early 1950s seems unreliable.
} 
Table 1: Growth Accounting

\begin{tabular}{|c|c|c|c|c|c|}
\hline \hline & \multicolumn{5}{|c|}{ average annual growth rate (in percents) of } \\
\hline & $\begin{array}{c}\text { per-worker GNP } \\
\frac{Y_{t}}{N_{t}}\end{array}$ & $\begin{array}{c}\text { TFP factor } \\
T F P_{t}^{\frac{1}{1-\theta}}\end{array}$ & $\begin{array}{c}\text { capital intensity } \\
\text { factor }\left(\frac{K_{t}}{Y_{t}}\right)^{\frac{\theta}{1-\theta}}\end{array}$ & $\begin{array}{c}\text { employment } \\
\text { rate } \frac{E_{t}}{N_{t}}\end{array}$ & $\begin{array}{c}\text { hours worked } \\
\text { per worker } h_{t}\end{array}$ \\
\hline $1885-1940$ & $2.1 \%$ & $2.9 \%$ & $-0.6 \%$ & $-0.4 \%$ & $0.2 \%$ \\
\hline $1960-1973$ & $7.2 \%$ & $7.3 \%$ & $0.8 \%$ & $-0.7 \%$ & $-0.2 \%$ \\
\hline
\end{tabular}

Note: Geometric means. $Y_{t}=\mathrm{GNP}, K_{t}=$ capital stock, $E_{t}=$ employment, $N_{t}=$ working-age population, $h_{t}=$ average hours per employed person. See (2.1) for the definition of TFP $. \theta=1 / 3$.

Figure 2: Japan's Overall TFP Factor, 1885-2000

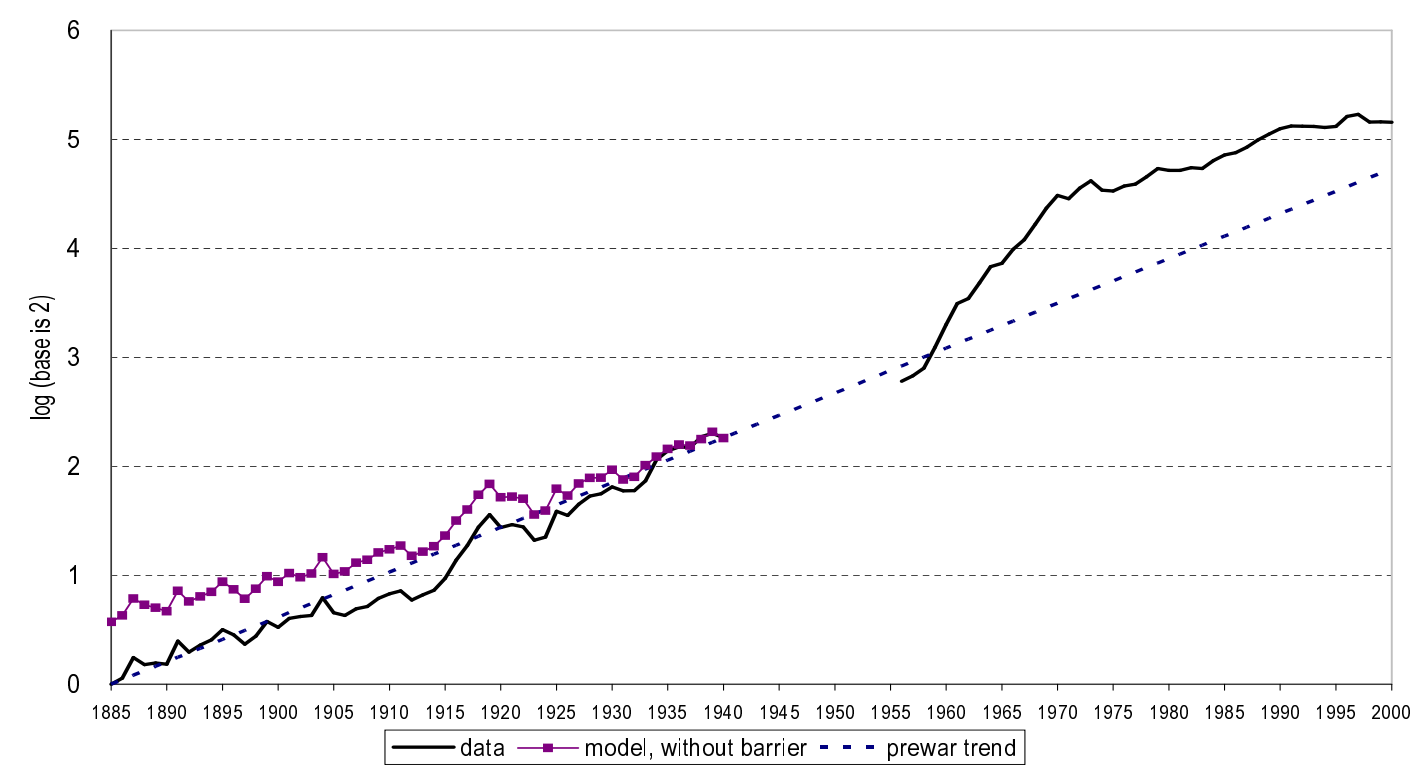

To summarize, Japan's prewar stagnation can be accounted for by the low level of overall TFP and falling capital intensity. 


\section{The Basic Idea and Summary of Results}

\section{The Sectoral Mis-allocation Hypothesis}

The thesis of this paper is that the labor barrier - a barrier limiting the extent of rural-to-urban emigration - contributed to Japan's pre-World War II stagnation. We were led to this thesis by the following observations. Figure 3 shows that employment in agriculture (here and elsewhere excluding forestry and fishery) was essentially constant at 14 million persons in prewar Japan. ${ }^{6}$ This figure strongly suggests that agricultural employment was constrained to be at least about 14 million. The figure also shows that, in sharp contrast to the prewar era, postwar Japan witnessed a steep decline in agricultural employment. As the labor force expands, a constant level of employment means a slowly declining employment share. This is shown in Figure 4, where the employment share of agriculture declined only gradually before the war and very sharply postwar. It took Japan 50 years to reduce the agricultural employment share from $60 \%$ to $40 \%$. In most other developed countries, the decline was faster: of 16 developed countries examined in Maddison (1991, Table C.5), agriculture's employment share in 1950 is highest for Japan (48.3\%), followed by Finland (46.0\%) and Italy (45.4\%).

${ }^{6}$ The source is Table 33, Volume 9 (covering agriculture) of LTES published in 1966. The estimation of employment in the LTES was carried out under the leadership of Mataji Umemura. His 1968 estimate of employment in agriculture (Umemura (1968)) differs from his 1966 estimate in that agricultural employment slowly declined to about 16 million by 1914, declined sharply to 14 million between 1914 and 1919, and stayed more or less constant at 14 million thereafter. However, more recent LTES estimate, included in Volume 2 (the lead author of the volume is Mataji Umemura) published in 1988, has agricultural employment virtually identical to the Volume 9 estimate. See Appendix 1 for a summary of the methodology used in estimating agricultural employment in the LTES. 
Figure 3: Employment in Agriculture, 1885-2003

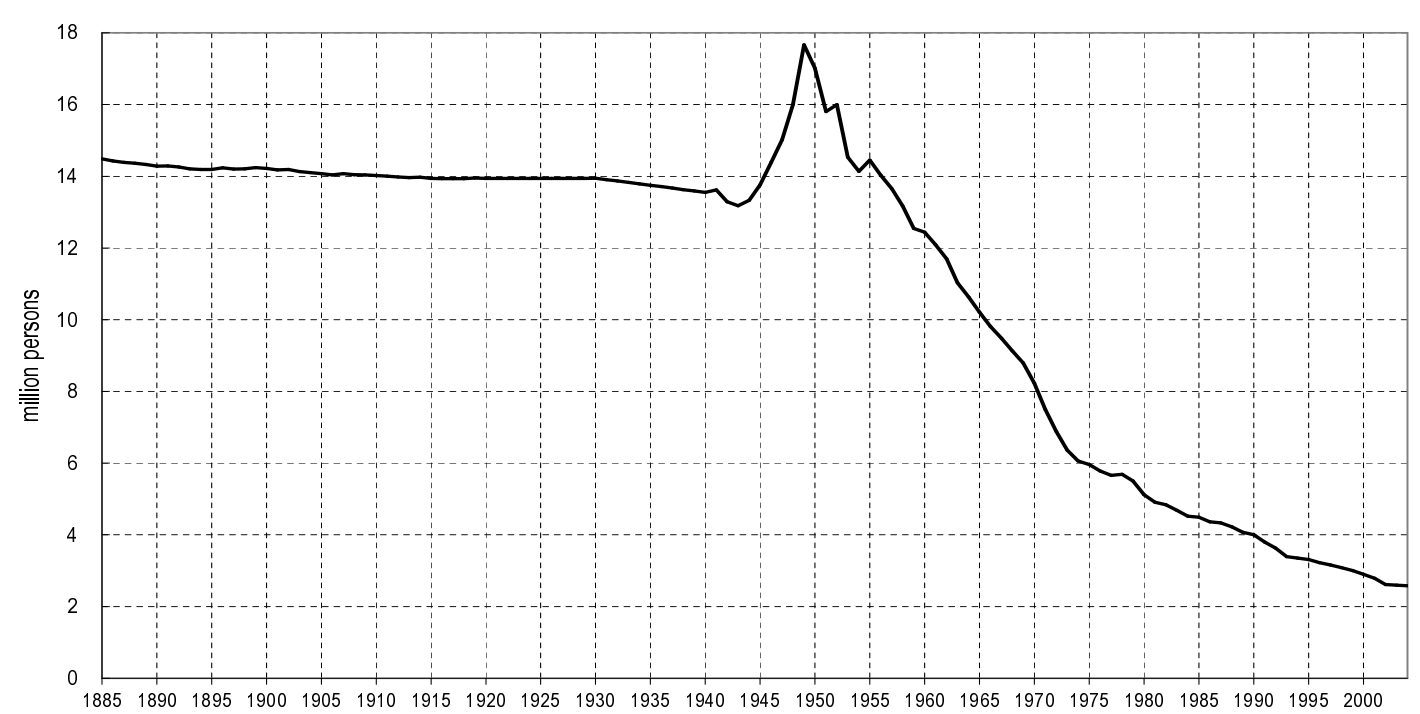

Figure 4: Agriculture's Employment Share

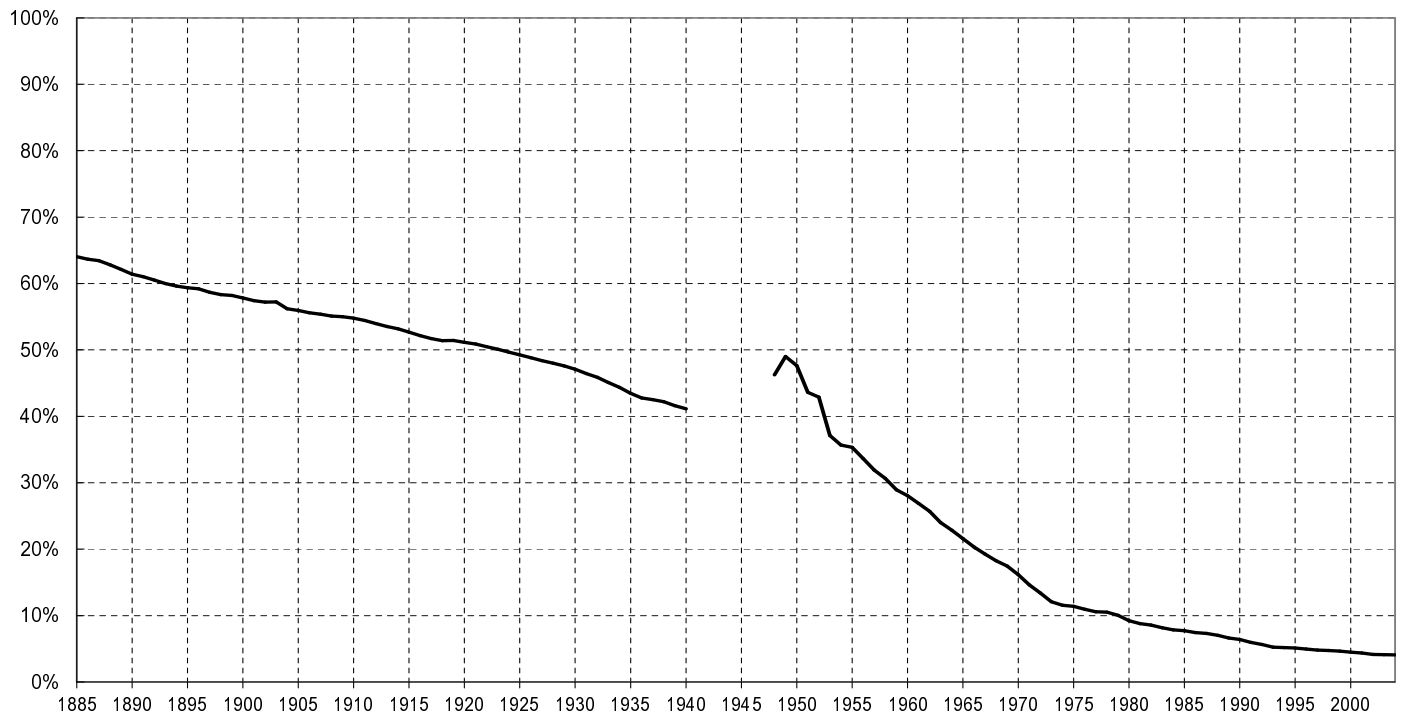

Thanks to the labor barrier setting the binding lower bound of 14 million on agricultural employment, there was too much labor tied up in the decreasing-returns-to-scale technology called agriculture. For reasons explored in Section 8, this barrier ceased to operate after World War II, which must have contributed at least in part to the rapid increase in the overall TFP in postwar Japan. Hansen and Prescott 
(2002) described the industrial revolution as a switch from a decreasing-returns-to-scale with respect to reproducible inputs technology (the Malthus technology) to a constant-returns-to-scale technology (the Solow technology). Our hypothesis can be rephrased as saying that the transition from Malthus to Solow was inhibited by the barrier to labor mobility.

\section{Main Results}

The rest of this paper formalizes our sectoral mis-allocation hypothesis for prewar Japan in a two-sector neoclassical growth model with agriculture and see to what extent the model with labor barrier can account for the prewar stagnation. The model's main features are as follows: (i) the actual path of sectoral TFPs (shown in Figure 5) is taken as given and was perfectly foreseen by agents as of 1885, (ii) the path of total employment is exogenously given to the model, (iii) the sectoral allocation of capital as well as capital accumulation are endogenous, (iv) the sectoral allocation of employment is endogenous, albeit subject to the labor barrier that sets the lower bound of 14 million for employment in the agricultural sector, and (v) a stringent Engel's law that the subsistence level of food consumption per worker is $90 \%$ of per-worker food consumption in 1885 . The paper's main results are the following.

Figure 5: Sectoral TFPs, $1885-1940(1885=100)$

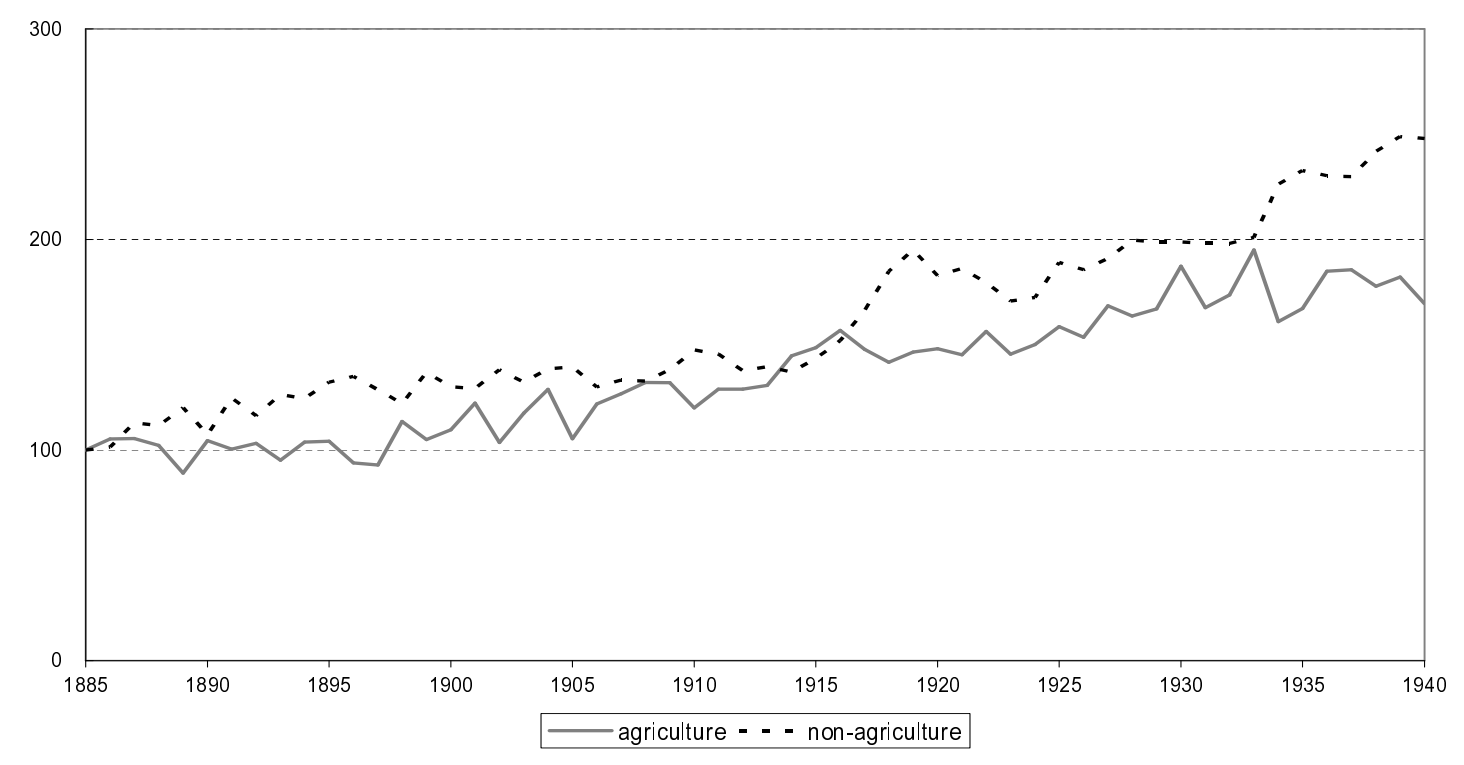

- Our simple two-sector model can account for the prewar stagnation. The simulation (i.e., the solution path of the model) in which the labor barrier is imposed tracks the prewar data closely. This is shown for per-worker GNP in Figure 6: the simulation represented by the dotted line labeled "with barrier" 
does not depart substantially from the actual - except for the post-World War I period where the model consistently over-predicts output (see below for more on the over-prediction for the interwar period). The lower bound for agricultural employment is binding throughout the prewar period.

Figure 6: GNP Per Worker, 1885-1940

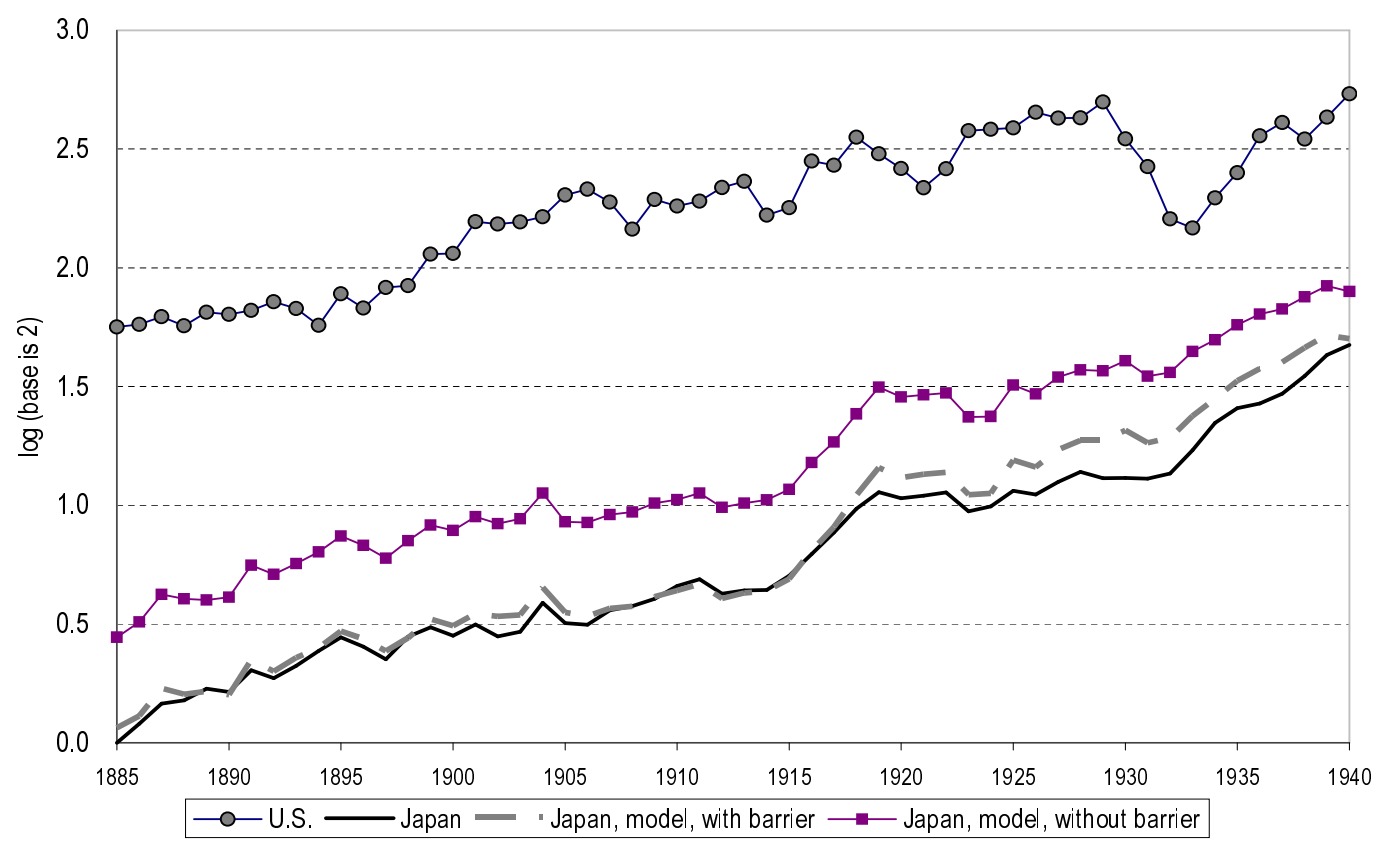

- The quantitative effect of the labor barrier is large. The counter-factual simulation - the solution path of the model that does not impose the labor barrier but still takes the sectoral TFPs as given - for per-worker GNP is the line labeled "without barrier" in Figure 6. Japan's GNP per worker, which was about a third of the U.S. level for much of the prewar period, would have been substantially higher (see Table 2 below for more quantitative information), were it not for the barrier.

- There are two main sources of this big gain in aggregate output. The first is a production efficiency gain due to the removal of the barrier. Going back to Figure 2, also shown in the figure is the overall TFP factor calculated from the counter-factual simulation. It shows that the removal of the barrierinduced mis-allocation of labor significantly raises the overall TFP. (The efficiency gain declines with time because the lower bound for agricultural employment gradually falls as a fraction of total employment.) The second is an investment boom sparked by the increased production efficiency. Figure 7 plots the capital stock per worker, $K_{t} / N_{t}$, for the three cases, actual and simulations with and without the barrier. In the counter-factual simulation (without the barrier), the capital stock rises 
sharply in the early prewar period when the improvement in overall production efficiency is greatest (see below for our comments on the interwar capital accumulation).

Figure 7: Capital Stock Per Worker, 1885-1940 (1885=100)

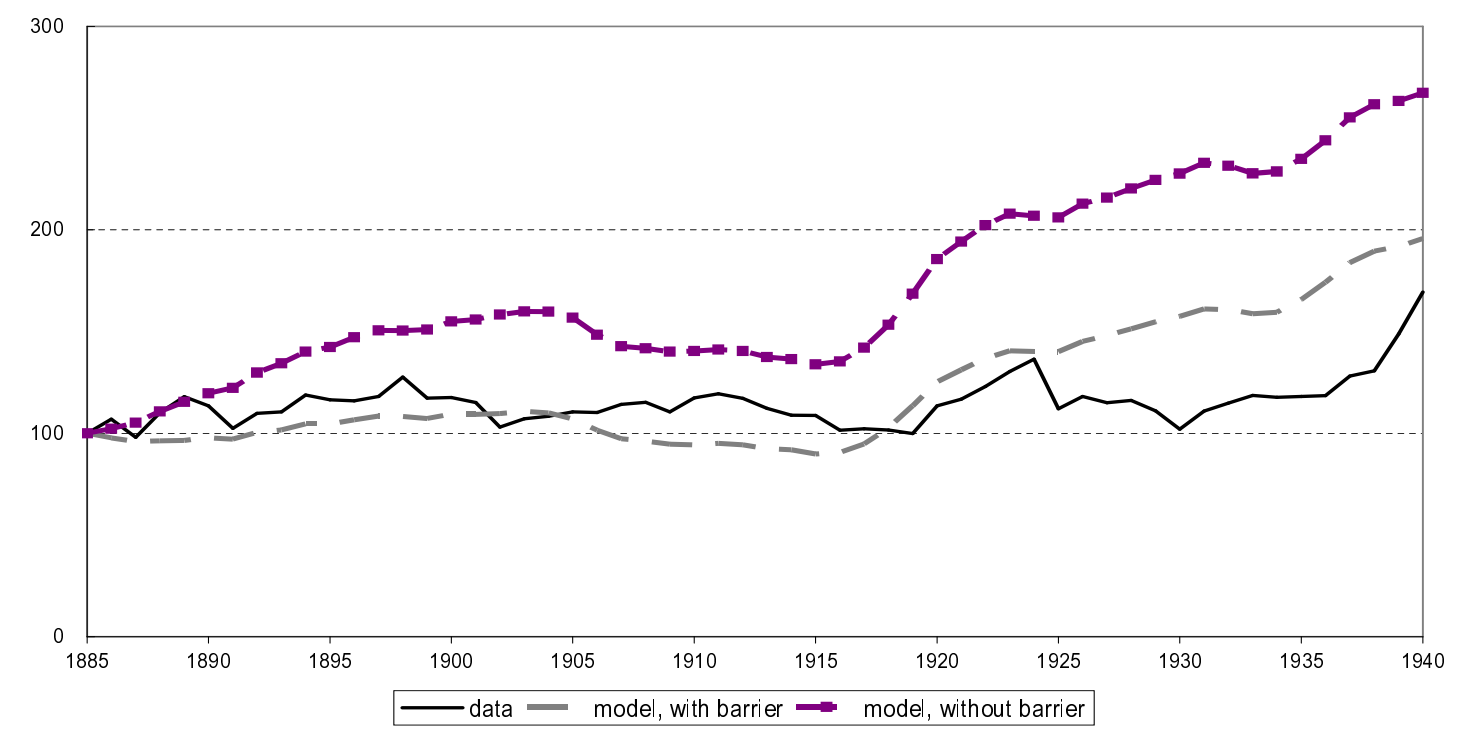

- These results are for a closed-economy version of the model in which food is a nontraded good. The ability of the model with the barrier to account for the prewar stagnation is undiminished even if food is a traded good. This is because too much labor forced upon agriculture makes the country nearly self-sufficient in food. The difference arises when the barrier is lifted. The small open-economy version of the model, if the barrier is not imposed, predicts that the country will specialize almost completely in good 2, thereby reaping a large gain from trade in addition to the gain in production efficiency and increased capital accumulation. However, as we will argue at the end of Section 7, such a large trade gain is unlikely because the production frontier describing the tradeoff between outputs of the two sectors is flat when the barrier is removed.

By way of summarizing, Table 2 reports the "level accounting", comparing actual prewar Japan with a hypothetical prewar Japan without the barrier predicted by the closed-economy version of the model. It measures the effect of lifting the labor barrier on each of the factors in (2.2) by calculating the prewar mean of the ratio of the factor from the counterfactual simulation to the actual value. It shows that the prewar output gain, which is $33 \%$ on average, comes from three sources: the improvement in overall efficiency (already shown in Figure 2), a rapid capital accumulation raising capital intensity, and, less importantly, a gain in average hours worked $h_{t}$. This last factor comes about because the employment 
share of agriculture (where hours worked are slightly lower) is lower in the counter-factual simulation (41\% of total employment in 1885).

Table 2: Level Accounting for 1885-1940, actual vs. counter-factual

\begin{tabular}{|l|c||c|c|c|c|}
\hline \hline & $\frac{Y_{t}}{N_{t}}$ & $T F P_{t}^{\frac{1}{1-\theta}}$ & $\left(\frac{K_{t}}{Y_{t}}\right)^{\frac{\theta}{1-\theta}}$ & $\frac{E_{t}}{N_{t}}$ & $h_{t}$ \\
\hline geometric mean of value without barrier for year $t$ & 1.33 & 1.24 & 1.04 & 1 & 1.02 \\
\hline
\end{tabular}

Note: See footnote to Table 1 for definition of symbols. Because the counter-factual simulation uses actual $E_{t}$ and $N_{t}$, the ratio for the employment rate $\frac{E_{t}}{N_{t}}$ is unity by construction.

Before turning to model specifics, two caveats should be noted.

- Our sectoral mis-allocation alone does not account for the low level of prewar overall TFP described in Figure 2. Studies on Japan's postwar growth accounting show that the non-agricultural TFP rose sharply precisely when the overall TFP did in the postwar period. ${ }^{7}$ With the sharp rise in the sectoral TFPs not taking place until after the war, the removal of the labor barrier alone is not enough to lift the prewar trend line of overall TFP to the postwar level.

- The model has difficulty tracking the capital stock in the interwar period. As seen in Figure 6, the simulation with labor barrier over-predicts interwar output. It comes about because the model wants to respond to the rise in non-agricultural TFP after World War I (shown in Figure 5) by raising the capital stock (see Figure 7). Why the actual capital stock ceased to increase after the mid 1920s is a puzzle to us. Perhaps it has to do with the rapid cartelization in the $1930 .{ }^{8}$

\section{The Two-Sector Model}

In this section we present our two-sector growth model. The first sector is agriculture and the second sector is the rest of the economy. Output of sector 1 will be referred to as good 1 or food.

\footnotetext{
${ }^{7}$ For example, a very detailed disaggregated study by Nomura (2004), which is unique in its inclusion of the 1960s, shows (see his Table 4-28) that the Japan-U.S. TFP ratio (defined as the ratio of Japan's TFP to U.S. TFP) for the whole economy increased from 0.487 in 1960 to 0.813 in 2000. There was a large decline in the TFP ratio for agriculture from 1.199 in 1960 to 0.737 in 2000 but there was also a rapid TFP growth in manufacturing. The TFP ratio for autos, for example, shot up from 0.680 in 1960 to 1.391 in 2000.

${ }^{8}$ According to Takahashi (1975), the number of cartels jumped from the pre-World War I figure of 7 to 12 in the 1920s and to 48 after 1930.
} 


\section{Households}

There is a stand-in household with $N_{t}$ working-age members at date $t$. The size of the household evolves over time exogenously. The stand-in household's utility function is

$$
\sum_{t=0}^{\infty} \beta^{t} N_{t} u\left(c_{1 t}, c_{2 t}\right)
$$

where $c_{j t}$ is per-member consumption of $\operatorname{good} j(j=1,2)$.

Measure $E_{t}$ of the household work. The household takes total employment $E_{t}$ as given and decides how it is divided between employment in sector $1\left(E_{1 t}\right)$ and in sector $2\left(E_{2 t}\right)$ (subject to the labor barrier to be introduced shortly). If employed in sector $j$, the member works for $h_{j t}$ hours per unit period $(j=1,2)$. Hours worked $\left(h_{1 t}, h_{2 t}\right)$ are exogenously given to the household. If $w_{j t}$ is the wage rate in sector $j$ and $s_{E t} \equiv E_{1 t} / E_{t}$ is the fraction of employment in sector 1, the household's total labor income is

$$
w_{1 t} h_{1 t} E_{1 t}+w_{2 t} h_{2 t} E_{2 t}=\left[w_{2 t} h_{2 t}+\left(w_{1 t} h_{1 t}-w_{2 t} h_{2 t}\right) S_{E t}\right] E_{t} .
$$

There is a barrier to labor mobility requiring employment in sector 1 to be at least $\bar{E}_{1 t}$ :

$$
\text { (the labor barrier) } \quad E_{1 t} \geq \bar{E}_{1 t} \text { i.e., } E_{1 t} / E_{t} \equiv s_{E t} \geq \bar{s}_{E t} \equiv \bar{E}_{1 t} / E_{t} \text {. }
$$

Looking at the expression (4.2) for labor income, we can easily see that the household will set $s_{E t}$ to the minimum possible value of $\bar{s}_{E t}$ (i.e., the labor barrier will be binding) if the income ratio $\frac{w_{11} h_{1 t}}{w_{2 t} h_{2 t}}$ is less than unity, to the maximum possible value of unity if it is greater than unity, and to any value between the minimum and the maximum if there is no income disparity. Thus the household's choice of $s_{E t}$ is the following correspondence (set-valued function) of the sectoral income ratio $\frac{w_{1 t} h_{1 t}}{w_{22} h_{2 t}}$ :

$$
s_{E t}=\left\{\begin{array}{l}
\bar{s}_{E t} \text { if } \frac{w_{1 t} h_{1 t}}{w_{2 t} h_{2 t}}<1, \\
1 \text { if } \frac{w_{11} h_{1 t}}{w_{2 t} h_{2 t}}>1, \\
{\left[\bar{s}_{E t}, 1\right] \text { if } \frac{w_{11} h_{1 t}}{w_{2 t} h_{2 t}}=1 .}
\end{array}\right.
$$

There are two other sources of income for the household. First, if $N_{t} k_{t}$ is the capital stock owned by the household (so $k_{t}$ is the capital stock per worker), its rental income is $r_{t} N_{t} k_{t}$. Unlike labor, we assume no barrier to capital mobility between sectors, so the rental rate $r_{t}$ does not depend on which sector rents capital. ${ }^{9}$ Second, there is a rent earned from land, an input to sector 1's production. The period-budget

\footnotetext{
${ }^{9}$ The rental rate is net of intermediation costs. See below on firms in sector 2.
} 
constraint for the household, then, is

$$
q_{t} N_{t} c_{1 t}+N_{t} c_{2 t}+N_{t+1} k_{t+1}-\left(1-\delta_{t}\right) N_{t} k_{t}=w_{1 t} h_{1 t} E_{1 t}+w_{2 t} h_{2 t} E_{2 t}+r_{t} N_{t} k_{t}-\tau_{t}\left(r_{t}-\delta_{t}\right) N_{t} k_{t}-\pi_{t}
$$

where $\delta_{t}$ is the depreciation rate (allowed to be time-dependent), $q_{t}$ is the relative price of good 1 in terms of good $2, \tau_{t}$ is the tax rate on net-of-depreciation capital income, and $\pi_{t}$ is taxes other than the capital income tax less land rent. The second good is the numeraire. So, for example, $w_{1 t}$ is the sector 1 wage rate in terms of good 2. Since hours worked as well as total employment $E_{t}$ are exogenous, the tax on labor income is not distortionary and is included in $\pi_{t}$.

With $s_{E t}\left(\equiv E_{1 t} / E_{t}\right)$ determined according to (4.4) for each $t$ and thus with the path of labor income $w_{1 t} h_{1 t} E_{1 t}+w_{2 t} h_{2 t} E_{2 t}$ given, the stand-in household chooses a sequence $\left\{c_{1 t}, c_{2 t}, k_{t+1}\right\}_{t=0}^{\infty}$ so as to maximize its utility (4.1) subject to the sequence of period-budget constraints (4.5) for $t=0,1,2, \ldots$ If $\beta^{t} \lambda_{t}^{-1}$ is the Lagrange multiplier for the period $t$ budget constraint (i.e., if $\lambda_{t}$ is the ratio of $\beta^{t}$ to the Lagrange multiplier), the first-order conditions with respect to $\left(c_{1 t}, c_{2 t}, k_{t+1}\right)$ are given by

$$
\begin{gathered}
\frac{\partial u\left(c_{1 t}, c_{2 t}\right)}{\partial c_{1 t}}=\frac{q_{t}}{\lambda_{t}}, \\
\frac{\partial u\left(c_{1 t}, c_{2 t}\right)}{\partial c_{2 t}}=\frac{1}{\lambda_{t}}, \\
\lambda_{t+1}=\beta \lambda_{t}\left[1+\left(1-\tau_{t+1}\right)\left(r_{t+1}-\delta_{t+1}\right)\right] .
\end{gathered}
$$

Since $\lambda_{t}$ is the reciprocal of the Lagrange multiplier for the budget constraint, it measures how wealthy the consumer is. The first-order conditions for consumption, (4.6) and (4.7), can be solved to obtain the Frisch demand system:

$$
c_{1 t}=c_{1}\left(q_{t}, \lambda_{t}\right) \text { and } \quad c_{2 t}=c_{2}\left(q_{t}, \lambda_{t}\right)
$$

Finally, the the transversality condition is

$$
\lim _{t \rightarrow \infty} \frac{\beta^{t} \lambda_{t}^{-1} k_{t}}{R_{1} \cdot R_{2} \cdots R_{t}}=0 \text { where } R_{t} \equiv 1+\left(1-\tau_{t}\right)\left(r_{t}-\delta_{t}\right)
$$

\section{Firms}

The production function for sector 1 is

$$
Y_{1 t}=T F P_{1 t} K_{1 t}^{\theta_{1}} L_{1 t^{\prime}}^{\eta}
$$

where $T F P_{1 t}$ is the sector's total factor productivity, $K_{1 t}$ is capital input (demand for capital services), and $L_{1 t}$ is labor input (total hours worked demanded) in sector 1. Land is the third input, but since 
it is constant, its contribution is submerged in the TFP. Because of the existence of the fixed factor of production, we have a decreasing returns to scale in capital and labor: $\theta_{1}+\eta<1$. The first-order conditions, which equate marginal productivities to factor prices, for firms in sector 1 are

$$
\begin{aligned}
r_{t} & =\theta_{1} q_{t} \operatorname{TFP}_{1 t} K_{1 t}^{\theta_{1}-1} L_{1 t^{\prime}}^{\eta} \\
w_{1 t} & =\eta q_{t} \operatorname{TFP}_{1 t} K_{1 t}^{\theta_{1}} L_{1 t}^{\eta-1} .
\end{aligned}
$$

Production in sector 2 does not require land and exhibits constant returns to scale:

$$
Y_{2 t}=T F P_{2 t} K_{2 t}^{\theta_{2}} L_{2 t}^{1-\theta_{2}}
$$

Unlike in sector 1, capital input in sector 2 involves costly financial intermediation. That is, if the household wishes to rent machines to sector 2, those machines need to be deposited at a bank. The bank then rents out those machines to firms in sector 2. This financial intermediation is costly because the bank incurs a cost of $\phi$ per machine for this intermediation service. This means that the rental rate faced by firms in sector 2 is $r_{t}+\phi$, while the rental rate for the household net of the intermediation cost is $r_{t}$ (as assumed in the household budget constraint (4.5)). Therefore, the first-order conditions for sector 2 is

$$
\begin{aligned}
r_{t}+\phi & =\theta_{2} \operatorname{TFP}_{2 t}\left(\frac{K_{2 t}}{L_{2 t}}\right)^{\theta_{2}-1}, \\
w_{2 t} & =\left(1-\theta_{2}\right) \operatorname{TFP}_{2 t}\left(\frac{K_{2 t}}{L_{2 t}}\right)^{\theta_{2}} .
\end{aligned}
$$

There are two reasons for assuming costly intermediation, one having to do with model calibration and the other with realism. First, the low level of capital intensity in prewar Japan means a high level of marginal productivity of capital. For the Euler equation (see (6.6) below) requiring consumption growth to be equated with the net rate of return from capital, we need a wedge between the gross return and the net return over and above depreciation. Second, there is some evidence that prewar intermediation costs were substantial. The long-term data on bank lending rate compiled by Fujino and Akiyama (1977) shows that the average spread (the difference between the bank lending rate and the time deposit rate) for $1899-1940$ was $4.0 \%$.

\section{Was Food a Nontraded Good?}

To state market equilibrium conditions, we need to decide if food (sector 1 output or good 1) is a nontraded good. The data on material balance for food, shown in Table 3, indicate to us that, as a first approximation, food was a nontraded good because net imports (imports less exports) of food were for most years less than $10 \%$ of domestic production. An alternative explanation of the unimportance 
of food imports is that food was freely tradable but the abundant labor input to agriculture due to the labor barrier made it unnecessary for the country to import food. We solved the model under these two alternative assumptions about the tradability of food and found that the solution is not sensitive to the assumption, provided that the labor barrier is imposed on the model. However, when the barrier is lifted, the model solution depends very much on whether the food market is open or not. We proceed under the assumption that food is a nontraded good and postpone our discussion of the open-economy case until the last two subsections of Section 7 , because for reasons stated there we find the prediction of the open-economy version of the model implausible.

Table 3: Food Material Balance for Selected Years in Millions of 1934-36 Yen

\begin{tabular}{|c|c|c|c|c|c|}
\hline \hline year & (1) domestic production & $(2)$ exports & $(3)$ imports & $\begin{array}{c}\text { (4) domestic consumption } \\
\text { (equals (1)-(2)+(3)) }\end{array}$ & $\begin{array}{c}\text { (5) net imports ratio } \\
\text { (equals ((3)-(2)/(1))) }\end{array}$ \\
\hline 1885 & $1,464.2$ & 36.6 & 3.7 & $1,431.3$ & $-2.2 \%$ \\
\hline 1900 & $1,846.3$ & 36.3 & 43.2 & $1,853.2$ & $0.4 \%$ \\
\hline 1910 & $2,135.2$ & 59.8 & 98.9 & $2,174.3$ & $1.8 \%$ \\
\hline 1920 & $2,867.8$ & 42.9 & 225.2 & $3,050.1$ & $6.4 \%$ \\
\hline 1930 & $3,202.7$ & 84.1 & 535.6 & $3,654.2$ & $14.1 \%$ \\
\hline 1939 & $3,450.5$ & 91.8 & 431.7 & $3,790.5$ & $9.9 \%$ \\
\hline
\end{tabular}

Note: Food here refers to the output of the agricultural sector (see Appendix 1 for a precise definition). The deflator for sector 1 output is used to convert nominal figures into real. The data source is LTES. See Appendix 1 for definition of the variables including food exports and imports.

\section{Market Equilibrium}

If sector 1 output (i.e., food) is nontraded, the market equilibrium condition for good 1 is (4.17) below. The second good can be either consumed or invested. We also assume that government purchases $G_{t}$ are on the second good. Thus the market equilibrium conditions are (recall that $s_{E t} \equiv E_{1 t} / E_{t}$ )

$$
\begin{aligned}
& (\operatorname{good} 1) \quad N_{t} c_{1 t}=Y_{1 t}, \\
& (\text { good } 2) N_{t} c_{2 t}+\left(N_{t+1} k_{t+1}-\left(1-\delta_{t}\right) N_{t} k_{t}\right)+G_{t}=Y_{2 t}-\phi K_{2 t}, \\
& \text { (capital services) } K_{1 t}+K_{2 t}=N_{t} k_{t}, \\
& \text { (labor in sector 1) } L_{1 t}=h_{1 t} s_{E t} E_{t}, \\
& \text { (labor in sector 2) } L_{2 t}=h_{2 t}\left(1-s_{E t}\right) E_{t} .
\end{aligned}
$$


In the equilibrium condition for good 2, the supply of good 2 is $Y_{2 t}-\phi K_{2 t}$, not $Y_{2 t}$, because of the resource dissipation incurred in moving capital from the household to sector 2.

A competitive equilibrium given the initial per-worker capital stock $k_{0}$ and the sequence of exogenous variables $\left\{G_{t}, E_{t}, h_{1 t}, h_{2 t}, T F P_{1 t}, T F P_{2 t}, \delta_{t}, \tau_{t}\right\}_{t=0}^{\infty}$ is a sequence of prices and quantities, $\left\{\lambda_{t}, q_{t}, w_{1 t}, w_{2 t}, r_{t}\right.$, $\left.k_{t+1}, K_{1 t}, K_{2 t}, s_{E t}, L_{1 t}, L_{2 t}\right\}_{t=0}^{\infty}$, satisfying the following conditions:

(i) the household's first-order conditions (4.4), (4.8), and (4.9), and the transversality condition (4.10),

(ii) the firms' first-order conditions (4.12), (4.13), (4.15), and (4.16),

(iii) the market-clearing conditions (4.17)-(4.21),

where $Y_{1 t}$ is given by (4.11) and $Y_{2 t}$ by (4.14).

Two remarks about the model:

- The model is "closed" in that food is a nontraded good, but the country can lend or borrow good 2 to and from abroad. As in Hayashi and Prescott (2002), we treat foreign capital (claims on the rest of the world) as part of the capital stock, so investment here $\left(N_{t+1} k_{t+1}-\left(1-\delta_{t}\right) N_{t} k_{t}\right)$ is the sum of domestic investment and the current account, and $q_{t} Y_{1 t}+Y_{2 t}$ is GNP (in terms of good 2), not GDP. This treatment of foreign capital implies an imperfect mobility of capital in that the rate of return on foreign capital is not exogenously given to the country. Appendix 5 shows that the sector 2 production function defined over total (domestic plus foreign) capital and labor can be derived from two technologies, one describing domestic output defined over domestic capital and labor, and the other describing the return from foreign capital. The Appendix also shows that the derived production function is essentially Cobb-Douglas for a particular form of imperfect capital mobility and a Cobb-Douglas production function for domestic output.

- As is standard in the real business-cycle models with non-distortionary taxes, the sequence of taxes is not included in the equilibrium conditions, because the amount of the lump-sum tax is endogenously determined so that the government budget constraint holds period-by-period. By the Ricardian equivalence, any other sequence of taxes with the same present value results in the same competitive equilibrium. This also means that the household budget constraint doesn't need to be included as part of the equilibrium conditions because it is implied by the market-clearing conditions, the government budget constraint, and the factor exhaustion condition (that payments to factors of production, including land, sum to output). 


\section{Reducing Equilibrium Conditions into a Two-Equation Detrended Dynamical System}

There are two trends in this two-sector economy. Define

$$
X_{Y t} \equiv T F P_{2 t}^{\frac{1}{1-\theta_{2}}} h_{2 t} E_{t} / N_{t} \quad \text { and } \quad X_{Q t} \equiv T F P_{1 t}^{-1}\left(h_{1 t} E_{t}\right)^{-\eta} T F P_{2 t}^{\frac{1-\theta_{1}}{1-\theta_{2}}}\left(h_{2 t} E_{t}\right)^{1-\theta_{1}}
$$

To anticipate, $X_{Q t}$ will be the trend for the relative price $q_{t}$, while $X_{Y t}$ serves to detrend $\lambda_{t}$ as well as per-worker quantities related to sector 2 such as $k_{t}, Y_{2 t} / N_{t}$, and $c_{2 t}$. Per-worker quantities related to sector 1 , such as $Y_{1 t} / N_{t}$ and $c_{1 t}$, are detrended by $X_{Y t} / X_{Q t}$. Therefore, sector 1's nominal output share, $\frac{q_{t} Y_{1 t}}{q_{t} Y_{1 t}+Y_{2 t}}$, will have no trend. We will assume that the sector 1 trend, $X_{Y t} / X_{Q t}$, grows without limit. If $X_{Q}$, too, grows (which is the case in our calibration of the model), then per-worker output grows for both sectors but sector 1 will become asymptotically insignificant in real terms.

Let detrended variables $\tilde{k}_{t}, \tilde{\lambda}_{t}$ and $\tilde{q}_{t}$ be defined by

$$
\tilde{k}_{t} \equiv \frac{k_{t}}{X_{Y t}}, \tilde{\lambda}_{t} \equiv \frac{\lambda_{t}}{X_{Y t}}, \tilde{q}_{t} \equiv \frac{q_{t}}{X_{Q t}}
$$

and let $s_{K t}$ be the capital share of sector 1 and $\psi_{t}$ be the government's share of sector 2 output:

$$
s_{K t} \equiv \frac{K_{1 t}}{K_{1 t}+K_{2 t}}, \quad \psi_{t} \equiv \frac{G_{t}}{Y_{2 t}} .
$$

It is shown in Appendix 2 (and in Appendix 3 for the case with intermediate inputs) that the above equilibrium conditions (i)-(iii) imply the following two nonlinear difference equations:

$$
\text { (resource constraint) } \frac{N_{t+1}}{N_{t}} \frac{X_{Y, t+1}}{X_{Y t}} \tilde{k}_{t+1}=\left[\left[1-\delta_{t}-\left(1-s_{K t}\right) \phi\right] \tilde{k}_{t}+\left(1-\psi_{t}\right) \tilde{y}_{2 t}-\frac{c_{2}\left(\tilde{q}_{t} X_{Q t}, \tilde{\lambda}_{t} X_{Y t}\right)}{X_{Y t}}\right],
$$

$$
\text { (Euler equation) } \quad \frac{X_{Y, t+1}}{X_{Y t}} \tilde{\lambda}_{t+1}=\beta \tilde{\lambda}_{t}\left\{1+\left(1-\tau_{t+1}\right)\left[\theta_{2} \frac{\tilde{y}_{2, t+1}}{\left(1-s_{k, t+1}\right) \tilde{k}_{t+1}}-\phi-\delta_{t+1}\right]\right\},
$$

where

$$
\tilde{y}_{2 t} \equiv \tilde{k}_{t}^{\theta_{2}}\left(1-s_{K t}\right)^{\theta_{2}}\left(1-s_{E t}\right)^{1-\theta_{2}}
$$

This is a dynamical system in two variables, the detrended capital stock $\tilde{k}_{t}$ and the detrended shadow price $\tilde{\lambda}_{t}$, because the other endogenous variables appearing in the system, $\left(s_{K t}, s_{E t}, \tilde{q}_{t}\right)$, are functions of $\left(\tilde{k}_{t}, \tilde{\lambda}_{t}\right)$.

Those functions relating $\left(\tilde{k}_{t}, \tilde{\lambda}_{t}\right)$ to $\left(s_{K t}, s_{E t}, \tilde{q}_{t}\right)$ can be obtained as follows (see Appendix 2 for more details). The market equilibrium condition for good 1 (4.17) and the equality of the marginal products 
of capital between two sectors (implied by (4.12) and (4.15)) can be written as

$$
\begin{gathered}
\text { (market equilibrium for good 1) } \quad \frac{\tilde{q}_{t} c_{1}\left(\tilde{q}_{t} X_{Q t}, \tilde{\lambda}_{t} X_{Y t}\right)}{X_{Y t} / X_{Q t}}=\tilde{q}_{t} \tilde{y}_{1 t}, \\
\text { (equqlity of marginal products of capital) } \quad \theta_{1} \frac{\tilde{q}_{t} \tilde{y}_{1 t}}{s_{K t} k_{t}}+\phi=\theta_{2} \frac{\tilde{y}_{2 t}}{\left(1-s_{K t}\right) k_{t}},
\end{gathered}
$$

where

$$
\tilde{y}_{1 t} \equiv \tilde{k}_{t}^{\theta_{1}} s_{K t}^{\theta_{1}} s_{E t}^{\eta} .
$$

Furthermore, when $\bar{s}_{E t}$ is low enough so that the labor barrier is not binding, we have $w_{1 t} h_{1 t}=w_{2 t} h_{2 t}$ or $\frac{w_{11} h_{1 t}}{w_{2 t} h_{2 t}}=1$, which can be reduced to

$$
\text { (equality of sectoral incomes) } \frac{\eta \frac{\tilde{q}_{t} \tilde{y}_{1 t}}{s_{E t}}}{\left(1-\theta_{2}\right) \frac{\tilde{y}_{2 t}}{1-s_{E t}}}=1 .
$$

For each period $t$, given $\left(\tilde{k}_{t}, \tilde{\lambda}_{t}\right)$, we can solve (4.28), (4.29), and (4.31) for $\left(s_{K t}, s_{E t}, \tilde{q}_{t}\right)$. If the $s_{E t}$ thus obtained does not satisfy the labor barrier $s_{E t} \geq \bar{s}_{E 1 t}$, then we set $s_{E t}=\bar{s}_{E t}$ and use (4.28) and (4.29) to solve for $\left(s_{K t}, \tilde{q}_{t}\right)$. Appendix 2 shows that this procedure solves for the equilibrium under the inequality constraint $s_{E t} \geq \bar{s}_{E t}$.

By way of summarizing this subsection, let $\mathbf{x}_{t} \equiv\left(\tilde{k}_{t}, \tilde{\lambda}_{t}\right)$ and $\mathbf{y}_{t} \equiv\left(s_{K t}, s_{E t}, \tilde{q}_{t}\right)$, and write the twoequation dynamical system (4.25) and (4.26) as

$$
\mathbf{x}_{t+1}=\mathbf{f}_{t}\left(\mathbf{x}_{t}, \mathbf{y}_{t}\right), \mathbf{y}_{t}=\mathbf{g}_{t}\left(\mathbf{x}_{t}\right)
$$

Here, $\mathbf{g}$ is the function described in the previous paragraph that determines $\mathbf{y}_{t}$ subject to the labor barrier. In standard one-sector real business cycle models, the relevant dynamical system governing the capital stock and the shadow price can be made autonomous (i.e., equations does not shift over time) upon suitable detrending, under the assumption that the exogenous variables (or the growth rates thereof) settle down to constants in the long run. Imposing the transversality condition is then accomplished by locating the stable saddle path of the autonomous sytem. In contrast, as will be verified in the next section, our two-sector model remain non-autonomous even after detrending, because Engel's law and the time-varying nature of the labor barrier render the $\mathbf{f}$ and $\mathbf{g}$ functions non-stationary (i.e., time-varying, with $t$ subscript). How to locate the stable saddle path for the present non-autnomous dynamical system is the subject of the next section, which shows that the familiar shooting algorithm is applicable. The reader can skip the next section without losing continuity. 


\section{Existence of An Asymptotic Steady State}

We assume that the share of government purchases and hours worked as well as the growth rates of the trending exogenous variables eventually become constant:

$$
\begin{aligned}
& \text { for sufficiently large } t, \psi_{t}=\psi, h_{1 t}=h_{1}, h_{2 t}=h_{2}, \bar{E}_{1 t}=\bar{E}_{1}, \\
& \qquad \frac{E_{t+1}}{E_{t}}=\frac{N_{t+1}}{N_{t}}=n, \frac{T F P_{1, t+1}}{T F P_{1 t}}=g_{1}, \frac{T F P_{2, t+1}}{T F P_{2 t}}=g_{2} .
\end{aligned}
$$

We assume $n>0$, so the lower bound $\bar{s}_{E t} \equiv \bar{E}_{1 t} / E_{t}$ goes to 0 as $t \rightarrow \infty$. Unlike in standard real business cycle models, an assumption like (5.1) is not enough to render the detrended dynamical system (4.32) autonomous in the long run for two reasons. First, since $X_{Y t}$ and $X_{Q t}$ are not constant, neither $\frac{c_{2}\left(\tilde{q}_{t} X_{Q_{t}}, \tilde{\lambda}_{t} X_{Y_{t}}\right)}{X_{Y_{t}}}$ in (4.25) nor $\frac{c_{1}\left(\tilde{q}_{t} X_{Q_{t}}, \tilde{\lambda}_{t} X_{Y_{t}}\right)}{X_{Y_{t}} / X_{X^{t}}}$ in (4.28) may be a stationary (i.e., time-invariant) function of $\left(\tilde{q}_{t}, \tilde{\lambda}_{t}\right)$. If $\frac{c_{2}\left(\tilde{q}_{t} X_{Q t}, \tilde{\lambda}_{t} X_{Y t}\right)}{X_{Y t}}$ is nonstationary, then so is the $\mathbf{f}$ function of the dynamical system (4.32), and if $\frac{c_{1}\left(\tilde{q}_{t} X_{Q_{t}}, \tilde{\lambda}_{t} X_{Y_{t}}\right)}{X_{Y t} / X_{Q t}}$ is nonstationary, then so is the $\mathbf{g}$ function of the dynamical system. Second, even if $\frac{c_{1}\left(\tilde{q}_{t} X_{Q t}, \tilde{\lambda}_{t} X_{Y t}\right)}{X_{Y t} / X_{Q t}}$ in (4.28) is stationary, the $\mathrm{g}$ function, which is derived from (4.28), (4.29), and (4.31), is still a non-stationary function of $\mathbf{x}_{t}=\left(\tilde{k}_{t}, \tilde{\lambda}_{t}\right)$ when the labor barrier is binding with the time-varying lower bound $\bar{s}_{E t}$ for sector 1 's employment share.

\section{The Shooting Algorithm}

To motivate the Stone-Geary utility function below, we temporarily assume that $\frac{c_{1}\left(\tilde{q} X_{Q_{t}} \tilde{\lambda} X_{Y_{t}}\right)}{X_{Y t} / X_{Q_{t}}}$ and $\frac{c_{2}\left(\tilde{q} X_{Q_{t}}, \tilde{X} X_{Y_{t}}\right)}{X_{Y t}}$ are time-invariant function of $(\tilde{q}, \tilde{\lambda})$ when $X_{Y_{t}}$ and $X_{Y_{t}} / X_{Q t}$ grow at constant rates, so the only reason the dynamical system is non-autonomous is the time-varying binding lower bound $\bar{s}_{E t}$. It is easy to show 
that the only Frisch demand system satisfying this assumption is ${ }^{10}$

$$
\begin{aligned}
& c_{1}(q, \lambda)=\mu_{1} \frac{\lambda}{q}, \\
& c_{2}(q, \lambda)=\mu_{2} \lambda .
\end{aligned}
$$

Therefore, $\frac{c_{1}\left(\tilde{q} X_{Q t} \tilde{\lambda} X_{Y t}\right)}{X_{Y t} / X_{Q t}}$ and $\frac{c_{2}\left(\tilde{q} X_{Q t}, \tilde{X} X_{Y t}\right)}{X_{Y t}}$ are stationary functions for any time path (not just exponential paths) of $\left(X_{Y t}, X_{Q t}\right)$. The utility function that generates this demand system is linear logarithmic:

$$
u\left(c_{1}, c_{2}\right)=\mu_{1} \log \left(c_{1}\right)+\mu_{2} \log \left(c_{2}\right) .
$$

We can now describe a method for finding the solution to the dynamical system under (5.2) and (5.3).

(i) There is a set over which the dynamical system is autonomous. As explained in the previous section, the labor barrier does not bind if and only if the $s_{E t}$ that solves (4.28), (4.29), and (4.31) is greater than $\bar{s}_{E t}\left(\equiv \bar{E}_{t} / E_{t}\right)$. Let $\mathcal{A}_{t}$ be the set of $(\tilde{k}, \tilde{\lambda})$ such that the labor barrier does not bind. The set depends on $t$ because $\bar{s}_{E t}$ is a function of time. Under (5.2), none of these three equations involve the trends, so the $\mathbf{g}$ function is stationary over $\mathcal{A}_{t}$. Furthermore, under (5.3), the $\mathbf{f}$ function is stationary because (4.25) no longer involves the time trends. So the dynamical system is autonomous over $\mathcal{A}_{t}$.

(ii) Since $\bar{s}_{E t}$ declines with time thanks to a positive employment growth $n>0$, this set $\mathcal{A}_{t}$ expands with time. Let $\left(\tilde{k}_{s s}, \tilde{\lambda}_{s s}, s_{K, s s}, s_{E, s s}, \tilde{q}_{s s}\right)$ be the steady state for the autonomous dynamical system. It is obtained by dropping the time subscript from $\left(s_{K t}, s_{E t}, \tilde{q}_{t}, \tilde{k}_{t}, \tilde{\lambda}_{t}\right)$ in (4.25)-(4.31). The Inada condition ensures that $s_{E, s s}>0$ (agriculture does not disappear in the long run, thanks to decreasing returns) so that, with $\bar{s}_{E t}$ approaching 0 as $t \rightarrow \infty,\left(\tilde{k}_{s s}, \tilde{\lambda}_{s s}\right)$ is an interior point of $\mathcal{A}_{t}$ for sufficiently large $t$.

(iii) It is verified numerically for the calibrated parameter values (see Appendix 3) that the eigenvalues of the two-dimensional linearlized system at the steady state $\left(\tilde{k}_{s s}, \tilde{\lambda}_{s s}\right)$ consist of one that is greater

\footnotetext{
${ }^{10}$ Here is a proof of (5.2) (proof of (5.3) is similar). Suppose $\frac{c_{1}\left(\tilde{q} X_{Q t}, \tilde{\lambda} X_{Y_{t}}\right)}{X_{Y_{t}} / X_{Q t}}$ is a stationary function of $(\tilde{q}, \tilde{\lambda})$ when $X_{Y t}=\exp (a t)$ and $X_{Q t}=\exp (b t)$. Then

$$
c_{1}(\tilde{q} \exp (a t), \tilde{\lambda} \exp (b t)) \exp ((b-a) t)=f(\tilde{q}, \tilde{\lambda}, a, b) .
$$
}

This has to hold for any $a, b$. Set $b=0$, differentiate both sides of this equation by $t$, and then set $a=0$ to obtain

$$
c_{1}(\tilde{q}, \tilde{\lambda})+\frac{\partial c_{1}(\tilde{q}, \tilde{\lambda})}{\partial \tilde{q}} \tilde{q}=0, \quad \text { i.e., } \quad \frac{\partial \log c_{1}(\tilde{q}, \tilde{\lambda})}{\partial \tilde{q}}=-\frac{1}{\tilde{q}} .
$$

This partial differential equation can be solved to yield: $c_{1}(\tilde{q}, \tilde{\lambda})=A(\tilde{\lambda}) \frac{1}{\tilde{q}}$. A similar argument gives $c_{1}(\tilde{q}, \tilde{\lambda})=B(\tilde{q}) \tilde{\lambda}$. So $A(\tilde{\lambda}) \frac{1}{\tilde{q}}=B(\tilde{q}) \tilde{\lambda}$. Set $\tilde{q}=1$ to obtain $A(\tilde{\lambda})=B(1) \tilde{\lambda}$. Define $\mu_{1} \equiv B(1)$. 
than unity and the other that is less than unity. Therefore, the steady state is a saddle point for the autonomous system defined over $\mathcal{A}_{t}$. So for sufficiently large $t$, the solution of the dynamical system is on the stable saddle path converging to the steady state $\left(\tilde{k}_{s s}, \tilde{\lambda}_{s s}\right)$. The intermediate path leading to the saddle path from a given capital stock $\tilde{k}_{0}$ can then be determined in the usual way, by the shooting algorithm that takes $\tilde{\lambda}_{0}$ as the "jumping variable". That is, take $T$ large enough so that the solution is near the steady state. If the initial value $\tilde{\lambda}_{0}$ is such that $\left(\tilde{k}_{T}, \tilde{\lambda}_{T}\right)$ is above the saddle path, then adjust the initial value $\tilde{\lambda}_{0}$ down; if $\left(\tilde{k}_{T}, \tilde{\lambda}_{T}\right)$ is below the saddle path, adjust the initial value up.

It should be noted in passing that the dynamical system starting from $\left(\tilde{k}_{s s}, \tilde{\lambda}_{s s}\right)$ would not stay there because at $t=0$ the labor barrier may be binding (that is, $\left(\tilde{k}_{s s}, \tilde{\lambda}_{s s}\right)$ may not be in $\left.\mathcal{A}_{0}\right)$. Therefore, $\left(\tilde{k}_{s s}, \tilde{\lambda}_{s s}\right)$ should be called an asymptotic steady state.

\section{The Stone-Geary Utility Function}

The problem with the linear-logarithmic utility function is its counter-factual implication that the share of food expenditure is constant at $\mu_{1}$. To accommodate Engel's law, we introduce minimum consumption for food: ${ }^{11}$

$$
u\left(c_{1}, c_{2}\right)=\mu_{1} \log \left(c_{1}-d_{1}\right)+\mu_{2} \log \left(c_{2}\right), d_{1}>0 .
$$

Now the food demand is given not by (5.2) but by

$$
c_{1}\left(\tilde{q} X_{Q t}, \tilde{\lambda} X_{Y t}\right)=d_{1}+\mu_{1} \frac{\tilde{\lambda} X_{Y t}}{\tilde{q} X_{Q t}} \quad \text { or } \quad \frac{c_{1}\left(\tilde{q} X_{Q t}, \tilde{\lambda} X_{Y t}\right)}{X_{Y t} / X_{Q t}}=d_{1} \frac{X_{Q t}}{X_{Y t}}+\mu_{1} \frac{\tilde{\lambda}}{\tilde{q}} .
$$

The Frisch demand system now consists of (5.5) and (5.3). Although the f function remains stationary, the $\mathrm{g}$ function is no longer stationary over $\mathcal{A}_{t}$ thanks to the existence of the detrended minimum consumption $d_{1} \frac{X_{\ell t}}{X_{Y t}}$, so nowhere in the $(\tilde{k}, \tilde{\lambda})$ plane is the dynamical system (4.32) autonomous.

However, this two-dimensional non-autonomous system can be converted to a three-dimensional autonomous system. ${ }^{12}$ Define

$$
z_{t} \equiv X_{Q t} / X_{Y t}
$$

\footnotetext{
${ }^{11}$ This is not the only utility function that exhibits Engel's Law and that is "asymptotically log linear" in the sense discussed in this paragraph. See Browning, Deaton, and Irish (1985) for other choices of the utility function. We choose Stone-Geary because it is the simplest.

${ }^{12}$ We are grateful to Lars Hansen for suggesting this idea.
} 
By the definition (4.22) of trends $X_{Y t}$ and $X_{Q t}$ and by the constant-growth assumption (5.1), $z_{t}$ for sufficiently large $t$ follows a first-order linear difference equation

$$
z_{t+1}=\frac{1}{g_{1} g_{2}^{\frac{\theta_{1}}{1-\theta_{2}}} n^{\theta_{1}+\eta-1}} z_{t} .
$$

Add this equation to the two-equation dynamical system to form a three-equation dynamical system in $\left(\tilde{k}_{t}, \tilde{\lambda}_{t}, z_{t}\right)$. Clearly, this augmented system is autonomous for sufficiently large $t$ when the labor barrier is not binding (because $\left(s_{K t}, s_{E t}, \tilde{q}_{t}\right)$ is a stationary function of $\left.\left(\tilde{k}_{t}, \tilde{\lambda}_{t}, z_{t}\right)\right)$. Suppose that the parameters of the model is such that $z_{t} \rightarrow 0$ as $t \rightarrow \infty$ (i.e., the trend in per-capita output of sector $2\left(X_{Y_{t}}\right)$ grows faster than the trend for the relative price $\left(X_{Q t}\right)$ in the long run), which is the case in our calibration below. Then the detrended minimum consumption $d_{1} \frac{X_{\mathcal{Q}}}{X_{Y t}}$ in (5.5) vanishes in the long run, so the steady state is given by $\left(\tilde{k}_{s s}, \tilde{\lambda}_{s s}, 0\right)$ where $\left(\tilde{k}_{s s}, \tilde{\lambda}_{s s}\right)$ is the steady state for the two-dimensional autonomous system with $d_{1}=0$ defined above. Obviously, the eigenvalues for the three-dimensional linearized system at this steady state consist of the two eigenvalues for the two-dimensional system with $d_{1}=0$ mentioned above and the stable growth factor for $z_{t}$ (the $z_{t}$ coefficient in (5.7)). So the system has two roots that are less than one and one that is greater than one under the calibrated parameter values. We were able to find the solution by a variant of the shooting algorithm, with $\tilde{\lambda}_{0}$ as the jumping variable. ${ }^{13}$

\section{Calibration of the Model and Specification of Exogenous Variables}

To numerically solve the model from 1885 on, we need to calibrate the model by providing parameter values, specify the path of exogenous variables, and give an initial condition. The initial capital stock is taken to be its actual value in 1885 . In this section, we describe our calibration of the model and specification of the path of exogenous variables.

\footnotetext{
${ }^{13}$ For a large $T$, the algorithm lowers (raises) $\tilde{\lambda}_{0}$ if $\left(\tilde{k}_{T}, \tilde{\lambda}_{T}\right)$ is above (below) the saddle path corresponding to $z_{t}=0$ for all $t$. Because convergence to the steady state is slow, we modified the algorithm as follows. We set $T=60$ and examine $\left(\tilde{k}_{t_{0}+T}, \tilde{\lambda}_{t_{0}+T}\right)$, initially for $t_{0}=1$. If we find $\tilde{\lambda}_{t_{0}}$ and $\tilde{\lambda}_{t_{0}}^{\prime}$ such that $\left|\tilde{\lambda}_{t_{0}}-\tilde{\lambda}_{t_{0}}^{\prime}\right|<0.01 \tilde{\lambda}_{s s}$, and $\left(\tilde{k}_{t_{0}+T}, \tilde{\lambda}_{t_{0}+T}\right)$ is above the saddle path for $\tilde{\lambda}_{t_{0}}$ and and below it for $\tilde{\lambda}_{t_{0}}^{\prime}$, then we fix $\tilde{\lambda}_{t_{0}+T / 2}$ at the average of the $\tilde{\lambda}_{t_{0}+T / 2}$ corresponding to those two $\tilde{\lambda}_{t_{0}}$ 's and move the initial period forward to $t_{0}=T / 2$. Starting from this new initial period $t_{0}$, we examine $\left(\tilde{k}_{t_{0}+T}, \tilde{\lambda}_{t_{0}+T}\right)$ and do the same procedure to move the initial date forward by another $T / 2$ periods. This process is repeated until the distance between the steady state and the solution path thus constructed is less than 0.01.
} 


\section{Calibration for Prewar Japan}

As explained in the previous section, we accommodate Engel's Law by the Stone-Geary utility function reproduced here:

$$
u\left(c_{1}, c_{2}\right)=\mu_{1} \log \left(c_{1}-d_{1}\right)+\mu_{2} \log \left(c_{2}\right), d_{1}>0 .
$$

Here, $d_{1}$ is the subsistence level of food consumption. We can normalize so that $\mu_{1}+\mu_{2}=1$. The associated Frisch demand system is

$$
c_{1}(q, \lambda)=d_{1}+\mu_{1} \frac{\lambda}{q} \quad \text { and } \quad c_{2}(q, \lambda)=\mu_{2} \lambda
$$

The preference parameters of the model are $\left(\mu_{1}, \mu_{2}, d_{1}\right)$ and the discounting factor $\beta$.

Turning to technology parameters, for expositional clarity, we have ignored intermediate inputs to production, whereas the model we actually solve with and without the labor barrier accomodates them. With intermediate inputs, the production functions for the two sectors are

$$
Y_{1 t}=T F P_{1 t} K_{1 t}^{\theta_{1}} L_{1 t}^{\eta} M_{1 t}^{\alpha_{1}} \quad \text { and } \quad Y_{2 t}=T F P_{2 t} K_{2 t}^{\theta_{2}} L_{2 t}^{\eta_{2}} M_{2 t}^{\alpha_{2}} \quad \text { with } \theta_{2}+\eta_{2}+\alpha_{2}=1,
$$

where $Y_{j t}$ is now gross output of sector $j(j=1,2), M_{1 t}$ is the amount of good 2 used in sector 1 and $M_{2 t}$ is good 1 used in sector 2. From here on, we use the symbol $Y$ for (gross) output. With new parameters, $\alpha_{1}$ and $\alpha_{2}$, representing the shares of intermediate inputs in output, gross output and value added are related by the formula:

$$
\begin{aligned}
& \text { value added in sector } 1 \text { in year } t=Y_{1 t}-q_{t} M_{1 t}=\left(1-\alpha_{1}\right) Y_{1 t} \\
& \text { value added in sector } 2 \text { in year } t=Y_{2 t}-M_{1 t} / q_{t}-\phi K_{2 t}=\left(1-\alpha_{2}\right) Y_{2 t}-\phi K_{2 t} .
\end{aligned}
$$

The model's technology parameters are the share parameters $\left(\theta_{1}, \eta, \alpha_{1}, \theta_{2}, \alpha_{2}\right)$ and the intermediation parameter $\phi$ (the fraction of capital dissipated in moving capital from the household to sector 2). Appendix 3 describes in detail how the model of the text, which does not recognize intermediate inputs, can be generalized with the production functions above. ${ }^{14}$

We calibrate this model with intermediate inputs as follows (see Appendix 1 for a documentation of the variables used in the calibration).

\footnotetext{
${ }^{14}$ With intermediate inputs, the dynamical system (4.25), (4.26), (4.28), (4.29), and (4.31) becomes (A3.24)-(A3.28). The required modifications are: (a) redefinition of TFPs as in (A3.9) and (A3.19), (b) a modification of the trends $X_{Y t}$ and $X_{Q t}$ (see (A3.21) and (A3.22)), (c) redefinition of detrended production functions (see (A3.23)), and (d) an explicit recognition of resources used up as sector 1's intermediate input in the resource constraint for good 2 (see the last term of (A3.24)) and as sector 2's intermediate input in the equilibrium condition for good 1 (see the second term on the left side of (A3.26)).
} 
- The definition of the two sectors. Sector 1 is agriculture proper, which consists of industries producing the following agricultural goods: rice, wheat, barley, rye, oats, miscellaneous cereals, potatoes, pulses, vegetables, fruits \& nuts, industrial crops, green manure \& forage crops, sericulture products, livestock \& poultry, and straw goods. Sector 2 is the rest of the economy.

- $\theta_{1}, \eta, \alpha_{1}$ (the share parameters for capital, labor, intermediate input sector 1 ): The share of intermediate inputs in agriculture for each year (call it $\alpha_{1 t}$ here) is reported in the LTES. Its prewar average of 0.146 is our calibrated value of $\alpha_{1}$. Gross output of sector 1 is calculated as the sector's value added (also available from the LTES) divided by $\left(1-\alpha_{1 t}\right)$. Table J-5 of Yamada and Hayami (1979) (reproduced as Table 2-11 of Hayami (1975)) has gross output factor shares in agriculture for selected years. Their capital cost, however, ignores depreciation. We construct capital cost from the LTES. ${ }^{15}$ The ratio of this capital cost to sector 1 gross output just described has no clear trend. The average over 1886-1940 is 0.144 , which is our calibrated value of $\theta_{1}$. The average of the Yamada-Hayami estimate of labor share is adjusted to reflect the difference in the capital cost estimate between theirs and ours. This produces: $\eta=0.545$ (so land rent's share is $1-0.146-0.144-0.545=0.165$ ). The labor share of value added, therefore, is $0.545 /(1-0.146)=0.638$.

- $\beta$ (discounting factor) and $\phi$ (proportional cost of intermediation): Under the Stone-Geary utility function (6.1), we have $c_{2 t}=\mu_{2} \lambda_{t}$. Substituting this into the Euler equation (4.8), we obtain

$$
\beta^{-1} \frac{c_{2, t+1}}{c_{2 t}}=1+\left(1-\tau_{t+1}\right)\left(r_{t+1}-\delta_{t+1}\right) .
$$

The right-hand-side of this equation can be written as

$$
\begin{aligned}
1+\left(1-\tau_{t+1}\right)\left(r_{t+1}-\delta_{t+1}\right) & =1+\left(r_{t+1}-\delta_{t+1}\right)-\tau_{t+1}\left(r_{t+1}-\delta_{t+1}\right) \\
& =1+\left(\theta_{2} \frac{Y_{2, t+1}}{K_{2, t+1}}-\phi-\delta_{t+1}\right)-\tau_{t+1}\left(r_{t+1}-\delta_{t+1}\right) \quad(\text { by }(4.15)) .
\end{aligned}
$$

Since we assume that the tax base for capital income taxation is net of depreciation, the last term $\tau_{t+1}\left(r_{t+1}-\delta_{t+1}\right)$ equals capital income tax per unit of capital, $T A X_{t+1} /\left(p_{2, t+1}\left(K_{1, t+1}+K_{2, t+1}\right)\right)$, where $T A X$ is the amount of capital income tax and $p_{2 t}$ is the deflator for good 2. Therefore, the Euler equation can be rewritten as

$$
\beta^{-1} \frac{c_{2, t+1}}{c_{2 t}}=1+\left(\theta_{2} \frac{Y_{2, t+1}}{K_{2, t+1}}-\phi-\delta_{t+1}\right)-\frac{T A X_{t+1}}{p_{2, t+1}\left(K_{1, t+1}+K_{2, t+1}\right)}
$$

\footnotetext{
${ }^{15}$ The LTES has gross investment and the capital stock by asset type for agriculture. From this we can calculate the implicit depreciation rates and the user cost of capital (we assumed a real rate of return of $5 \%$ when calculating the user cost).
} 
We set $\beta$ to the standard value of 0.96 . The depreciation rate $\delta$ is calculated from data for each year $t$ (see Appendix 1 on $\delta_{t}$ for more details). We take the sample average of both sides for 1885-1940 and solve for $\phi$, which gives a calibrated value of $\phi=0.0371$. If, instead, we set $\phi=0$ and use this Euler equation to solve for $\beta$, the calibrated $\beta$ is $\beta=0.928$.

- $\alpha_{2}$ (the share of intermediate inputs in sector 2): The difference between the sum of gross output and net imports and domestic consumption equals the amount of good 1 used in sector 2 . Let $x$ be the prewar average of

$$
\frac{\text { (gross output of good } 1+\text { net imports of good } 1-\text { consumption of good } 1) \times q_{t}}{\text { value added in sector } 2+\phi K_{2 t}} .
$$

This $x$ should be an estimate of $\alpha_{2} /\left(1-\alpha_{2}\right)$ because the denominator equals $\left(1-\alpha_{2}\right)$ times gross output in sector 2 (see (6.5)). The calibrated value of $\alpha_{2}$ is $x /(1+x)$.

- $\theta_{2}$ (capital's share in sector 2's gross output): With intermediate inputs, this $\theta_{2}$ divided by $\left(1-\alpha_{2}\right)$ is capital's share in value added. The LTES has no income accounts, so this parameter cannot be estimated solely from the LTES. There is an estimate of capital's share in value added for the prewar private nonagricultural sector by Minami and Ono (1978). It rises from $39.4 \%$ for 1896 to $54.2 \%$ for 1940. They note, however, that the capital share does not show a trend in prewar U.S., Canada, and the U.K. A trend is absent in Ohkawa and Rosovsky (1973, Table 17), whose capital share estimate for 1908-1938 is between $33.5 \%$ and $50.2 \%$. Our view is that there is no definitive evidence in favor of a trend in capital share. So we set $\theta_{2} /\left(1-\alpha_{2}\right)$ to the customary value of $1 / 3$. Under constant returns to scale for sector 2 , labor's share in value added is $2 / 3 .^{16}$

- $d_{1}$ (food subsistence level) and $\mu_{1}, \mu_{2}$ (expenditure shares in the Stone-Geary utility function (6.1)): We set $d_{1}$ equal to $90 \%$ of per-worker consumption of good 1 (sector 1 output) in 1885 . Under the Stone-Geary utility function, the Frisch demand system is $c_{1 t}=d_{1}+\mu_{1} \frac{\lambda_{t}}{q_{t}}$ and $c_{2 t}=\mu_{2} \lambda_{t}$, which imply

$$
\frac{\mu_{1}}{\mu_{2}}=\frac{\left(c_{1 t}-d_{1}\right) q_{t}}{c_{2 t}}
$$

The calibrated value of $\mu_{1} / \mu_{2}$ is the prewar average of this. $\mu_{1}$ and $\mu_{2}$ can be obtained from this because $\mu_{2}=1-\mu_{1}$. Therefore, the calibrated value of $\left(\mu_{1}, \mu_{2}\right)$ depends on $d_{1}$. With the Stone-Geary utility function, food expenditure share approaches $\mu_{1}$ as the household gets wealthier. When $d_{1}$ is

\footnotetext{
${ }^{16}$ If $\eta_{2}$ is labor's share in gross output in sector 2 , the constant-returns-to-scale assumption is that $\alpha_{2}+\theta_{2}+\eta_{2}=1$. So $\frac{\theta_{2}}{1-\alpha_{2}}+\frac{\eta_{2}}{1-\alpha_{2}}=1$. Labor's share in value added equals $\frac{\eta_{2}}{1-\alpha_{2}}$.
} 
$90 \%$ of per-worker food consumption in 1885 , the implied value of $\mu_{1}$ is 0.142 , which is in line with food expenditure share in most present-day developed countries. ${ }^{17}$

Calibrated values are displayed in Table 4.

Table 4: Calibration of the Model

\begin{tabular}{|l|l|}
\hline \multicolumn{1}{|c|}{ parameter } & \multicolumn{1}{c|}{ calibrated value } \\
\hline$d_{1}$ (minimum subsistence level for good 1) & $90 \%$ of per-worker food consumption in 1885 \\
\hline$\mu_{1}$ (asymptotic consumption share of good 1) & 0.142 \\
\hline$\mu_{2}$ (asymptotic consumption share of good 2$)$ & 0.858 \\
\hline$\beta$ (discounting factor) & 0.96 \\
\hline$\theta_{1}$ (capital share in sector 1 gross output) & 0.144 \\
\hline$\eta$ (labor share in sector 1 gross output) & 0.545 \\
\hline$\alpha_{1}$ (share of intermediate inputs in sector 1) & 0.146 \\
\hline$\theta_{2} /\left(1-\alpha_{2}\right)$ (capital share in sector 2's value added) & $1 / 3$ \\
\hline$\alpha_{2}$ (share of intermediate inputs in sector 2) & 0.0587 \\
\hline$\phi$ (proportional intermediation cost) & 0.0371 \\
\hline
\end{tabular}

\section{Time Path of Exogenous Variables}

The exogenous variables are:

$h_{1 t}, h_{2 t}$ (hours worked in two sectors), TFP $P_{1 t}$ and TFP $2 t$ (sectoral TFPs), $E_{t}$ (aggregate employment), $\bar{E}_{1 t}$ (lower bound for sector 1 employment $E_{1 t}$ ), $\psi_{t}$ (share of government expenditure in sector 2's output), $N_{t}$ (working-age population), $\delta_{t}$ (time-varying depreciation rate), and $\tau_{t}$ (tax rate on capital income).

For these variables except for $\bar{E}_{1 t}$, we use their actual values for the sample period (1885-1940). See Appendix 1 for a detailed discussion of the construction of those exogenous variables. Regarding the lower bound $\bar{E}_{1 t}$, which is not necessarily observable, we set it equal to the actual employment in sector 1. This does not amount to forcing the labor barrier to bind during the sample period; if we relax the

\footnotetext{
${ }^{17}$ As will be reported in the next section, however, simulation results are similar when $d_{1}$ is $50 \%$, instead of $90 \%$, of per-worker food consumption in 1885 with an implied value of $\mu_{1}$ is 0.255 .
} 
labor barrier by setting $\bar{E}_{1 t}$ slightly below the actual sector 1 employment, the solution of the model sets $E_{1 t}$ equal to this lower value $\bar{E}_{1 t}$ and the income ratio $\frac{w_{1 t} h_{1 t}}{w_{22} h_{2 t}}$ remains less than one during the sample period.

For periods beyond the sample period, the projected values of those exogenous variables are set as in Table 5 (later we will examine the sensitivity of simulations to the projected value for $g_{2}$ (the TFP growth for sector 2)). We are assuming that in the prewar period agents did not anticipate the actual development of the exogenous variables in the postwar period, let alone the war.

Table 5: How Exogenous Variables are Projected into the Future

\begin{tabular}{|l|l|}
\hline \hline \multicolumn{1}{|c|}{ the exogenous variable } & \multicolumn{1}{c|}{ its projection } \\
\hline$h_{1}, h_{2}$ (hours worked) & $h_{1 t}=h_{1,1940}=59.0$ and $h_{2 t}=h_{2,1940}=62.3$ for $t>1940$ \\
\hline$\delta$ (depreciation rate) & $\delta_{t}=\delta_{1940}=5.06 \%$ for $t>1940$ \\
\hline$g_{1}, g_{2}$ (TFP growth factors for two sectors) & $\begin{array}{l}\text { projected growth rates set to their averages for } 1885-1940 \\
\text { of } 0.96 \% \text { and } 1.66 \% \text {, respectively. So } g_{1 t}=1.0096, g_{2 t}=1.0166 \\
\text { for } t>1940 .\end{array}$ \\
\hline$n$ (growth factor of aggregate employment & $\begin{array}{l}\text { set to the geometric mean over } 1885-1940 \text { of the growth } \\
\text { rate of working-age population of } 1.10 \% . \text { So } n_{t}=1.0110 \\
\text { for } t>1940 .\end{array}$ \\
\hline$\psi$ and working-age population) & $\psi_{t}=\psi_{1940}=27.4 \%$ for $t>1940$ \\
\hline$\tau$ (tax rate on capital income) & $\tau_{t}=\tau_{1940}=47.2 \%$ for $t>1940$ \\
\hline $\bar{E}_{1 t}$ (lower bound for sector 1 employment) & $\bar{E}_{1 t}=\bar{E}_{1,1940}=13.55$ million persons \\
\hline
\end{tabular}

\section{Findings}

With the model calibrated, the path of exogenous variables specified, and the initial condition given, we can now answer two questions: How closely does the model track historical data? What would have happened had there been no labor barrier? The first question is answered by solving the model with the labor barrier in place, namely, by conducting a simulation with the barrier. The latter question is answered by solving the model without the labor barrier, namely, by the counter-factual simulation.

Solving the model consists of two steps. We first solve the detrended dynamical system (4.25), (4.26), (4.28), (4.29), and (4.31) (or more precisely, with intermediate inputs, (A3.24)-(A3.28)) for the path of 
$\tilde{k}_{t}$ (detrended capital stock), $\tilde{\lambda}_{t}$ (the co-state variable measuring the household's wealth), $\tilde{q}_{t}$ (detrended relative price of food), $s_{E}$ (agriculture's employment share), and $s_{K}$ (agriculture's capital share) for $t=1885,1886, \ldots$, with and without the labor barrier. Second, we undo the detrending by multiplying $\left(\tilde{k}_{t}, \tilde{\lambda}_{t}\right)$ by $X_{Y t}$ and $\tilde{q}_{t}$ by $X_{Q t}$ to back out the solution $\left(k_{t}, \lambda_{t}, q_{t}\right)$ before detrending.

The model presented in the text (and more fully in Appendix 3 with intermediate inputs) assumes that food (sector 1 output) is a nontraded good. This model will be referred to as the "closed-economy" version although, as noted in Section 4 and more formally in Appendix 5, the country can borrow and lend good 2 from abroad. For the most part, our discussion of simulation results is for this case. The other case - the small open-economy version of the model where the country is allowed to trade good 1 for good 2 at a given terms of trade - will be discussed in the last two subsections.

\section{Closed-Economy Results about Sectoral Resource Allocation}

Simulation results for $\left(s_{E t}, s_{K t}, q_{t}\right)$ with and without the barrier are displayed in Figures 8-10. With the barrier in place, the constraint setting the lower bound on sector 1 employment is binding for more than 150 years. This occurs despite the declining lower bound as a fraction of employment because sector 2's TFP surges during the interwar years and is assumed to grow faster than sector 1's TFP after 1940. This is why, in Figure 8, the graph of $s_{E t}$ from the simulation with the barrier coincides with the data. For

the same reason, the income ratio $\frac{w_{1} h_{1 t}}{w_{2 t} h_{2 t}}$ (not graphed here) remains at about one quarter throughout the sample period. Figure 8 also shows that, without the labor barrier, substantially lower fraction of the labor force would have been employed in sector 1. With minimum food consumption taking up $90 \%$ of food consumption in 1885 and with no option to import food, the country is on the yoke of Engel's law. Even so, devoting as high a fraction of the labor force as observed is by no means an efficient way to deliver food to the starving population; a more efficient way to deliver food is less labor and more capital. This is why $s_{K t}$ (agriculture's capital share) is lower with the labor barrier than without the barrier, as shown in Figure 9. 
Figure 8: Agriculture's Share of Employment, 1885-1940

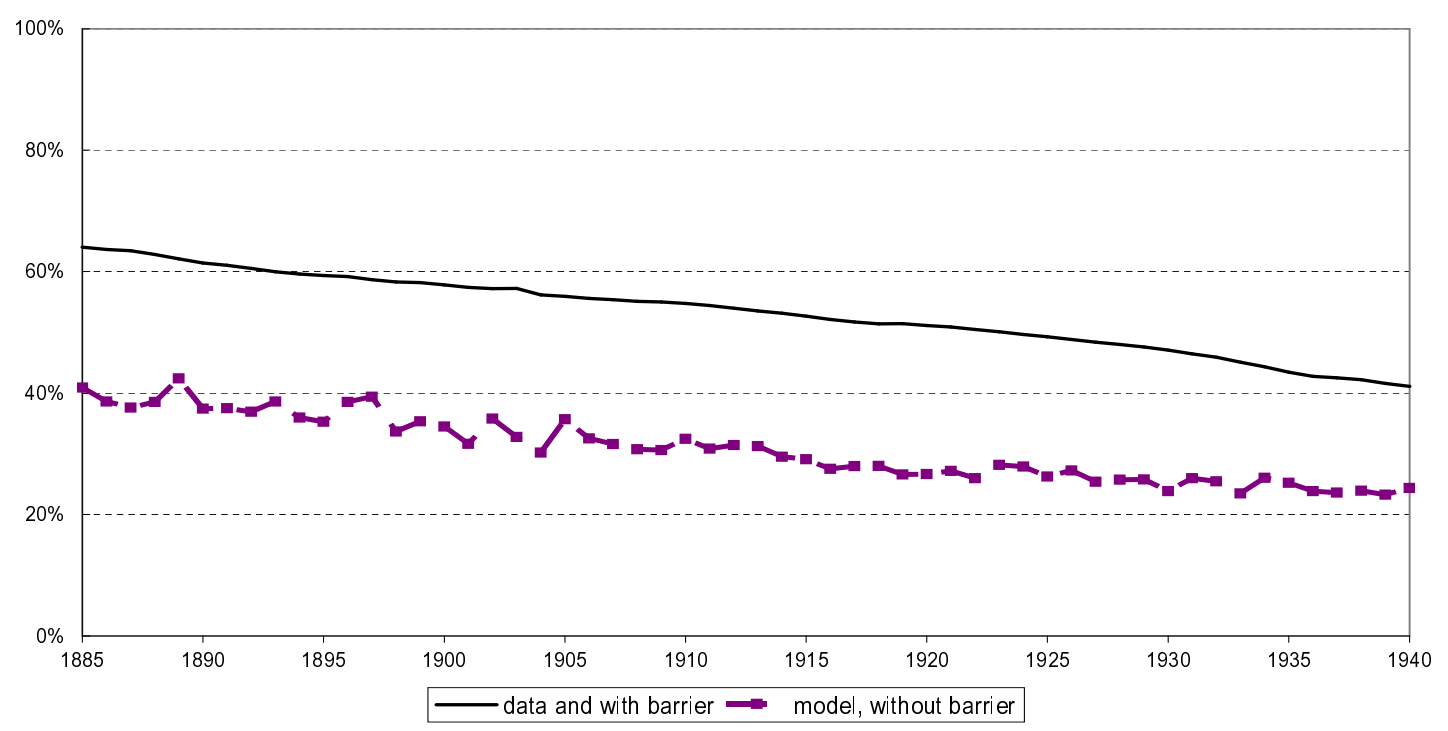

Figure 9: Agriculture's Share of Capital, 1885-1940

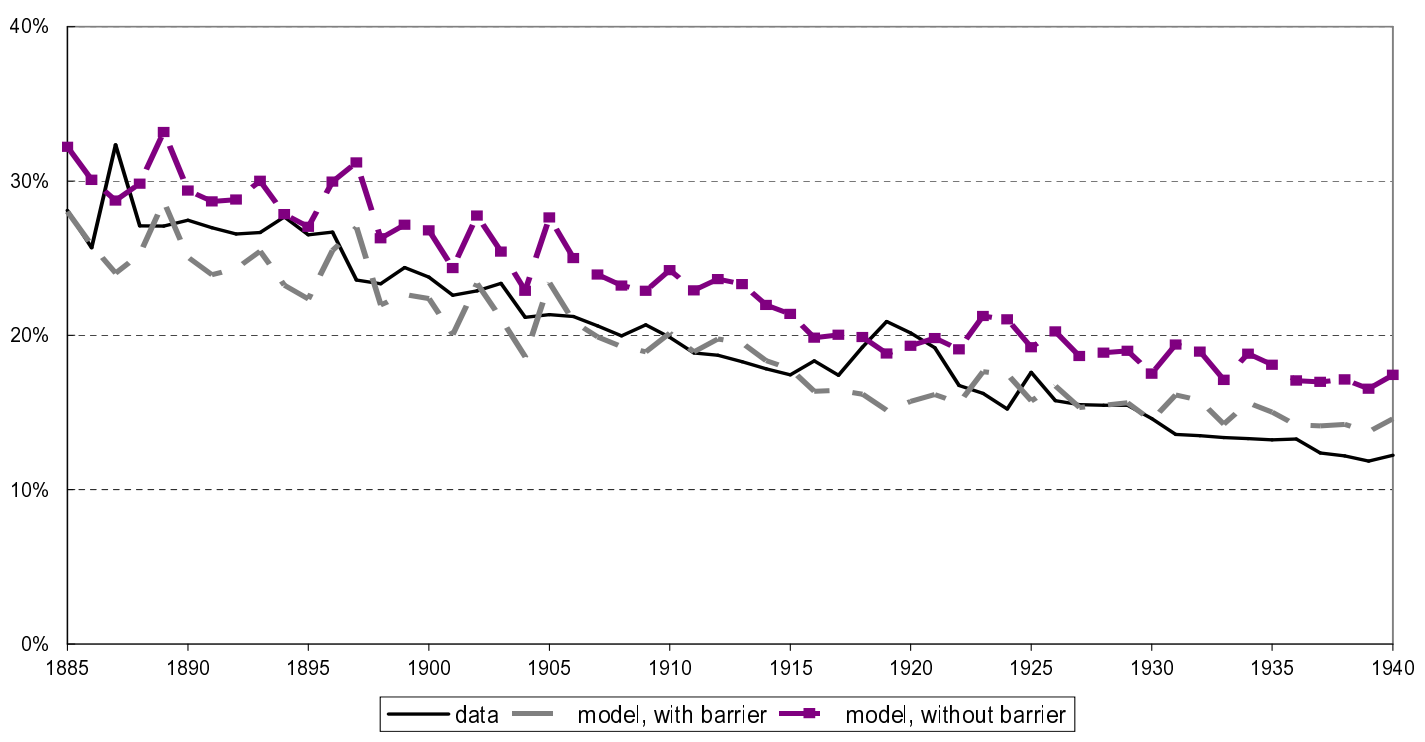

Turning to $q_{t}$ (the relative price of food in terms of non-food), which is endogenous in the present case of the closed-economy version of the model, Figure 10 shows that the model with the barrier tracks the observed relative price fairly well. This means that, with the labor barrier, there would not have been much trade even if food were tradable. The divergence between the data and the simulation with the barrier in the 1930s may be due to the fact, shown in Table 3, that food imports became significant 
during that period. Figure 10 also shows, predictably, that food would have been far more expensive if the labor barrier did not exist.

Figure 10: Relative Price of Food, 1885-1940 (1934-36 in data=1)

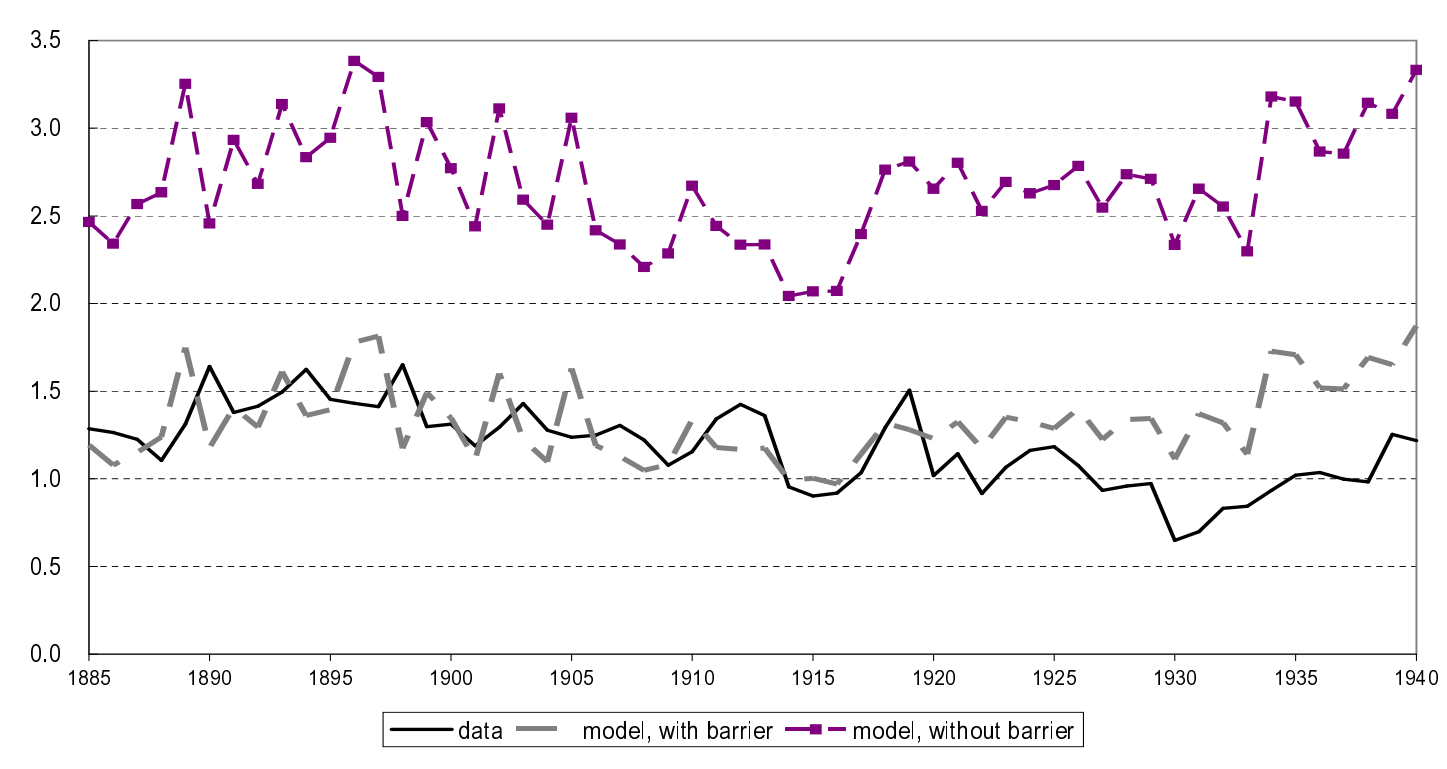

To illustrate the effect of the barrier-induced sectoral mis-allocation of labor and capital, Figure 11 displays two production frontiers implied by the model for 1885 given the 1885 value of the capital stock. The solid black line, the one closer to the origin, is the frontier when sector 1's employment share is constrained to be $64 \%$ (the 1885 value). The output measure here is net output (defined as gross output less intermediate inputs) per worker, so the frontier is well-defined for negative values. ${ }^{18}$ The gray thick line, which has much less curvature, is the frontier when the barrier is removed. The black constrained frontier is tangent to it. The production frontier with the labor barrier requiring sector 1's employment share to be at least $64 \%$ is the black line to the left of the point of tangency and the gray line to the right of it. The per-worker consumption vector implied by the model with the barrier is indicated in the figure by the black circle. The vector of net output is the white circle on the frontier. It is to the left of the tangency point, so the labor barrier is binding. The two circles are lined up vertically because good 1 is neither used for investment nor consumed by the government. The vertical distance between the two circles,

\footnotetext{
${ }^{18}$ Using the notation introduced in (6.3) where the symbol $Y$ refers to gross output, net output is defined as $Y_{1 t}-M_{2 t}$ for sector 1 and $Y_{2 t}-M_{1 t}-\phi K_{2 t}$ for sector 2, with $\phi K_{2 t}$ representing the intermediation cost. Net output should not be confused with value added defined in (6.4) and (6.5).
} 
therefore, is the sum of investment (domestic investment plus the current account) and government expenditure. Without the barrier, the consumption vector is indicated by the black triangle and the net-output vector is the white triangle on the frontier. The white triangle is far above the black triangle, implying that there would have been an investment boom in 1885 and so the production frontiers in subsequent years would have expanded more rapidly than they actually did, were it not for the barrier.

Figure 11: Effect of Labor Barrier on Production Frontier, 1885

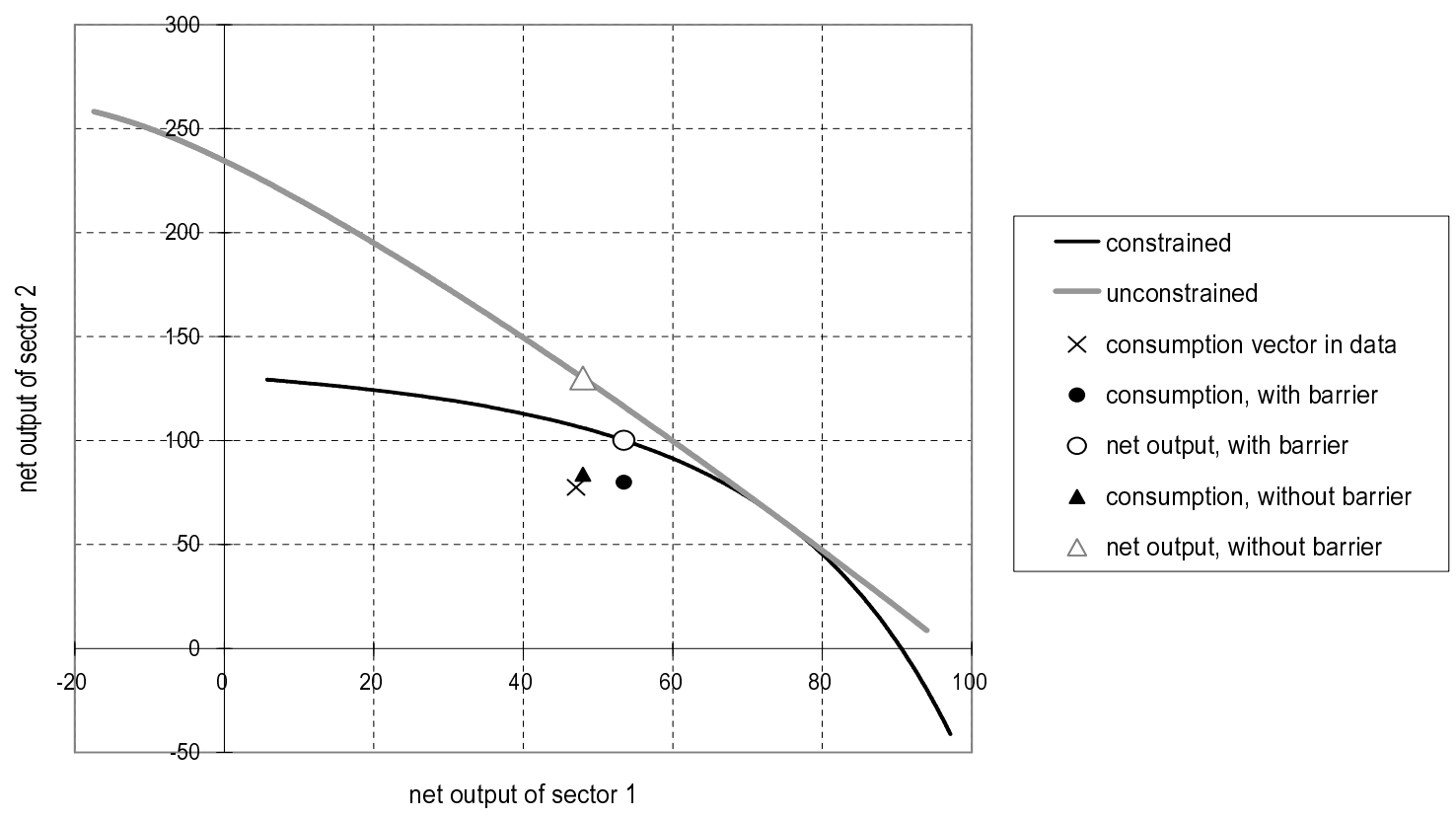

\section{Closed-Economy Results about Aggregate Variables}

For each simulation, given the solution $\left(k_{t}, \lambda_{t}, s_{E t}, s_{K t}, q_{t}\right)$ and given the path of the exogenous variables, other variables of interest can be calculated using the formulas in Section 4 (or more precisely, with intermediate inputs, the formulas in Appendix 3). Those variables include the aggregate capital stock $K_{t}$, average hours worked $h_{t}$, real GNP, and the overall TFP. Regarding real GNP, since the relative price $q_{t}$ in data and from the simulation can and do differ (see Figure 10), we need to do a PPP (purchasing power parity) calculation to make the real GNP in data and from the simulation comparable. For the base year of 1935, PPP-adjusted real GNP from the simulation is calculated using the Geary-Khamis 
formula. ${ }^{19}$ Real GNP for other years are extended from this 1935 value using the chain-type Fisher quantity index using sectoral value added and the relative price from the simulation. Given real GNP, employment, average hours worked, and the capital stock, the overall TFP implied by the simulation can be calculated as in the growth accounting of Section 2 .

In Section 3 we have already commented on the simulation results about real per-worker GNP (in Figure 6), the overal TFP (in Figure 2), and capital accumulation (in Figure 7). Our main finding was that labor barrier had two depressing effects. First, it prevented the economy's factor endowments to be allocated efficiently, thus reducing the overall production efficiency measured by TFP. (The efficiencyreducing effect of the labor barrier was visually illustrated by the two production frontiers in Figure 11.) Second, this distortion in factor allocation was a powerful hindrance to capital accumulation.

A summary for the simulation results discussed so far is displayed in the first row of Table 6 .

Table 6: Alternative Assumptions

\begin{tabular}{|c|c|c|c|c|c|c|c|c|c|c|c|c|}
\hline \multicolumn{2}{|c|}{ model } & \multicolumn{4}{|c|}{ simulation with barrier } & \multicolumn{7}{|c|}{ counter-factual simulation, without barrier } \\
\hline \multirow[t]{2}{*}{$\begin{array}{l}\text { Is food } \\
\text { tradable? }\end{array}$} & \multirow[t]{2}{*}{$\frac{d_{1}}{c_{1,1885}}$} & \multicolumn{3}{|c|}{$\begin{array}{l}\text { geometric mean of ratio } \\
\text { of model to data }\end{array}$} & \multirow[t]{2}{*}{$\begin{array}{l}\text { geometric } \\
\text { mean of } \\
\text { sectoral } \\
\text { income } \\
\text { ratio }\end{array}$} & \multicolumn{2}{|c|}{$\begin{array}{l}\text { agriculture's } \\
\text { employment } \\
\text { share }(64.0 \% \\
\text { for } 1885 \text { and } \\
41.1 \% \text { for } 1940 \\
\text { in data) }\end{array}$} & \multicolumn{5}{|c|}{$\begin{array}{l}\text { level accounting: geometric mean of } \\
\frac{\text { value without barrier for year } t}{\text { its actual value for year } t} \text { in } \\
\frac{Y_{t}}{N_{t}}=\operatorname{TFP}_{t}^{\frac{1}{1-\theta}}\left(\frac{K_{t}}{Y_{t}}\right)^{\frac{\theta}{1-\theta}}\left(\frac{E_{t}}{N_{t}}\right) h_{t}\end{array}$} \\
\hline & & $\frac{Y_{t}}{N_{t}}$ & $K_{t}$ & $q_{t}$ & & 1885 & 1940 & $\frac{Y_{t}}{N_{t}}$ & $T F P^{\frac{1}{1-\theta}}$ & $\left(\frac{K_{t}}{Y_{t}}\right)^{\frac{\theta}{1-\theta}}$ & $\frac{t}{v_{t}}$ & $h_{t}$ \\
\hline No. & $90 \%$ & 1.042 & 1.035 & 1.129 & 0.253 & $40.9 \%$ & $24.3 \%$ & 1.327 & 1.243 & 1.044 & 1 & 1.023 \\
\hline No. & $50 \%$ & 1.051 & 1.047 & 1.111 & 0.288 & $32.5 \%$ & $23.5 \%$ & 1.351 & 1.237 & 1.063 & 1 & 1.028 \\
\hline Yes. & $90 \%$ & 1.015 & 1.041 & 1 & 0.246 & $0.70 \%$ & $0.04 \%$ & 1.671 & 1.556 & 1.017 & 1 & 1.055 \\
\hline
\end{tabular}

Note: $c_{1,1885}$ here is actual per-worker food consumption in 1885.

\footnotetext{
${ }^{19}$ The formula, when applied to two countries, is as follows. For two countries, $x=a, b$, let $\left(Y_{1}^{x}, Y_{2}^{x}, q^{x}\right)$ be the outputs (measured in value added) of two sectors and the relative price (the price of good 1 in terms of good 2) and let $P^{x}$ be the PPP price level. Country $b^{\prime}$ PPP price level, $P_{b}$, is calculated from the following system of equations:

$$
P^{a}=\frac{q^{a} Y_{1}^{a}+Y_{2}^{a}}{\frac{Y_{1}^{a}}{v_{1}}+\frac{Y_{2}^{a}}{v_{2}}}, \quad P^{b}=\frac{q^{b} Y_{1}^{b}+Y_{2}^{b}}{\frac{Y_{1}^{b}}{v_{1}}+\frac{Y_{2}^{b}}{v_{2}}}, \quad \text { where } \quad v_{1}=\frac{Y_{1}^{a}+Y_{1}^{b}}{\frac{q^{a} Y_{1}^{a}}{P^{a}}+\frac{q^{b} Y_{1}^{b}}{P^{b}}} \quad v_{2}=\frac{Y_{2}^{a}+Y_{2}^{b}}{\frac{q^{a} Y_{2}^{a}}{P^{a}}+\frac{q^{b} Y_{2}^{b}}{P^{b}}}
$$

This is a system of four equations in four unknowns $\left(P^{a}, P^{b}, v_{1}, v_{2}\right)$. Because the system is homogeneous, a scalar multiple of a solution is also a solution. So without loss of generality we can normalize $P^{a}=1$.
} 
Still maintaining the assumption that food is a nontraded good, we examine several variations of the model. The first is to loosen the grip of Engel's law. Recall from our calibration that $d_{1}$ (minimum food consumption) in the Geary-Stong utility function was assumed to be $90 \%$ of per-worker food consumption in 1885 and that the implied asymptotic food share $\mu_{1}$, calculated from (6.10), was 0.142 . If, instead, we assume $d_{1}$ to be $50 \%$ of the 1885 per-worker food consumption, the implied asymptotic food share is $\mu_{1}=0.255$. Simulation results for this case are summarized in the second row of Table 6 . With or without the barrier, weakening Engel's law does not materially change results, except that, predictably, agriculture's unconstrained employment share in the early years of the prewar period is lower.

We also tried three further variations of the model with the barrier: (i) assume $\tau_{t}$ (the tax rate on capital income) to be constant at the prewar average of $30.8 \%$, (ii) change the projected TFP growth rate (for $t=1941,1942, \ldots$ ) for sector 2 from $1.66 \%$ to $5 \%$, and (iii) assume that the surge in sector 2's TFP after 1914 shown in Figure 5 did not take place by setting the growth rate of $T F P_{2 t}$ from 1915 on at 1.09\%, the average growth rate from 1885 to 1914 . Simulation results for (i) and (ii) are very similar to the base case. In particular, the investment boom during the interwar years predicted by the model with the barrier but not observed in data, shown in Figure 7, is still there. The simulated capital stock for (ii) is lower than in the base case by more than 5\% only for the final 4 years of the sample period of 1885-1940. In the simulation for (iii), there is no interwar investment boom, with the capital stock slightly higher for several years before 1915 and substantially lower from 1915 on. Therefore, the investment boom predicted by the model is indeed due to the surge in sector 2's TFP after 1914.

\section{Results for the Small-Open Economy}

Now drop the assumption that food is a nontraded good and assume that food is tradable. Unlike in the closed-economy case with nontraded food, domestic expenditure (the sum of consumption, investment, and government expenditure) is no longer constrained to equal (net) output. For discussions below, the material balance for food, which is neither used for investment nor consumed by the government, is

$$
\begin{aligned}
& \text { net output (i.e., gross output - intermediate input to sector 2) } \\
& \qquad+ \text { net imports }=\text { domestic consumption. }
\end{aligned}
$$

The country is now off the yoke of Engel's law because food can be imported to pre-empt starvation. We also assume that the country is not large enough to influence the terms of trade, which means the relative price of food, $q_{t}$, is the exogenously given terms of trade for the country. We use the observed relative price $q_{t}$ for the sample period of $1885-1940$. To project $q_{t}$ beyond the sample period, we assume that its 
detrended value remains constant at its 1940 value. ${ }^{20}$ In terms of the detrended dynamical system, the effect of this small-open economy assumption is that the resource constraint (4.25) (or, with intermediate inputs, more precisely (A3.24)) is integrated with the market equilibrium condition for sector 1 output and becomes (A4.1) of Appendix 4.

Turning to simulation results for this small open-economy version of the model, the effect of opening up to trade depends on whether the labor barrier is in place or not: the trade gain is very modest with the barrier and huge without. With the barrier in place, agriculture's high share of employment makes the country nearly self-sufficient in food. This corresponds to the fact noted earlier for the closed-economy case that the model-determined relative price is close to the observed relative price. Consequently, the summary simulation results with the barrier, shown in the third row of Table 6, are very similar to the closed-economy case. ${ }^{21}$ In contrast, without the barrier, the same row of the table for the counterfactual simulation shows that the relative price of food is so low that the country becomes specialized almost completely in non-food production. ${ }^{22}$ A large-scale reallocation of labor from agriculture to non-agriculture triggered by a lifting of the barrier raises greatly the production efficiency measured by the overall TFP. The gain in real GNP from lifting the barrier is $67 \%$, far larger than the $33 \%$ gain for the closed-economy case.

\section{A Large Gain from Trade?}

To illustrate this drastic effect of opening up to free trade, consider Figure 12, which contains the same production frontiers as in Figure 11. The black circle is the consumption vector and the white circle is net output, both from the simulation with the barrier for the small open-economy version of the model. Unlike in the closed-economy case, the two circles are not lined up vertically because now food is traded (see the material balance equation shown above). The gray circle represents the vector of expenditures (consumption for good 1 and the sum of consumption, investment, and government expenditure for good 2). The net-output vector is to the right of the consumption and expenditure vectors, so the model is predicting that, consistent with the data shown in Table 3 for 1885, the country in 1885 was a net exporter of agricultural products. The slope of the line (not shown) connecting the white and gray circles

\footnotetext{
${ }^{20}$ Simulation results are not very sensitive to the projected value for $q_{t}$.

${ }^{21}$ The prewar average for GNP of 1.015 is slightly lower than that for the closed-economy case of 1.042 because the relative price is different (recall that the relative price in the closed-economy case is endogenous). The representative agent's discounted utility sum is higher for the small open-economy case than for the closed-economy case.

${ }^{22}$ Sector 1 (agriculture) does not disappear completely thanks to decreasing returns to scale.
} 
is the observed relative price of food or the terms of trade, with the white circle representing net output being the point of tangency.

Figure 12: Effect of Labor Barrier on Production Frontier, 1885, Small Open Economy

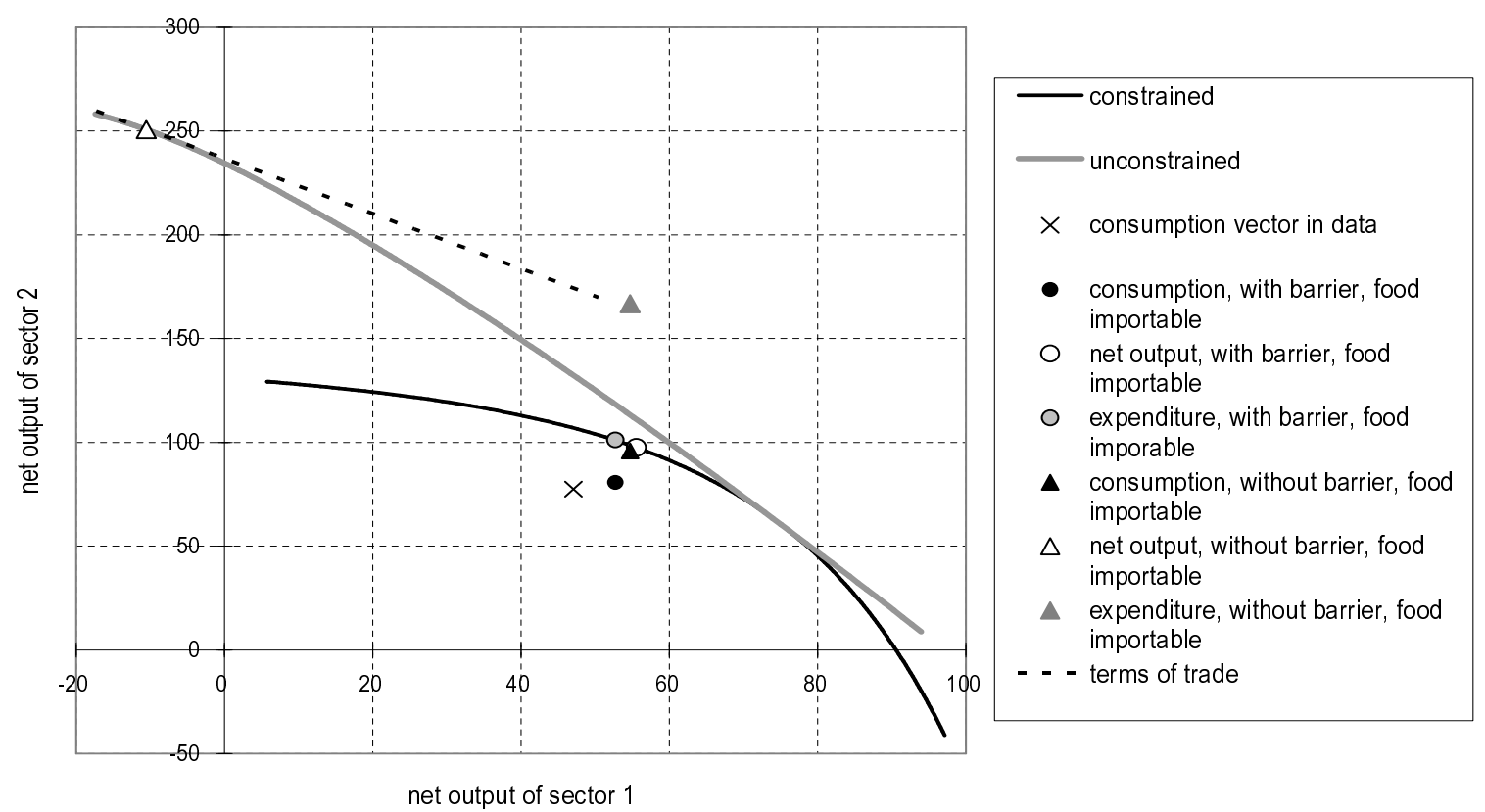

The three triangles in the figure summarize the counter-factual simulation (without the barrier) for 1885. The black triangle is the consumption vector, while the net-production vector, indicated by the white triangle, is far away, in the north-west segment of the production frontier without the barrier. Net output of good 1 is negative; food imports are used not only for domestic food consumption but also as an intermediate input to sector 2. The slope of the dotted line connecting the net-output vector (the white triangle) and the expenditure vector (the gray triangle) is the observed relative price of food, which is the terms of trade faced by the country. ${ }^{23}$ The counter-factual simulation predicts that Japan would have been a huge exporter of good 2 .

Given the lack of curvature of the production frontier without the barrier and given the terms of trade that is greater than the near-constant slope of the frontier, we find the prediction of the small open-economy version of the model of a virtual disappearance of agriculture unlikely. Probably, the

\footnotetext{
${ }^{23} \mathrm{GNP}$ in terms of good 2 is the intercept of this dotted line. That is, if $Y$ is gross output, $q_{t}\left(Y_{1 t}-M_{2 t}\right)+\left(Y_{2 t}-M_{1 t}-\phi K_{2 t}\right)$ equals $q_{t}\left(1-\alpha_{1}\right) Y_{1 t}+\left[\left(1-\alpha_{2}\right) Y_{2 t}-\phi K_{2 t}\right]$ because $q_{t} M_{2 t}=\alpha_{2} Y_{2 t}$ and $M_{1 t}=q_{t} \alpha_{1} Y_{1 t}$.
} 
prewar international trade environment is better modeled as one in which the terms of trade even for a then-small country such as Japan responds to the volume of trade. An increase in exports of good 2 by Japan would drive up the relative price of food, which should reduce the terms of trade and place the net-production vector closer to the middle flat part of the frontier. If so, the huge trade gain under the small-country assumption found for the counterfactual simulation would not have materialized. We therefore conclude that whether food is a nontraded good or not would not greatly affect the quantitative effect of lifting the barrier, although it would surely affect the pattern of the country's specialization.

\section{Why Did the Barrier Exist?}

In this section, we explore reasons for the existence of the lower bound for agricultural employment, which we have taken for granted so far.

\section{The Cityward Movement of the Peasant}

In prewar Japan, as already emphasized, agricultural employment was virtually constant at 14 million. Related facts about prewar Japan are the following.

- The number of farm households (households whose head's main occupation is farming) was constant at 5.5 million $^{24}$ and the population in those farm households was constant at 30 million or about 5.5 persons per household throughout the prewar era. ${ }^{25}$ Because there was virtually no migration from the city, ${ }^{26}$ the constancy of the number of farm households implies that the head of the farm household

\footnotetext{
${ }^{24}$ The sources are the tables in the Annual Department of Agriculture Tabulations and the censuses at various years.

${ }^{25}$ See Appendix 1 for the method used in the LTES to estimate the number of farm households.

${ }^{26}$ See Takagi (1956) and Taeuber (1957, pp. 126-127, particularly nootnote 8 ) for census data and various other sources on the population supporting the lack of reverse migration from the city. One major non-census evidence is a classic study on the cityward movement of the peasant by Nojiri (1942). Based on voluminous data collected from field work, he concludes (see Section 1, Chapter 2 of Part 1) that the incidence of a household head (and hence the entire household) leaving the village for the city is negligible when compared to the number of non-head household members doing the same. A survey cited in Namiki (1957, Section 3) reports that in 18 villages between 1899 and 1916 there were only 21 households whose head changed occupations from agriculture. Since, as shown by these studies, there was virtually no attrition of farm households and since the number of farm households was constant, we can conclude that there was no reverse movement of individuals from the city. There was a fair amount of regional variation in the distribution of farm households, with Hokkaido (the northernmost island previously only sparsely populated) gaining at the expense the Kinki area (where Kyoto and Osaka are located). This merely implies
} 
was almost always succeeded by one of its children upon its death or retirement. ${ }^{27}$

- Prewar fertility rate in rural areas was about $5 .^{28}$ As shown in Honda (1950), it follows by simple algebra from the constancy of the number of farm households and the relatively small household size of 5.5 that all children except for the heir and its spouse left the village. ${ }^{29}$

- Primogeniture was prevalent at least in rural areas. Inheritance was impartible and the entire estate went to one of the sons (usually the eldest son) who also succeeded the father's occupation as a farmer. ${ }^{30}$

that there was migration from one rural area to another.

${ }^{27}$ That the occupation as farmer is inherited from one generation to the next is quite well known in Japanese agricultural economics, but there is no official statistics on social mobility directly documenting it. There is a survey called the "SSM (Social Stratification and Social Mobility) Survey" conducted every ten years since 1955 by the Institute of Social Science of University of Tokyo, which asks the respondent about the father's occupation (among other things). Sato (1998, Appendix 2) reports that about 90\% (650 in number) of 732 respondents born between 1896 and 1925 who were currently in agriculture at the times of the survey replied that their father was in agriculture. The remaining 10\% probably entered agriculture after the war. Between 1945 and 1949, when the majority of the population had difficulty getting enough to eat, agricultural employment increased from slightly below 14 million to nearly 17 million.

${ }^{28}$ See, e.g., the table on the gross reproduction rate by industrial type reported on p. 246 (right below Table 96) in Taeuber (1958). The prewar urban fertility rate was about 4 .

${ }^{29}$ The infant mortality rate was such that only 4 of 5 children survive into adulthood. Assuming that a generation is 27 years, a natural increase of 4 adults occurs in about 200 thousand (= 5.5 million/27) households, and in equally numerous households a natural decrease of 2 adults (death of two old parents) occurs every year. That's a natural net annual increase of 400 thousand persons ( $=80$ thousand less 40 thousand). In each of those 200 thousand households, two of the four adult children succeed their deceased parents and remain in the village. Those two successors are the heir (one of the sons, usually the eldest) and a daughter who came from a different farm household as his wife. The remaining two children leave the household well before the death of their parents but not immediately after finishing primary education.

${ }^{30} \mathrm{As}$ far as we know, there is no direct prewar evidence for the impartibility for farm households. The prewar Civil Code stipulates impartible inheritance to be the default mode, namely, the next head inherit the whole property if the current head died without leaving a will. In the early postwar period, out of the concern that the new Civil Code, which stipulates equal division of the estate as the default mode, would result in widespread subdivision of farmland, a quasi-government body conducted a series of surveys on the inheritance of the farmland. The earliest such survey, conducted between January 1948 and August 1949 with the help of local governments, collected about 33 thousand cases of the inheritance of the farmland. Matsumura (1957) reports that one child inherited the entire farmland in $84.7 \%$ of those cases. A 1978 survey also asked 5,326 farmers over the age of 60 about their intention regarding inheritance. $79 \%$ of them said they would leave the entire farmland to the heir, according to a report by Zenkoku Nogyo Kaigisho (1979). Therefore, impartible inheritance was the norm even under the new Civil Code. It would have been more prevalent in the prewar era when the Civil Code made it the default mode of inheritance. 
- There was a large rural-urban disparity in household income. Kazushi Ohkawa (1955, Chapter 1) was probably the first to verify this long-alleged fact on a national account basis. The LTES shows that value added per employment in agriculture is only $1 / 5$ to $1 / 3$ of that in non-agriculture in the prewar era. A series of work by Ryoshin Minami (collected in Minami (1973)) finds an increasing disparity between manufacturing and agriculture in wages and productivities in prewar Japan. For example, Figure 10 of Minami (1973) shows that the ratio of the average male wage income in manufacturing for establishments with 30 or more employees to the average male wage income for farm laborer on yearly contracts rises from slightly above 2 in 1902 to about 4.5 in 1933. For females, the rise is much less pronounced, but the ratio stays above 1 , between 1.5 and $2.0 .^{31}$

- The steep postwar decline in agricultural employment after 1955 (see Figure 3) was initiated by young cohorts. In his perceptive essay on postwar employment in agriculture, Namiki (1957), drawing on data from the 1955 census and other sources, noticed that the decline was concentrated in the 14-19 age bracket. His speculation, which was proved correct by time, was that the youth defecting to the city include eldest sons, who in the prewar tradition are expected to succeed their fathers' occupation as farmer.

\section{Why Did Agricultural Employment Remain Constant?}

Given the large rural-urban income disparity in prewar Japan, we are not surprised that household members not designated as heir left agriculture. The mystery is why the son designated as heir (and his wife) stayed in agriculture. An explicit calculation of farm and urban incomes relevant for the peasant contemplating on migration was given by Masui (1969). He notes that for a son and his prospective wife the comparison should be between farm labor income for both the son and his wife combined and

\footnotetext{
Regarding the succession by eldest son, available evidence from non-government surveys shows that it was less prevalent than might have been commonly assumed. For example, Tsuburai (1998, Table 6) finds that, in the 1965 and 1995 waves of the SSM Survey mentioned in footnote 27, about $57 \%$ of those respondents born between 1896 and 1925 who succeeded the father's occupation as a farmer (246 persons) were the eldest son. Nojiri (1942) finds that, in his field work data covering 20 villages and about ten thousand farm households, $23 \%$ of those males who left the village were eldest sons (see his Table 225).

${ }^{31}$ The ratio is based on nominal wage incomes. According to LTES (see Chapter 5 of Volume 8), it is hard to obtain information on prices in rural areas. Nevertheless, Minami and Ono (1977) utilize their own estimate of the rural consumer price level to calculate real wages. Visual inspection of their Figure 1 shows that prices were cheaper in rural areas by 20 to $25 \%$ in the 1910 s and 1920s, but the price difference shrank since then and almost vanished by 1935.
} 
urban labor income for the son only because the wife's employment opportunity in the city was severely limited in the prewar era. Furthermore, if the son is the heir, his farm income should also include imputed rent from the farm property he would eventually inherit. Masui's calculation for 1923-39 shows that the heir's farm income, with wife's labor income and imputed rent figured in and with an allowance for difference in rural and urban price levels, is less than urban income for 1928-37.

Besides the issue of why peasants didn't leave the village during those depressed years, three questions can be raised about Masui's thesis. First, the heir could sell the inherited farmland and live in the city to collect the higher urban income. However, to prevent this, the father could require the son to remain on the farm until he inherits the land. By the time his son inherits the estate, it may be too late for him to start a career in the city. ${ }^{32}$

Second, there may not have been much to inherit for the heir to a sharecropper. According to Momose (1990, p. 149), the right to cultivate had a property value, between $10 \%$ and $30 \%$ of the value of land. Even if the cultivation right is transferable from father to son (which we don't know is the case), the property value may not have been large enough to make up for the rural-urban income disparity for tenant farmers. To the extent that it was not, it is difficult to explain on purely economic grounds why tenant farmers, comprising about $30 \%$ to $40 \%$ of all farm households, ${ }^{33}$ did not leave agriculture.

Third, as pointed out by Namiki (1957), the land reform instituted by SCAP (the Supreme Commander of the Allied Powers, namely Douglas MacArthur) in 1951, which transferred land ownership to tenant farmers, should have made it more attractive for previous tenant farmers to stay in agriculture in the postwar period. The postwar large-scale defection to the city took place despite the land reform.

Our explanation of the constancy of agricultural employment is an elaboration of Namiki's (1957) conjecture that the economic forces favoring migration to the city, which had been held in check by patriarchy in the prewar era, were let loose in the years following the defeat of Japan. To appreciate his logic, it is necessary to understand the nature of patriarchy that regulated the behavior of individuals in prewar Japan through the Civil Code. The distinguishing feature of the prewar Civil Code (as opposed to the new postwar Civil Code) is its recognition of the institution called the ie (sometimes translated "house") and its headship. The ie is "a 'stem family' — an organization that transcended its present

\footnotetext{
${ }^{32}$ This argument was suggested to me by Andrew Foster.

${ }^{33}$ According to the agricultural department tabulations mentioned in footnote 24 . The percentage is substantially higher if those owner farmers who also cultivates someone else's land are included.
} 
members through history and spanned generations through the eldest son" (Ramseyer (1996, p. 82)). ${ }^{34}$ Vogel (1967, pp. 92-94) describes the ie in the context of the cityward migration mentioned above:

The $i e$ is a patrilineal organization with rapid segmentation in each generation. One son, usually the first, inherits all the family property, including land, home, and ancestral treasures. Daughters enter their husband's ie upon marriage, and sons who do not succeed in their parents' ie can either be adopted as heirs in families with no sons or start relatively independent "branch" lineages of their own ie. .... Because one son remained in the rural area and inherited the family property, the ie was maintained and remained the basic unit of rural organization. Sometimes it was the first son who migrated to the city, but in any case the head of the ie has remained remarkably powerful in deciding who would and would not go to the city.

As we mentioned already, those sons not designated as heir to the headship left the village for a good economic reason, and it would also have been the head's wish anyway, since the size of the farmland the family owns (or the family has the right to cultivate) would not have been enough to support those "excess sons". ${ }^{35}$ Why did the heir remain in the village and how was he able to find a bride? The power of the head sanctioned by the prewar Civil Code explains it. According to Oda (1992, p. 232), under the Code "the head of the family had the power to designate the place where family members should live, to control their choice of marriage-partner and to expel them from the family when necessary." ${ }^{\prime 36}$ Takeyoshi Kawashima, a prominent legal scholar in Japan, notes that the peasant life before the introduction of the Civil Code in 1898 did not quite honor the sort of patriarchy described in the Code (Kawashima (1957, pp. 8-9, 46)). He then notes, however, that the Code, along with the indoctrination by the government (much like the sort practiced in North Korea today, we imagine) whereby every schoolchild was required

\footnotetext{
${ }^{34}$ For a more detailed description of $i e$ by a westerner, see Taeuber (1958, Chapter VI).

${ }^{35}$ The annual department of agriculture tabulations mentioned in footnote 24 show that the size distribution of land managed by farm households was remarkably equal and stable, with $50 \%$ to $60 \%$ concentrated in the $0.5-2.0$ ha bracket. How to feed second and third sons without subdividing the family plot of land was a major issue in Japanese agricultural economics in the very early postwar period.

${ }^{36}$ Relevant articles of the prewar Civil Code are the following (copied from Ramseyer (1996, Chapter 5)). Article 749: "members of a house may not determine their place of residence, if the head of the house objects to their choice"; article 750(a): "In order for a family member to marry or to enter an adoptive relationship, he or she must obtain the consent of the family head"; article 750(b): "If a family member marries or enters an adoptive relationship in violation of the previous subsection, the head may, within one year of the date of such marriage or adoption, expel such member from the family or refuse his or her reentry into the family"; article 772(a) states that until man and woman reach the statutory age - thirty for men, twenty-five for women - they could marry only if both of their parents consented.
} 
to study a textbook (called Kyoiku Chokugo, see Figure 13 which is the front page of a textbook wide in use in 1890) expounding on obedience to the father and to the emperor, must have made a profound influence, particularly on the peasant population as can be surmised, for example, from the decline of peasant rebellions since the end of the 19th century. ${ }^{37}$ The heir stayed in the village, and a daughter married into a farm household, because it was what father wished.

Figure 13: How Children were Indoctrinated

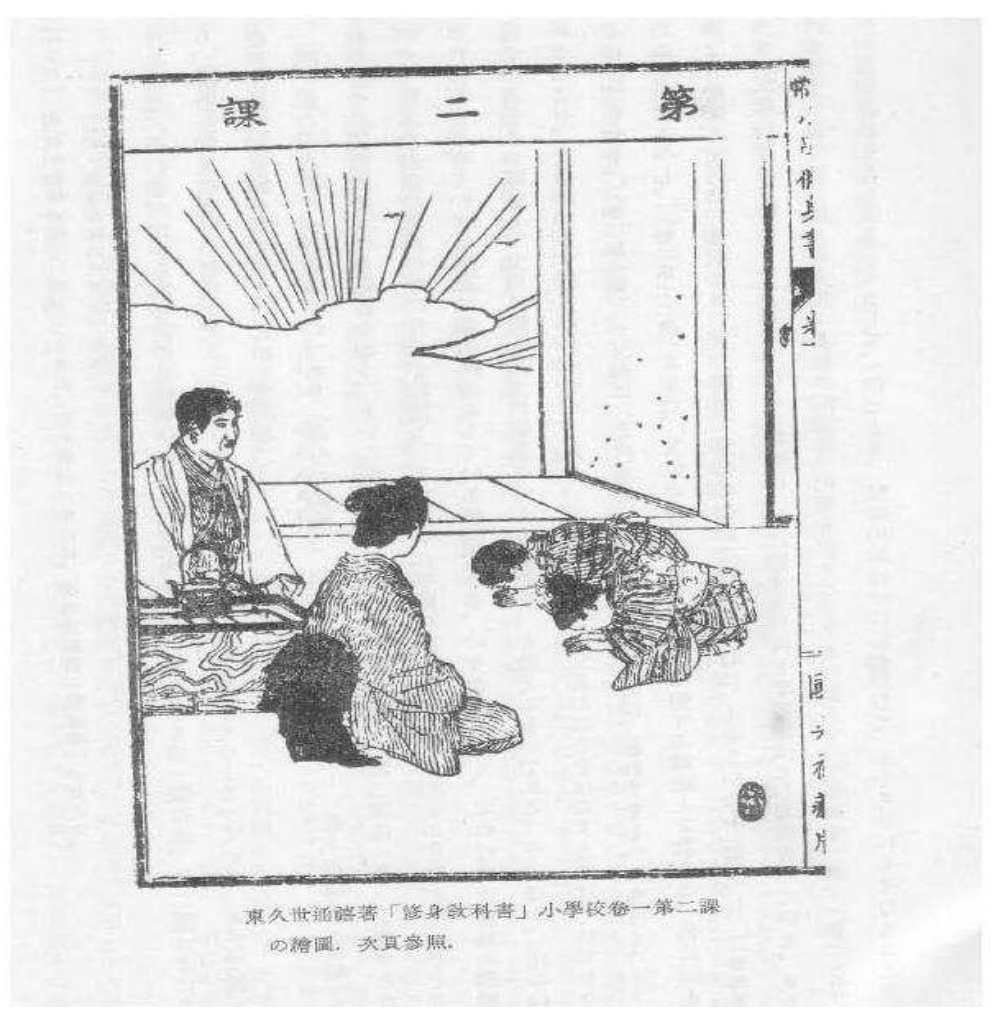

This explanation of the constancy of agricultural employment in prewar Japan also explains its steep postwar decline. A new Constitution was adopted in 1947 and there was a wholesale revision of the Civil Code under the direction of SCAP. Article 24 of the new Constitution states that "....With regard

\footnotetext{
${ }^{37}$ Kawashima (1957, p. 10, and Chapter 1, particularly pp. 46-47). Ramseyer (1996, Sections 2 and 3 of Chapter 5) argues that the prewar Civil Code did not confer the head the power to control residence and marriages of the family members. However, the court cases he cites are not about disputes between the head and the heir, and the census data he cites for his point that family members did not stay in the family (which means the head's threat to expel had no bite) actually reinforces our claim that all the non-heir siblings left the stem household.
} 
to choice of spouse, property rights, inheritance, choice of domicile,... laws shall be enacted from the standpoint of individual dignity ...". The new Civil Code no longer recognizes the $i e$ and the dictatorial power of the head. School textbooks were rewritten to fully reflect those changes. It is not surprising at all, then, that the large-scale defection to the city since around 1955 was initiated by young cohorts, who were not subject to the prewar indoctrination of the supremacy of the ie over the individual. Reinforcing the tide to the city was the fact that the new Civil Code encourages equal division while the old Code facilitated (but did not require) primogeniture. Now the eldest son who inherits the entire estate by the will of his father is obligated to pay the other siblings a minimum claim (half of what they would have received under the default mode of inheritance (i.e., equal division)), which certainly makes it less economically attractive for the eldest son to stay in the village.

\section{Conclusion}

According to the standard Lewisian theory of development, the supply curve of industrial labor is horizontal and the cityward movement of the peasant is limited only by demand. We argued for prewar Japan that the rural-to-urban migration was limited by supply. Prewar Japan is certainly not the only case in history of a large and persistent rural-urban income disparity. Even today, the disparity can be observed for a large number of developing countries. ${ }^{38}$ Our model of a dual economy may be applicable to those countries as well. Their per-capita income is low because they have their own version of the labor barrier.

The quantitative implication of our theory is big time. In terms of per-worker GNP, Japan was $71 \%$ of the U.S. in 1990 and 36\% on average during the prewar period of 1885-1940. According to our two-sector model, Japan's prewar GNP per worker would have been higher by 33\% if the labor barrier were absent. In this sense, our dual economy model accounts $12(=36 \times 0.33)$ percentage points, or about a third, of the U.S.-Japan gap of $35(=71-36)$ percentage points. We argued that the rest of the gap is due mostly to the rapid postwar TFP growth outside agriculture.

Japanese Manufacturing TFP went up, once during the interwar period, and another time during the postwar high-growth period. Exploring reasons why the rapid TFP growth took place when it did is obviously a major future research topic. Hints abound. Hayami and Ogasawara (1999) and Godo

\footnotetext{
${ }^{38}$ See, e.g., a documentation by Vollrath (2005) using an ILO database.
} 
and Hayami (2002) argue that a threshold level of average educational level was reached in the interwar period so that foreign advanced technology could be profitably adopted. Braun, Okada, and Sudou (2005) find a close connection in the postwar period between U.S. R\&D expenditure and Japanese TFP growth three years after. Gordon (2004) documents that the rapid technological catch-up occurred in postwar Europe as well. Another, perhaps more concrete, research topic is to explain why the interwar capital accumulation predicted by theory didn't occur. We conjectured that the rapid cartelization in the 1930s must have had something to do with it.

We end by responding to two criticisms raised to us on the constancy of agricultural employment.

- Some argued that the lack of mechanization in rice production in prewar Japan could explain the constancy. The introduction of the tractor started only after 1955 and mechanization of other tasks such as rice planting and rice reaping didn't start until the mid 1960s in Japan. If the prewar agricultural technology was like the Leontief technology with limited substitutability between land area and labor, it would explain the constancy of agricultural employment. However, this explanation is inconsistent with the well-documented fact that the rural-urban income disparity was very large in prewar Japan. Furthermore, it is a long tradition of agricultural economics (see, e.g., Hayami (1975)) to admit substantial substitutability between land, labor, and capital, as in the Cobb-Douglas production function.

- The barrier may have existed in the city, not in the countryside, in the form of inadequate urban housing and infrastructure. This, however, does not explain why the scale of the cityward emigration was such that the population left behind in the countryside remained constant. Virtually every non-heir child left for the city, the living condition in the city such as it was. 


\section{Appendix 1: Data Description}

This appendix describes the construction of the variables used in the text. It consists of three parts. The first part covers the prewar period. The postwar values, which are used only in the standard growth accounting, are described in the second part. The third part is about U.S. GNP. The raw data, the constructed series along with the formula used for construction, and a complete list of data sources are in an Excel file downloadable from http://fhayashi.fc2web.com/Hayashi-Prescott2 .htm.

\section{Prewar}

The basic source of prewar macro variables for Japan (except for hours worked and income accounts) is the fourteen-volume series entitled the Long Term Economic Statistics (hereafter LTES), which is a consistent system of national income accounts compiled by a group of academics affiliated with Hitotsubashi University led by Kazushi Ohkawa. It contains not only data series but also a detailed documentation of data sources and derivations. An English summary of the LTES is Ohkawa and Shinohara (1979) (hereafter OS), which for some LTES series contains updates. If the series is updated in OS, we use the updated series in OS instead of the older series in LTES. Many prewar series in the LTES start before 1885 , but the first year for which GNP is available is 1885 . We therefore take 1885 to be the first year in our analysis. Real series in the LTES are in 1934-36 prices.

As in Hayashi and Prescott (2002), we don't recognize the government capital stock, so all government expenditures, including those classified as government investment (gross government capital formation), are expensed in our accounting framework. The agricultural sector (the first sector) in our analysis is agriculture proper, exclusive of forestry and fishery. Our definition of agriculture proper is the same as in LTES. It is the set of industries that produce the following agricultural goods:

rice, wheat, barley, rye, oats, miscellaneous cereals, potatoes, pulses, vegetables, fruits \& nuts, industrial crops, green manure \& forage crops, sericulture products, livestock \& poultry, and straw goods.

The non-agriculture sector (the second sector) is the rest of the economy. The boundary of Japan in our study is that of Japan proper that excludes former colonies.

Sectoral employment and hours worked: conceptual issues. The definition of sectoral employment in the LTES is the same as that in the Censuses. Thus, employment in agriculture, $E_{1}$, refers to the number of persons whose primary occupation is agriculture. For those in agriculture and for those in farm households but not in agriculture, prewar documents (the Censuses and available surveys by the Agricultural Ministry of the Japanese government) do not indicate the fraction of their time spent in agriculture, so we have no choice but to assume that those whose primary occupation is agriculture work full time in agriculture and those whose primary occupation is not agriculture do not spend any time at all in agriculture. That is, we calculate total hours in agriculture as $h_{1} E_{1}$ (where $h_{1}$ is hours worked if one works full time in agriculture). There is, however, a survey by the Ministry of Agriculture done in April 1946 that classifies farm population into categories roughly indicative of the degree of participation in agriculture. Appendix Table 1 is a summary of it. If we apply the Census 
definition, employment in agriculture $\left(E_{1}\right)$ is $17.443(=14.470+1.849+1.033+0.091)$ million persons, 1.94 millions of which spend up to half of their work hours outside agriculture. ${ }^{39}$ Despite this, our calculation of total hours worked when applied to 1946 assumes that those 1.94 million people work full time, $h_{1}$ hours (see below for how $h_{1}$ (hours worked in agriculture) is estimated). The table also indicates that the census definition would include $3.0(=2.165+0.835)$ millions who spend up to half of their work hours in agriculture as part of $E_{2}$ (employment outside agriculture). Our calculation when applied to 1946 assumes that those 3 million people in $E_{2}$ work full time, $h_{2}$ hours. Because (at least in this 1946 survey) there are more people primarily but not fully in non-agriculture (3.00 million) than those primarily but not fully in agriculture (1.94 million), our total hours worked in agriculture $\left(h_{1} E_{1}\right)$ would understate true total hours. However, it is possible that those who answered in the survey that they work full time in agriculture may have spent some time during agricultural off seasons working in the city to supplement household income. ${ }^{40}$

Appendix Table 1: Composition of Family Members at Farm Households in Million Persons

\begin{tabular}{|l|l|c|}
\hline \multirow{3}{*}{ Work at the farm of residence } & full time in agriculture & 14.470 \\
\cline { 2 - 3 } & primarily in agriculture & 1.849 \\
\cline { 2 - 3 } & primarily in non-agriculture & 2.165 \\
\hline \multirow{3}{*}{ Work off the farm of residence } & full time in agriculture & 1.033 \\
\cline { 2 - 3 } & primarily in agriculture & 0.091 \\
\cline { 2 - 3 } & primarily in non-agriculture & 0.835 \\
\hline Dependents & & 14.723 \\
\hline Total & & 34.240 million \\
\hline
\end{tabular}

Note: The source if Survey of Agricultural Population conducted by the Ministry of Agriculture in April 1946. Reprinted on p. 9 of Handbook of Agricultural Statistics, Ministry of Agriculture, 1950.

Data sources for $E_{1}, E_{2}$. For the prewar census years of 1920,30, and 40, the data on sectoral employment in the LTES are directly from those Censuses. For other years, the LTES estimates employment in agriculture as the product of the number of farm households and the number of persons in agriculture per farm household. From 1906 on, there is an annual official series on the number of farm households. The LTES estimates pre-1906 values from various sources. Regarding the number of persons in agriculture per farm household, it can be obtained for 1920, 1930, and 1940 from the Censuses for those years, and for 1879 and 1887 from Census-type information available for two prefectures. The LTES estimates values for all other years by linear interpolation. $E_{1}$ (employment in agriculture) thus

\footnotetext{
${ }^{39}$ The figure of more than 17 million is much higher than the prewar constant of 14 million, because there was a reverse emigration from urban to rural during the aftermath of World War II, with people looking for ways to feed themselves.

${ }^{40}$ Prewar Censuses collected some information on subsidiary jobs. For example, the 1920 Census shows that about 6.4 million of those 13.9 million in agriculture have subsidiary jobs (see LTES, Vol. 2, Table 29). However, it is not clear what fraction of subsidiary jobs held by 6.4 million people is outside agriculture. For example, if a rice grower spends a fraction of his time in producing sericulture products (another agricultural product), he is deemed to have a secondary job in the 1920 Census (see, LTES, Vol. 2, p. 160).
} 
estimated is from LTES, Vol. 9, Table 33, which reports the constancy of agricultural employment at 14 million. However, Table A18 of OS (Ohkawa and Shinohara (1979)), which was published 13 years after LTES Volume 9, shows that agricultural employment was higher, nearly 16 million, until 1914 and that it declined by about 2 million to about 14 million during the interwar years between 1914 and 1918. However, Mataji Umemura, who wrote the chapter on population and employment in OS on which Table A18 is based, was the lead author of LTES Volume 2 (on labor force), which was published in 1988. Its Table 10 shows a series on agricultural employment that is almost identical to the series in Table 33 of Volume 9. Total employment is available for 1885-1920 (1920 was the first year a national census was taken) in Vol. 2, Table 5 and for 1920-1940 in Vol. 2, Table 6. We use the Vol. 2, Table 5 series to extrapolate the Table 6 series back from 1920 to 1885. $E_{2}$, employment outside agriculture, is obtained by subtracting $E_{1}$ from total employment.

$h_{1}, h_{2}$ (hours worked) For agriculture, an estimate of total days worked per year for 1874-1977 is in Shintani (1981). It is the sum of the days worked in the production of various crops and livestock. See pp. 23-24 of Hayami (1975) for a discussion of the details and limitations of this type estimate. Dividing this by $E_{1}$ gives an estimate of days worked per year per worker. Let $x_{t}$ be this variable for year $t$. Hours worked per week for year $t, h_{1 t}$, in agriculture is calculated as: $\left(x_{t} / x_{1948}\right)$ times 48.4. This figure of 48.4 hours is the average hours worked in agriculture \& forestry for 1948 for workers 14 years or older in the postwar Labor Force Survey and reported in Table 3-14, Volume 1 of Japan Statistical Association (1986). (The Labor Force Survey is a survey on individals, not on establishments, conducted and published by the Statistics Bureau of the Management and Coordination Agency of the Japanese government.) Therefore, we are assuming that hours worked per day in agriculture had been constant from 1885 to 1948. Estimating $h_{2}$ is even more problematical. There is a survey, reproduced in Volume 10 of Rodo Undo Shiryo Iinkai (1959), on factories with 10 or more workers for days worked per year (for 1906-1918) and hours worked per day (for 1909-1918). The hours worked per day are in integers. The figure is 11 except in 1917 when it is 12 hours. We set the 1917 figure to 11 to avoid a discontinuous change in total hours worked. For 1909-1918, $h_{2}$ is set equal to the implied total hours per year divided by 52 . For $1906-1908, h_{2}$ is calculated similarly except that hours worked per day is assumed to be 11 hours (the 1909 value from the above source). The same volume reports a separate survey on factory workers for days worked per month and hours worked per day for 1923-1941. Thus for 1923-41 $h_{2}$ is set equal to the implied total hours per month divided by 31/7. For $1885-1905, h_{2}$ is set to the 1906 value, and for $1919-1922, h_{2}$ is set to the 1923 value.

$N$ (working-age population) The population aged 15 or older in millions, from LTES, Vol. 2, Table 1.

$Y_{1}, Y_{2}$ (value added in two sectors), $p_{1}, p_{2}$ (their deflators), $q$ (relative price), real private GNP. Since we don't recognize government capital while LTES does, to obtain nominal private GNP we need to subtract depreciation due to government capital from the LTES estimate of nominal GNP (Vol. 1, Table 1). The government portion of depreciation is calculated as: $s$ (government's share of total capital stock) times total depreciation (from Vol. 1, Table 6). This $s$ is calculated as the ratio of gross government capital stock (available from a database maintained at Hitotsubashi University's website http://rcisss.ier.hit-u.ac.jp/cgi-bin/Ltes, as series JK102__001) to gross private capital stock (OS, Table A42). The implicit GNP deflator is the ratio of LTES nominal GNP to its real counterpart (GNP in 1934-36 prices, OS, Table A3). Real private GNP is obtained by dividing nominal private 
GNP obtained above by this implicit GNP deflator. $Y_{1}$, real value added in agriculture in 1934-36 prices, is from OS, Table A17. It is a revision of the estimate in the LTES (Vol. 9, Table 4). $p_{1}$, the implicit deflator for $Y_{1}$, is the ratio of nominal value added (OS, Table A16) to the real value added. $Y_{2}$ is real private GNP less $Y_{1}$. (Therefore, real private GNP equals $Y_{1}+Y_{2}$.) Similarly, nominal $Y_{2}$ is nominal private GNP less nominal value added in agriculture. $p_{2}$, the implicit deflator for $Y_{2}$, is the ratio of nominal $Y_{2}$ to $Y_{2}$. The relative price equals $p_{1} / p_{2}$.

Share of intermediate inputs in sector 1 The value added ratio (the ratio of value added to gross output) for agriculture is available for each year (OS, Table A16). As discussed in the text on calibration, this is used to translate value added to gross production for sector 1 , and the parameter $\alpha_{1}$ is defined as 1 minus the average over $1885-1940$ of this value added ratio.

$K_{1}, K_{2}$ (real physical capital stocks) To obtain real capital stocks, we first calculate nominal capital stocks. The LTES has real net capital stocks (in 1934-36 prices) by asset type (plants \& livestock, equipments, and structures) for the entire economy and also for agriculture (see the Excel file mentioned above for their source). It also has nominal and real investment (gross capital formation) by asset for the private sector and for agriculture. From nominal and real investments, we calculate the implicit deflator by asset for both the private sector and agriculture. Nominal private capital stock is calculated as $s$ (the private share, defined above) times the nominal value of the capital stock for the entire economy, calculated from real capital stocks by asset and the implicit deflators just described. Nominal capital stock for agriculture is calculated from real capital stocks by asset and the implicit deflators for agriculture just described. Nominal capital stock for non-agriculture (sector 2) is nominal private capital stock less nominal agriculture capital stock. $K_{1}$ (real capital stock for sector 1 , agriculture) is the ratio of nominal capital stock for agriculture to $p_{2}$ (the implicit deflator for sector 2, already described). $K_{2}$ (real capital stock for sector 2) is the ratio of nominal capital stock for non-agriculture to $p_{2}$. We divide nominal capital stocks by the same deflator, $p_{2}$, because in our theoretical model only sector 2 output can be used for investment.

$T F P_{1 t}, T_{F} P_{2 t}$ (TFP for two sectors) With intermediate inputs, the TFPs refer to the TFPs in the gross production functions with intermediate inputs (6.3). Given the calibrated parameter values for $\left(\alpha_{1}, \theta_{1}, \eta\right)$ for sector 1 , and given the time-series data on $Y_{1 t}$ (value added), $L_{1 t}$, and $K_{1 t}$, we calculate $\widetilde{T F P}_{1 t}$ by (A3.8) (note that the $Y$ in Appendix 3 is gross output, which we calculate as the ratio of value added to $\left(1-\alpha_{1}\right)$ ). We then recover $T F P_{1 t}$ by (A3.9). Equivalently, we can substitute (A3.7) into (A3.1) and solve for TFP $1 t$. TFP $2 t$ is calculated similarly.

Consumption of two goods. Consumption by households of good 1 (agricultural products) in current yen is from LTES, Vol. 6, Tables 5 and 6. It is defined as the sum of: rice, wheat, barley, rye, oats, miscellaneous cereals, potatoes, pulses, vegetables, fruits \& nuts, dairy products. Total nominal consumption is from Table 1 of OS (which is the same as the series in LTES, Vol. 1, Table 1). Nominal consumption of good 2 is defined as total nominal consumption less nominal consumption of good 1 .

Exports and imports of agricultural goods. Nominal exports of agricultural goods is from LTES, Vol. 14, Table 1, column 10. It excludes fishery and forestry. As mentioned in footnote 9 on p. 96 of this volume, sericulture products (which is included in our definition of agricultural products displayed above) are not included in column 10 of the Table and are treated as a manufactured good. Nominal 
imports of agricultural goods is from Table 2 of the same volume. In the table, "agricultural products" (column 10) consists of crude foodstuff (column 10.1) and "textile materials" (column 10.2). We use column 10.1 for our estimate of imports, thus excluding textile materials from imports of agricultural products. We do this because sericulture products are not included in agricultural exports (column 10 of Table 1 of the volume).

Foreign assets. We use the net claims on the rest of the world in Fujino and Teranishi (2000, pp. 550 and 553). Their estimate is based on available balance-sheet information.

$\psi_{t}$ (government share of sector 2 output) This is the ratio of nominal government expenditure to nominal gross output of sector 2. Nominal gross output is calculated as nominal value added $Y_{2}$ mentioned above divided by $\left(1-\alpha_{2}\right)$ where $\alpha_{2}$ is the share of intermediate inputs. Government expenditure is calculated as the sum of government consumption and government investment (both available from LTES, Vol. 1, Table 1) minus the government component of nominal depreciation (already discussed above in the context of calculating private GNP).

$\delta_{t}$ (depreciation rate) The depreciation rate is calculated for each year. Given that we calculated real capital stock by dividing nominal capital stock by $p_{2}$, we would calculate $\delta_{t}$ as the ratio of real depreciation (defined as nominal depreciation divided by $p_{2}$ ) to real capital stock (at the end of previous year), or equivalently, as the ratio of nominal depreciation to nominal capital stock. However, this ratio turned out to be more volatile (although the mean is similar) than the ratio of real depreciation (in 1934-36 prices) to real capital stock in 1934-36 prices at the end of previous year. We take this real-to-real ratio to be our $\delta_{t}$ for year $t$. In calculating this ratio, both real depreciation and real capital stock are for the economy as a whole, not for the private sector. This is because, as already mentioned, the government components of depreciation and the capital stock are not available as data. $\delta_{t}$ has an upward trend; it increases from $2.8 \%$ for 1887 to $5.1 \%$ for 1940 .

$T A X_{t}$ (tax on capital income) Revenue from capital income taxes is needed to calculate $\tau_{t}$, the tax rate on capital income. The calculation of involves three steps. First, total tax revenue is divided into three categories, direct taxes on persons, direct taxes on corporations, and indirect taxes. Second, the land tax, which was a major revenue source in prewar Japan and which is included in indirect taxes, is subtracted from indirect taxes. Third, the capital income tax revenue is defined as: $0.1 \times$ (direct taxes on persons) + (direct taxes on corporations) $+0.5 \times$ (indirect taxes less the land tax). Regarding the first step, for 1930-40, Table 26 of Keizai Shingicho (1954) of the Japanese government reports this three-way breakdown for 1930-50 and we take their figures. For 1885-1929, LTES, Vol. 7, Table 7b has the three-way breakdown for the central government, while Table $7 \mathrm{~d}$ divides total tax revenue between direct taxes (with no further breakdown between personal and corporate taxes) and indirect taxes. We use the shares of personal and corporate taxes in national direct taxes to divide local direct taxes between personal and corporate taxes. Regarding the second step, Japan Statistical Association (1986) reports the land tax for the central government for all sample years. For local governments, the primary data source on government finance in general is Chiho Zaisei Gaiyo, an annual publication on local public finance by the Interior Ministry of the Japanese government. It has data on the land tax collected by local governments, but it is available only from 1901, and our library (the University of Tokyo economics department library) has it only from 1903. For 1885-1902, the local land tax is 
calculated as: LTES series on local indirect taxes times the ratio of the local land tax for 1903 available from Chiho Zaisei Gaiyo to the 1903 value of the LTES series.

$\tau_{t}$ (tax rate on capital income) Having calculated revenue from capital income, we need the tax base to calculate $\tau_{t}$. We assume that for tax purposes the replacement cost depreciation can be deducted from gross capital income. Thus the tax base for year $t$ is calculated by the formula

$$
\begin{aligned}
& \left(r_{t}-\delta_{t}\right) p_{2 t}\left(K_{1 t}+K_{2 t}\right) \\
& =r_{t} p_{2 t}\left(K_{1 t}+K_{2 t}\right)-\delta_{t} p_{2 t}\left(K_{1 t}+K_{2 t}\right) \\
& =r_{t} p_{2 t} K_{1 t}+r_{t} p_{2 t} K_{2 t}-\delta_{t} p_{2 t}\left(K_{1 t}+K_{2 t}\right) \\
& =\left(\theta_{1} q_{t} \frac{Y_{1 t}}{K_{1 t}}\right) p_{2 t} K_{1 t}+r_{t} p_{2 t} K_{2 t}-\delta_{t} p_{2 t}\left(K_{1 t}+K_{2 t}\right) \quad(\text { by (4.11) and (4.12) or by (A3.1) and (A3.3)) } \\
& =\left(\theta_{1} q_{t} \frac{Y_{1 t}}{K_{1 t}}\right) p_{2 t} K_{1 t}+\left(\theta_{2} \frac{Y_{2 t}}{K_{2 t}}-\phi\right) p_{2 t} K_{2 t}-\delta_{t} p_{2 t}\left(K_{1 t}+K_{2 t}\right) \quad(\text { by (4.14) and (4.15)) } \\
& =\theta_{1} p_{1 t} Y_{1 t}+\theta_{2} p_{2 t} Y_{2 t}-\delta_{t} p_{2 t}\left(K_{1 t}+K_{2 t}\right)-\phi p_{2 t} K_{2 t}, \quad\left(\text { since } q_{t}=p_{1 t} / p_{2 t}\right)
\end{aligned}
$$

where, as already defined, $p_{j t}$ is the deflator for sector $j$ output, $Y_{j t}$ is real value added in sector $j, \theta_{j}$ is the capital share in sector $j, K_{j t}$ is real capital stock in sector $j(j=1,2), \alpha_{t}$ is the value added ratio in sector 1 , and $\phi$ is the intermediation cost per unit of capital. The calibrated values for $\theta_{1}, \theta_{2}, \phi$ are shown in the text. $\tau_{t}$ is calculated as the ratio of revenue from capital income taxes (TAX, already discussed above) to the tax base shown above. The prewar mean is $30.8 \%$. Although the calculation of $\tau_{t}$ requires $\phi$ to be calibrated, calculation of $\tau_{t}\left(r_{t}-\delta_{t}\right)$, which is needed to calibrate $\phi$ in (6.9) in the text, does not. This can be seen from the above expression for the tax base. Since the tax base equals $\left(r_{t}-\delta_{t}\right) p_{2 t}\left(K_{1 t}+K_{2 t}\right)$, we have

$$
\tau_{t}\left(r_{t}-\delta_{t}\right)=\frac{T A X_{t}}{\left(r_{t}-\delta_{t}\right) p_{2 t}\left(K_{1 t}+K_{2 t}\right)}\left(r_{t}-\delta_{t}\right)=\frac{T A X_{t}}{p_{2 t}\left(K_{1 t}+K_{2 t}\right)} .
$$

Chained real GNP. Our construction of prewar real private GNP for year $t$ in 1934-36 prices is already described and is equal to $Y_{1 t}+Y_{2 t}$ for all $t$. We also calculated chained real private GNP as the chain-type Fisher quantity index. It is calculated as follows: its value for $t=1935$ equals nominal private GNP described above. GNP for other years are calculated using the Fisher quantity index. Namely, the Fisher formula for real GNP in year $t$ relative to its value in year $t-1$ is

$$
\sqrt{\frac{p_{1, t-1} Y_{1 t}+p_{2, t-1} Y_{2 t}}{p_{1, t-1} Y_{1, t-1}+p_{2, t-1} Y_{2, t-1}} \times \frac{p_{1 t} Y_{1 t}+p_{2 t} Y_{2 t}}{p_{1 t} Y_{1, t-1}+p_{2 t} Y_{2, t-1}}}=\sqrt{\frac{q_{t-1} Y_{1 t}+Y_{2 t}}{q_{t-1} Y_{1, t-1}+Y_{2, t-1}} \times \frac{q_{t} Y_{1 t}+Y_{2 t}}{q_{t} Y_{1, t-1}+Y_{2, t-1}}} .
$$

The difference between this chain index and $Y_{1 t}+Y_{2 t}$, however, is small. For example for 1885, the former is 3,818 while the latter is 3,853. The implicit deflator associated with chained real private GNP is the ratio of nominal private GNP to this chained GNP.

Minor details. We altered the LTES figures at three places. First, the real stock of structures for the economy as a whole in 1934-36 prices (which we need to calculate private real capital stock, as described above) exhibits a discontinuous jump from 1885 to 1886 . This is because the series for nonfarm residential structures starts in 1886, not 1885 (see LTES, Vol. 3, Table 6). The LTES 1885 value of 
residential structures is replaced by $x$ which is obtained by solving the perpetual inventory formula for $x$ : $K_{1886}=(1-\delta) x+I_{1885}$, where $K_{1886}$ is residential structures at the end of 1886 in 1934-36 prices and $I_{1885}$ is real investment in residential structures from LTES. The depreciation rate for structures, $\delta$ here, is the average of the depreciation rate for 1886-1940 implied by the LTES series on real capital stock and real investment through the perpetual inventory formula. Second, private real investment in nonresidential structures for 1939 seemed too large for us. The 1939 value is assumed to be the simple average of the 1938 and 1940 values. Third, the depreciation rates $\delta_{t}$ calculated as described above for 1885 and 1886 differ substantially from other years. We set $\delta_{t}$ for $t=1885$ and 1886 to $\delta_{1887}$.

\section{Extending Prewar Series to the Postwar Period}

The standard growth accounting in the text requires series on $Y$ (real private GNP), $K$ (real private capital stock including foreign assets), $N$ (working-age population), and $h E$ (total hours worked). Total hours worked $h E$ equals $h_{1} E_{1}+h_{2} E_{2}$, where $h_{i}$ and $E_{i}$ are average hours worked per week and employment in sector $i(i=1,2)$. Following the one-sector analysis of Hayashi and Prescott (2002), real private capital stock in the growth accounting in the text is defined as nominal private capital stock (including foreign assets) divided by the implicit GNP deflator $P$. We describe below how $h_{1}, E_{1}, h_{2}, E_{2}, N$, and nominal private capital stock are extended to the postwar period and how $Y$ (real GNP) and $P$ (its deflator) are defined for the entire period 1885-2000. The primary data source for employment and hours worked is the Labor Force Survey which, as mentioned above, is a survey on individuals. There is an establishment survey on employment and hours worked (called the Monthly Labor Survey (Maitsuki Kinro Tokei Chousa in Japanese)), but it does not cover agriculture.

$Y$ (real private GNP) and $P$ (its deflator) for 1885-2000. For 1885-1940, $Y$ is the chain index described above. Real GNP for 1930-1964 (except for 1945) is available from the 1966 White Paper on National Income, the Economic Planning Agency of the Japanese government. $Y$ is extended from 1941 to 1956 (except for 1945) using this series. The dataset developed from Japanese national accounts on the SNA68 basis (System of National Accounts on 1968 basis) in Hayashi and Prescott (2002), downloadable from http://fhayashi.fc2web.com/Hayashi-Prescott1.htm, has real private GNP for 1956-2000. This series is used to extend $Y$ from 1956 to 2000. $P$ for 1885-1940 is the implicit deflator associated with the chain index described above. Nominal private GNP is available from the above Hayashi-Prescott dataset for 1956-2000. Nominal GNP for 1930-71 is available from LTES, Table 1A. Nominal private GNP for 1941-55 (except for 1945) is calculated as the LTES nominal GNP times the ratio of the Hayashi-Prescott nominal private GNP for 1956 to the LTES nominal GNP for 1956. P for 1941-2000 is the ratio of nominal private GNP to real private GNP.

$N$ (working-age population) For postwar, $N$ is defined as population aged 20 or older. For 1947-1955, Census data on population by age are available only for 1947, 1950, and 1955 (their values are reported in Table 2-9, Volume 1 of Japan Statistical Association (1986)). $N$ for intervening years are by linear interpolation. From 1955 on, $N$ is available annually from publications by the Statistics Bureau of the Management and Coordination Agency of the Japanese government.

$E_{1}, E_{2}$ (employment in two sectors) The LTES series we used for prewar $E_{1}$ (from LTES, Vol. 9, Table 33) actually extends to 1963. For 1941-47, $E_{1}$ is the LTES series for 1941-1947. The Labor Force Survey has employment for agriculture proper from 1970 on and for agriculture \& forestry from 1948 on (the 
figure for the latter for 1948-85 are in Table 3-8, Volume 1 of Japan Statistical Association (1986)). For 1970-2004, $E_{1}$ is this Labor Force Survey series for agriculture proper for 1970-2000. For 1948-69, $E_{1}$ is calculated as the Labor Force Survey series for agriculture \& forestry times $x / y$, where $x$ here is employment in agriculture proper and $y$ is employment in agriculture \& forestry, both for 1970 and from the Labor Force Survey. $E_{1}$ for 1948 thus calculated is 15.99 million. The LTES series for 1948 stands at 15.85 million. Data on $E_{1}+E_{2}$ since 1948 are from the Labor Force Survey (we used the figures reported in Table 3-8, Volume 1 of Japan Statistical Association (1986) for 1948-85). Workers in the Labor Force Survey are 14 years or older for 1948-55 and 15 years or older thereafter.

$h_{1}, h_{2}$ (hours worked per week) $h_{1}$ for 1948-2004 is average hours worked per week in agriculture \& forestry for workers from the Labor Force Survey. $h_{2}$ for 1949-2004 is average hours worked per week for workers outside agriculture \& forestry, from the Labor Force Survey. Figures for 1948-85 are from Table 3-14, Volume 1 of Japan Statistical Association (1986). Figures for recent years are in Table 10 of the annual reports on the Labor Force Survey.

Nominal private capital stock (including foreign assets) The end-of-year values for 1955-2000 are available from the Hayashi-Prescott dataset mentioned above.

\section{U.S. GNP}

U.S. real GNP for 1929-2000 in chained 2000 dollars is taken from Table 7.1 of the NIPA (National Income and Product Accounts, complied by the Bureau of Economic Analysis), which is a chain-type quantity index using the Fisher formula. Extending back the series to 1885 is done using the Balke-Gordon series available in Balke and Gordon (1989). Working-age population is population aged 16 or older for 18851945 and aged 21 or older for 1946-2000. Population aged 16 or older for 1900-1945 is from Historical Statistics of the United States. This series is extended back to 1885 using total population, also available from the Historical Statistics. Population aged 21 or older for 1946-1970 is from the Historical Statistics. This series is extended to 2000 by civilian noninstitutional population aged 20 or older available from the Bureau of Labor Statistics website http://www.bls.gov/cps/. 


\section{Appendix 2: Reducing Equilibrium Conditions to the Two-Equation Dynamical System}

This appendix describes in detail how the equilibrium conditions in Section 4 can be reduced to the two-equation dynamical system.

- We first reduce the equilibrium conditions except the employment arbitrage condition (4.4) and the transversality condition (4.10) - the eleven equations (4.8), (4.9), (4.12), (4.13), (4.15), (4.16), (4.17)(4.21) - into seven equations. Defining $s_{K t} \equiv K_{1 t} /\left(K_{1 t}+K_{2 t}\right)$, recalling that $s_{E t} \equiv E_{1 t} / E_{t}$ and $\psi_{t} \equiv G_{t} / Y_{2 t}$, and substituting the Frisch demands (4.9) and the factor market equilibrium conditions (4.19)-(4.21) into the rest of the eleven equations, we obtain

$$
\begin{gathered}
N_{t} c_{2}\left(q_{t}, \lambda_{t}\right)+N_{t+1} k_{t+1}-\left(1-\delta_{t}\right) N_{t} k_{t}=\left(1-\psi_{t}\right) Y_{2 t}-\phi N_{t}\left(1-s_{K t}\right) k_{t} \\
\lambda_{t+1}=\beta \lambda_{t}\left[1+\left(1-\tau_{t+1}\right)\left(r_{t+1}-\delta_{t+1}\right)\right], \\
N_{t} q_{t} c_{1}\left(q_{t}, \lambda_{t}\right)=q_{t} Y_{1 t} \\
r_{t}=\theta_{1} \frac{q_{t} Y_{1 t}}{s_{K t} N_{t} k_{t}} \\
r_{t}+\phi=\theta_{2} \frac{Y_{2 t}}{\left(1-s_{K t}\right) N_{t} k_{t}}, \\
w_{1 t}=\eta \frac{q_{t} Y_{1 t}}{s_{E t} h_{1 t} E_{t}}, \\
w_{2 t}=\left(1-\theta_{2}\right) \frac{Y_{2 t}}{\left(1-s_{E t}\right) h_{2 t} E_{t}}
\end{gathered}
$$

where, as before, $Y_{1 t}$ and $Y_{2 t}$ are given by (4.11) and (4.14), reproduced here for convenience:

$$
Y_{1 t}=\operatorname{TFP}_{1 t} K_{1 t}^{\theta_{1}} L_{1 t^{\prime}}^{\eta} Y_{2 t}=T F P_{2 t} K_{2 t}^{\theta_{2}} L_{2 t}^{1-\theta_{2}}
$$

- We now reduce these seven equations into six equations written in terms of detrended variables. To reproduce the definition of detrended variables in Section 4,

$$
\begin{gathered}
X_{Y t} \equiv T F P_{2 t}^{\frac{1}{1-\theta_{2}}} h_{2 t} E_{t} / N_{t}, \quad X_{Q t} \equiv T F P_{1 t}^{-1}\left(h_{1 t} E_{t}\right)^{-\eta} T F P_{2 t}^{\frac{1-\theta_{1}}{1-\theta_{2}}}\left(h_{2 t} E_{t}\right)^{1-\theta_{1}}, \\
\tilde{k}_{t} \equiv \frac{k_{t}}{X_{Y t}}, \quad \tilde{\lambda}_{t} \equiv \frac{\lambda_{t}}{X_{Y t}}, \tilde{q}_{t} \equiv \frac{q_{t}}{X_{Q t}} .
\end{gathered}
$$

A somewhat tedious algebra yields:

$$
q_{t} Y_{1 t}=N_{t} X_{Y t} \tilde{q}_{t} \tilde{y}_{1 t} \quad \text { and } \quad Y_{2 t}=N_{t} X_{Y t} \tilde{y}_{2 t},
$$

where

$$
\tilde{y}_{1 t} \equiv \tilde{k}_{t}^{\theta_{1}} s_{K t}^{\theta_{1}} s_{E t}^{\eta}, \tilde{y}_{2 t} \equiv \tilde{k}_{t}^{\theta_{2}}\left(1-s_{K t}\right)^{\theta_{2}}\left(1-s_{E t}\right)^{1-\theta_{2}} .
$$


Using this relation and eliminating $r_{t}$ from the system, we can easily obtain

$$
\begin{gathered}
\text { (resource constraint) } \frac{N_{t+1}}{N_{t}} \frac{X_{Y, t+1}}{X_{Y t}} \tilde{k}_{t+1}=\left[1-\delta_{t}-\left(1-s_{K t}\right) \phi\right] \tilde{k}_{t}+\left(1-\psi_{t}\right) \tilde{y}_{2 t}-\frac{c_{2}\left(\tilde{q}_{t} X_{Q t}, \tilde{\lambda}_{t} X_{Y t}\right)}{X_{Y t}} \\
\text { (Euler equation) } \frac{X_{Y, t+1}}{X_{Y t}} \tilde{\lambda}_{t+1}=\beta \tilde{\lambda}_{t}\left\{1+\left(1-\tau_{t+1}\right)\left[\theta_{2} \frac{\tilde{y}_{2, t+1}}{\left(1-s_{K, t+1}\right) \tilde{k}_{t+1}}-\phi-\delta_{t+1}\right]\right\}, \\
\text { (market equilibrium for good } 1) \frac{\tilde{q}_{t} c_{1}\left(\tilde{q}_{t} X_{Q t}, \tilde{\lambda}_{t} X_{Y t}\right)}{X_{Y t} / X_{Q t}}=\tilde{q}_{t} \tilde{y}_{1 t}, \\
\text { (equality of marginal products of capital) } \quad \theta_{1} \frac{\tilde{q}_{t} \tilde{y}_{1 t}}{s_{K t} \tilde{k}_{t}}+\phi=\theta_{2} \frac{\tilde{y}_{2 t}}{\left(1-s_{K t}\right) \tilde{k}_{t}} \\
\text { (sectoral income ratio) } \frac{w_{1 t} h_{1 t}}{w_{2 t} h_{2 t}}=\frac{\eta \frac{\tilde{q}_{t} \tilde{y}_{1 t}}{s_{E t}}}{\left(1-\theta_{2}\right) \frac{\tilde{y}_{2 t}}{1-s_{E t}}}
\end{gathered}
$$

and

$$
w_{2 t}=\operatorname{TFP}_{2 t}^{\frac{1}{1-\theta_{2}}}\left(1-\theta_{2}\right) \frac{\tilde{y}_{2 t}}{1-s_{E t}} .
$$

- We now show that $\left(s_{K t}, s_{E t}, \tilde{q}_{t}\right)$ given $\left(\tilde{k}_{t}, \tilde{\lambda}_{t}, X_{Y t}, X_{Q t}\right)$ is uniquely determined by (A2.14)-(A2.16) and (4.4), so that the equilibrium conditions reduce to the two-equation dynamical system (A2.12) and (A2.13) in two variables $\left(\tilde{k}_{t}, \tilde{\lambda}_{t}\right)$. The graph of (4.4), which is a correspondence from income ratio $\frac{w_{1 t} h_{1 t}}{w_{2} h_{2 t}}$ to labor share $s_{E t}$, is the staircase shown in Appendix Figure 1. This can be interpreted as the supply curve of sector 1 labor. To derive a demand curve, we solve (A2.14) and (A2.15) for $\left(\tilde{q}_{t}, s_{K t}\right)$ given $\left(s_{E t}, \tilde{k}_{t}, \tilde{\lambda}_{t}, X_{Y t}, X_{Q t}\right)$, and then substitute these solved-out values into (A2.16) to obtain $\frac{w_{1 t} h_{1 t}}{w_{2 t} h_{2 t}}$ as a function of $\left(s_{E t}, \tilde{k}_{t}, \tilde{\lambda}_{t}, X_{Y t}, X_{Q t}\right)$. It is easy to show that the function is strictly decreasing in $s_{E t}$, so the graph of $\frac{w_{1} h_{1 t}}{w_{2} h_{2 t}}$ as a function of $s_{E t}$ is downward-sloping. This is the demand curve for sector 1 labor. Three possible cases are drawn in Appendix Figure 1. In Case A, the demand curve intersects with the vertical portion of the staircase (the graph of the arbitrage condition) at $s_{E t}=\bar{s}_{E t}$. In thise case, the labor barrier $s_{E t} \geq \bar{s}_{E t}$ is binding. Case $\mathrm{B}$ is that the intersection is on the horizontal portion of the staircase. In this case, $\frac{w_{11} h_{1 t}}{w_{2 t} h_{2 t}}=1$, so from (A2.16) we have

$$
1=\frac{\eta \frac{\tilde{q}_{t} \tilde{y}_{1 t}}{s_{E t}}}{\left(1-\theta_{2}\right) \frac{\tilde{y}_{2 t}}{1-s_{E t}}} .
$$

The final case, Case $C$, is that the demand curve intersects with the staircase at $s_{E t}=1$. In either case, given $\left(\tilde{k}_{t}, \tilde{\lambda}_{t}, X_{Y t}, X_{Q t}\right), s_{E t}$ is uniquely determined. Given $\left(s_{E t}, \tilde{k}_{t}, \tilde{\lambda}_{t}, X_{Y t}, X_{Q t}\right),\left(s_{K t}, \tilde{q}_{t}\right)$ is uniquely determined by (A2.14) and (A2.15), as just explained. 
Figure 1: The Three Cases

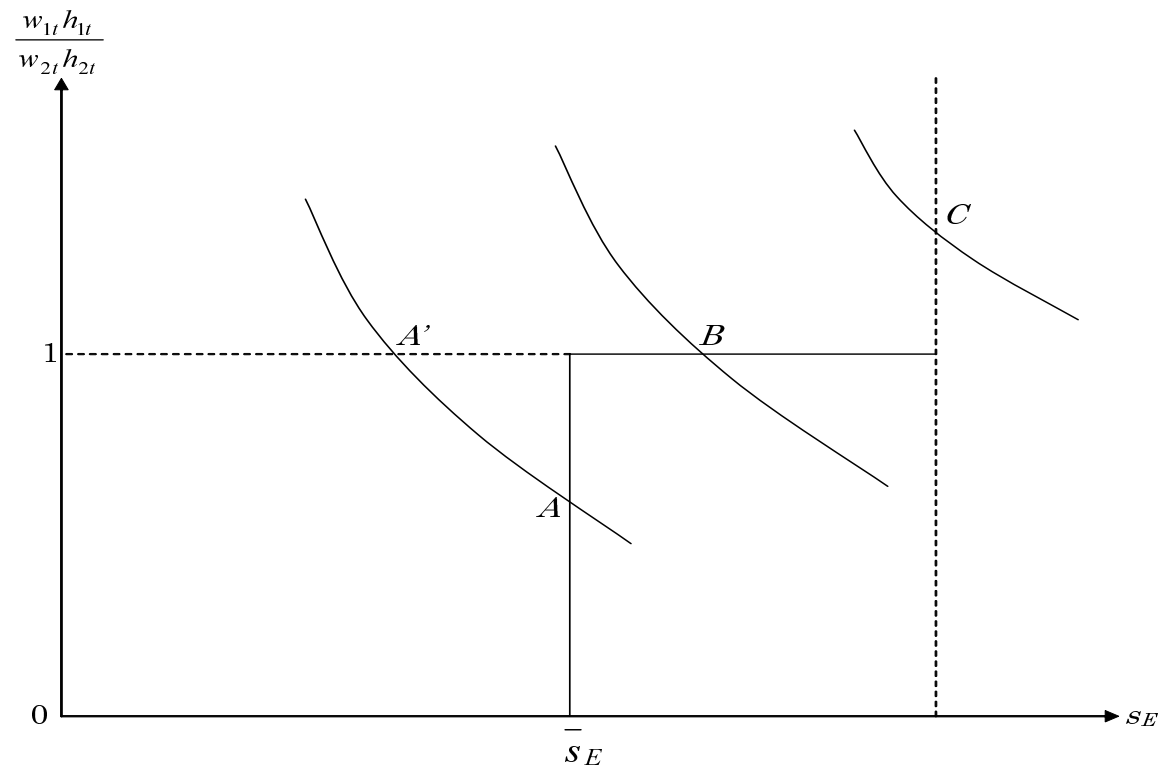

- In Case C, sector 1 is so productive that all employment is in agriculture (which means $L_{2 t}=0$ ). Under the calibrated parameter values and the initial conditions specified in the text about the model, this case does not arise in any period. Assuming that only Case A and Case B are relevant, the value of $s_{E t}$ satisfying (A2.14)-(A2.16), and (4.4) can be determined as follows. Notice from the previous paragraph that in Case B $\left(s_{K t}, s_{E t}, \tilde{q}_{t}\right)$ solves (A2.14), (A2.15), and (A2.18). If Case C is impossible, then Case A (where the labor barrier $s_{E t} \geq \bar{s}_{E t}$ is binding) obtains if and only if the $s_{E t}$ that solves these three equations is less than $\bar{s}_{E t}$ (this corresponds to point $A^{\prime}$ in Appendix Figure 1). Therefore, to find $\left(s_{K t}, s_{E t}, \tilde{q}_{t}\right)$ that solves (A2.14)-(A2.16) and (4.4) given $\left(\tilde{k}_{t}, \tilde{\lambda}_{t}, X_{Y t}, X_{Q t}\right)$, we can proceed as follows:

1. Solve (A2.14),(A2.15), and (A2.18) for $\left(s_{K t}, s_{E t}, \tilde{q}_{t}\right)$. If $s_{E t} \geq \bar{s}_{E t}$, then the solution is found.

2. If $s_{E t}<\bar{s}_{E t}$, then set $s_{E t}=\bar{s}_{E t}$ and use (A2.14) and (A2.15) to solve for $\left(s_{K t}, \tilde{q}_{t}\right)$ given $s_{E t}$ thus determined. 


\section{Appendix 3: Incorporating Intermediate Inputs}

In this appendix, we allow each sector to use the output of the other sector as an intermediate input. For this more general model, we derive a two-equation dynamical system, compute its steady state, and show that the steady state is a saddle.

\section{The Equilibrium Conditions}

Start with sector 1 (agriculture). If $M_{1 t}$ is the intermediate input from sector 2 to sector 1, the production function for sector 1 is

$$
Y_{1 t}=T F P_{1 t} K_{1 t}^{\theta_{1}} L_{1 t}^{\eta} M_{1 t}^{\alpha_{1}} .
$$

The contribution of land is implicit in this production function, so we have a decreasing returns to scale in capital, labor, and the intermediate input:

$$
\theta_{1}+\eta+\alpha_{1}<1
$$

The firms' first-order conditions with respect to $K_{1 t}, L_{1 t}$, and $M_{1 t}$ for sector 1 are:

$$
\begin{aligned}
r_{t} & =\theta_{1} q_{t} \operatorname{TFP}_{1 t} K_{1 t}^{\theta_{1}-1} L_{1 t}^{\eta} M_{1 t}^{\alpha_{1}}, \\
w_{1 t} & =\eta q_{t} \operatorname{TFP}_{1 t} K_{1 t}^{\theta_{1}} L_{1 t}^{\eta-1} M_{1 t}^{\alpha_{1}} \\
1 & =\alpha_{1} q_{t} \operatorname{TFP}_{1 t} K_{1 t}^{\theta_{1}} L_{1 t}^{\eta} M_{1 t}^{\alpha_{1}-1} .
\end{aligned}
$$

Solving (A3.5) for $M_{1 t}$ gives

$$
M_{1 t}=\alpha_{1}^{\frac{1}{1-\alpha_{1}}} q_{t}^{\frac{1}{1-\alpha_{1}}} \operatorname{TFP}_{1 t}^{\frac{1}{1-\alpha_{1}}} K_{1 t}^{\frac{\theta_{1}}{1-\alpha_{1}}} L_{1 t}^{\frac{\eta}{1-\alpha_{1}}} .
$$

Combining this with (A3.1) gives

$$
\begin{gathered}
M_{1 t}=\alpha_{1} q_{t} Y_{1 t} \\
Y_{1 t}=q_{t}^{\frac{\alpha_{1}}{1-\alpha_{1}}} \widetilde{T F P}_{1 t} K_{1 t}^{\tilde{\theta}_{1}} L_{1 t^{\prime}}^{\tilde{\eta}}
\end{gathered}
$$

where

$$
\widetilde{T F P}_{1 t} \equiv \alpha_{1}^{\frac{\alpha_{1}}{1-\alpha_{1}}} \operatorname{TFP}_{1 t}^{\frac{1}{1-\alpha_{1}}}, \quad \tilde{\theta}_{1} \equiv \frac{\theta_{1}}{1-\alpha_{1}}, \quad \tilde{\eta} \equiv \frac{\eta}{1-\alpha_{1}} .
$$

Substituting (A3.6) into the marginal productivity conditions (A3.3) and (A3.4) yields

$$
\begin{aligned}
& r_{t}=\left(1-\alpha_{1}\right) \tilde{\theta}_{1} q_{t}^{\frac{1}{1-\alpha_{1}}} \widetilde{T F P}_{1 t} K_{1 t}^{\tilde{\theta}_{1}-1} L_{1 t^{\prime}}^{\tilde{\eta}} \\
& w_{1 t}=\left(1-\alpha_{1}\right) \tilde{\eta} q_{t}^{\frac{1}{1-\alpha_{1}}} \widetilde{T F P}_{1 t} K_{1 t}^{\tilde{\theta}_{1}} L_{1 t}^{\tilde{\eta}-1} .
\end{aligned}
$$

(A3.8) replaces (4.11), (A3.10) replaces (4.12), and (A3.11) replaces (4.13). Noting that an amount $M_{1 t}=$ $\alpha_{1} q_{t} Y_{1 t}$ of good 2 goes into sector 1 , the equilibrium condition for good 2, (4.18), is now

$$
(\operatorname{good} 2) N_{t} c_{2 t}+\left(N_{t+1} k_{t+1}-\left(1-\delta_{t}\right) N_{t} k_{t}\right)+G_{t}+\alpha_{1} q_{t} Y_{1 t}=Y_{2 t}-\phi K_{2 t} .
$$


Turning to sector 2, if $M_{2 t}$ is the intermediate input from sector 2 to sector 1, the Cobb-Douglas production function for sector 2 is

$$
Y_{2 t}=\operatorname{TFP}_{2 t} K_{2 t}^{\theta_{2}} L_{2 t}^{\eta_{2}} M_{2 t}^{\alpha_{2}} .
$$

The constant-returns-to-scale assumption for sector 2 implies

$$
\theta_{2}+\eta_{2}+\alpha_{2}=1 \text {. }
$$

It is straightforward to derive the following corresponding expressions for sector 2:

$$
\begin{gathered}
M_{2 t}=\alpha_{2} q_{t}^{-1} Y_{2 t}, \\
Y_{2 t}=q_{t}^{\frac{-\alpha_{2}}{1-\alpha_{2}}} \widetilde{T F P}_{2 t} K_{2 t}^{\tilde{\theta}_{2}} L_{2 t}^{1-\tilde{\theta}_{2}}, \\
r_{t}+\phi=\left(1-\alpha_{2}\right) \tilde{\theta}_{2} q_{t}^{\frac{-\alpha_{2}}{1-\alpha_{2}}} \widetilde{T F P}_{2 t}\left(\frac{K_{2 t}}{L_{2 t}}\right)^{\tilde{\theta}_{2}-1}, \\
w_{t}=\left(1-\alpha_{2}\right)\left(1-\tilde{\theta}_{2}\right) q_{t}^{\frac{-\alpha_{2}}{1-\alpha_{2}}} \widetilde{T F P} 2 t\left(\frac{K_{2 t}}{L_{2 t}}\right)^{\tilde{\theta}_{2}},
\end{gathered}
$$

where

$$
\widetilde{T F P}_{2 t} \equiv \alpha_{2}^{\frac{\alpha_{2}}{1-\alpha_{2}}} \operatorname{TFP}_{2 t}^{\frac{1}{1-\alpha_{2}}}, \quad \tilde{\theta}_{2} \equiv \frac{\theta_{2}}{1-\alpha_{2}} .
$$

(A3.16) replaces (4.14), (A3.17) replaces (4.15), and (A3.18) replaces (4.16). With fraction $\alpha_{2}$ of sector 1 output going to the production of good 2, the market equilibrium condition for good 1 is

$$
(\operatorname{good} 1) \quad N_{t} q_{t} c_{1 t}+\alpha_{2} Y_{2 t}=q_{t} Y_{1 t} .
$$

\section{The Detrended Dynamical System}

With intermediate inputs, the trend $X_{Q t}$ and $X_{Y t}$ in (4.22) are now

$$
\begin{gathered}
X_{Q t} \equiv\left[\widetilde{T F P}_{1 t}^{-1}\left(h_{1 t} E_{t}\right)^{-\tilde{\eta}} \widetilde{T F P}_{2 t}^{\frac{1-\tilde{\theta}_{1}}{1-\tilde{\theta}_{2}}}\left(h_{2 t} E_{t}\right)^{1-\tilde{\theta}_{1}}\right]^{\frac{1}{\zeta}} \quad \text { with } \quad \zeta \equiv \frac{1}{1-\alpha_{1}}+\frac{\alpha_{2}\left(1-\tilde{\theta}_{1}\right)}{\left(1-\alpha_{2}\right)\left(1-\tilde{\theta}_{2}\right)^{\prime}}, \\
X_{Y t}=\widetilde{T F P}_{2 t}^{\frac{1}{1-\tilde{\theta}_{2}}} X_{\mathrm{Qt}}^{\frac{-\alpha_{2}}{\left(1-\alpha_{2}\right)\left(1-\tilde{\theta}_{2)}\right)}}\left(h_{2 t} E_{t}\right) / N_{t} .
\end{gathered}
$$

A very tedious algebra shows that the same relation (A2.10) holds, provided that $\tilde{y}_{1 t}$ and $\tilde{y}_{2 t}$ are now defined as

$$
\tilde{y}_{1 t} \equiv \tilde{q}_{t}^{\frac{\alpha_{1}}{1-\alpha_{1}}} \tilde{k}_{t}^{\tilde{\theta}_{1}} s_{K t}^{\tilde{\theta}_{1}} s_{E t^{\prime}}^{\tilde{\tilde{\eta}}} \quad \tilde{y}_{2 t} \equiv \tilde{q}_{t}^{\frac{-\alpha_{2}}{1-\alpha_{2}}} \tilde{k}_{t}^{\tilde{\theta}_{2}}\left(1-s_{K t}\right)^{\tilde{\theta}_{2}}\left(1-s_{E t}\right)^{1-\tilde{\theta}_{2}}
$$


It is then straightforward to show that the five equations corresponding to (A2.12)-(A2.16) are:

(resource constraint) $\frac{N_{t+1}}{N_{t}} \frac{X_{Y, t+1}}{X_{Y t}} \tilde{k}_{t+1}=\left[1-\delta_{t}-\left(1-s_{K t}\right) \phi\right] \tilde{k}_{t}+\left(1-\psi_{t}\right) \tilde{y}_{2 t}-\frac{c_{2}\left(\tilde{q}_{t} X_{Q t}, \tilde{\lambda}_{t} X_{Y t}\right)}{X_{Y t}}-\alpha_{1} \tilde{q}_{t} \tilde{y}_{1 t}$,

(Euler equation) $\frac{X_{Y, t+1}}{X_{Y t}} \tilde{\lambda}_{t+1}=\beta \tilde{\lambda}_{t}\left\{1+\left(1-\tau_{t+1}\right)\left[\left(1-\alpha_{2}\right) \tilde{\theta}_{2} \frac{\tilde{y}_{2, t+1}}{\tilde{k}_{t+1}\left(1-s_{K, t+1}\right)}-\phi-\delta_{t+1}\right]\right\}$,

$$
\text { (market equilibrium for good 1) } \frac{\tilde{q}_{t} c_{1}\left(\tilde{q}_{t} X_{Q t}, \tilde{\lambda}_{t} X_{Y t}\right)}{X_{Y t} / X_{Q t}}+\alpha_{2} \tilde{y}_{2}=\tilde{q}_{t} \tilde{y}_{1 t}
$$

(equality of marginal products of capital) $\quad\left(1-\alpha_{1}\right) \tilde{\theta}_{1} \frac{\tilde{q}_{t} \tilde{y}_{1 t}}{\tilde{k}_{t} s_{K t}}=\left(1-\alpha_{2}\right) \tilde{\theta}_{2} \frac{\tilde{y}_{2 t}}{\left(1-s_{K t}\right) \tilde{k}_{t}}-\phi$,

$$
\text { (sectoral income ratio) } \frac{w_{1 t} h_{1 t}}{w_{2 t} h_{2 t}}=\frac{\left(1-\alpha_{1}\right) \tilde{\eta} \frac{\tilde{q}_{t} \tilde{y}_{1 t}}{s_{E t}}}{\left(1-\alpha_{2}\right)\left(1-\tilde{\theta}_{2}\right) \frac{\tilde{y}_{2 t}}{1-s_{E t}}} \text {. }
$$

\section{The Autonomous System and its Steady State}

To study the asymptotic property of the autonomous system, in the rest of this Appendix, assume:

(a) the trends $N_{t}$ and $X_{Y t}$ grow at constant rates (let $n \equiv \frac{N_{t+1}}{N_{t}}$ and $\gamma \equiv \frac{X_{Y, t+1}}{X_{Y t}}$ ) and $\psi_{t}=\psi$,

(b) the demand functions $c_{1}$ and $c_{2}$ are those given in (5.2) and (5.3), reproduced here:

$$
\frac{c_{1}\left(\tilde{q} X_{Q t}, \tilde{\lambda} X_{Y t}\right)}{X_{Y t} / X_{Q t}}=\mu_{1} \frac{\tilde{\lambda}}{\tilde{q}}, \frac{c_{2}\left(\tilde{q} X_{Q t}, \tilde{\lambda} X_{Y t}\right)}{X_{Y t}}=\mu_{2} \tilde{\lambda} .
$$

Clearly, under these two conditions, the detrended dynamical system (A3.24)-(A3.28), with $\frac{w_{1 t} h_{1 t}}{w_{2 t} h_{2 t}}$ set equal to 1 , is autonomous. In this autonomous system, the path of $X_{Q t}$ can be arbitrary (it does not have to be a constant-growth-rate path, for example) simply because $X_{Q t}$ does not enter the system. However, as mentioned in the text, for the non-autonomous system exhibiting Engel's law to asymptotically behave like the autonomous system to be studied below, we need $X_{Y t} / X_{Q t}$ to grow without limit. 
The steady-state $\left(\tilde{k}, \tilde{\lambda}, \tilde{q}, s_{K}, s_{E}\right)$ of this dynamical system satisfies the following five equations that can be obtained by dropping the time subscript in the system and by recalling that $\gamma \equiv X_{Y, t+1} / X_{Y t}$ :

$$
\begin{gathered}
n \gamma=\left[1-\delta-\left(1-s_{K}\right) \phi\right]+(1-\psi) \frac{\tilde{y}_{2}}{\tilde{k}}-\mu_{2} \frac{\tilde{\lambda}}{\tilde{k}}-\alpha_{1} \frac{\tilde{q} \tilde{y}_{1}}{\tilde{k}}, \\
g_{2}^{\frac{1}{1-\theta_{2}}}=\beta\left\{1+(1-\tau)\left[\left(1-\alpha_{2}\right) \tilde{\theta}_{2} \frac{\tilde{y}_{2}}{\left(1-s_{K}\right) \tilde{k}}-\phi-\delta\right]\right\}, \\
\mu_{1} \tilde{\lambda}+\alpha_{2} \tilde{y}_{2}=\tilde{q} \tilde{y}_{1}, \\
\left.11-\alpha_{1}\right) \tilde{\theta}_{1} \frac{\tilde{q} \tilde{y}_{1}}{s_{K} \tilde{k}}=\left(1-\alpha_{2}\right) \tilde{\theta}_{2} \frac{\tilde{y}_{2}}{\left(1-s_{K}\right) \tilde{k}}-\phi, \\
1=\frac{\left(1-\alpha_{1}\right) \tilde{\eta} \frac{\tilde{y} \tilde{y}_{1}}{s_{E}}}{\left(1-\alpha_{2}\right)\left(1-\tilde{\theta}_{2}\right) \frac{\tilde{y}_{2}}{1-s_{E}} .}
\end{gathered}
$$

where

$$
\tilde{y}_{1}=\tilde{q}^{\frac{\alpha_{1}}{1-\alpha_{1}}} \tilde{k}^{\tilde{\theta}_{1}} s_{K}^{\tilde{\theta}_{1}} s_{E^{\prime}}^{\tilde{\eta}} \quad \tilde{y}_{2}=\tilde{q}^{\frac{-\alpha_{2}}{1-\alpha_{2}}} \tilde{k}^{\theta_{2}}\left(1-s_{K}\right)^{\theta_{2}}\left(1-s_{E}\right)^{1-\theta_{2}} .
$$

This five-equation system can be solved explicitly. For example, the closed-form expression for $s_{K}$ is

$$
s_{K}=\frac{1-\delta+\left[\left(1-\psi+\frac{\mu_{2}}{\mu_{1}} \alpha_{2}\right) \frac{r+\phi}{\left(1-\alpha_{2}\right) \tilde{\theta}_{2}}-\phi\right]-n \gamma}{\left[\left(1-\psi+\frac{\mu_{2}}{\mu_{1}} \alpha_{2}\right) \frac{r+\phi}{\left(1-\alpha_{2}\right) \widetilde{\theta}_{2}}-\phi\right]+\frac{\left(\alpha_{1}+\frac{\mu_{2}}{\mu_{1}}\right) r}{\left(1-\alpha_{1}\right) \tilde{\theta}_{1}}},
$$

where

$$
r \equiv \frac{\frac{\gamma}{\beta}-1}{1-\tau}+\delta
$$

is the steady-state gross pretax rate of return from capital.

Under the calibrated parameter values, the Jacobian of the mapping from $\left(\tilde{k}_{t}, \tilde{\lambda}_{t}\right)$ to $\left(\tilde{k}_{t+1}, \tilde{\lambda}_{t+1}\right)$ for the dynamical system is numerically calculated and its engenvalues are $(1.19,0.87)$. So the steady state is a saddle. 


\section{Appendix 4: The Open Economy Version}

This appendix describes the model obtained from opening up the model of Appendix 3 to trade in goods and services.

\section{The Detrended Dynamical System}

If the country can exchange good 1 for good 2 at a given relative price of $q_{t}$, the market equilibrium conditions for good 1 and good 2 can be combined into one. This means that, in the detrended dynamical system of Appendix 3, we can drop (A3.26) and modify the resource constraint (A3.24) as

$$
\begin{aligned}
\text { (resource constraint) } \frac{N_{t+1}}{N_{t}} \frac{X_{Y, t+1}}{X_{Y t}} \tilde{k}_{t+1}= & {\left[1-\delta_{t}-\left(1-s_{K t}\right) \phi\right] \tilde{k}_{t}+\left(1-\psi_{t}\right) \tilde{y}_{2 t}-\frac{c_{2}\left(\tilde{q}_{t} X_{Q t}, \tilde{\lambda}_{t} X_{Y t}\right)}{X_{Y t}}-\alpha_{1} \tilde{q}_{t} \tilde{y}_{1 t} } \\
& +\left[\tilde{q}_{t} \tilde{y}_{1 t}-\frac{\tilde{q}_{t} c_{1}\left(\tilde{q}_{t} X_{Q t}, \tilde{\lambda}_{t} X_{Y t}\right)}{X_{Y t} / X_{Q t}}-\alpha_{2} \tilde{y}_{2 t}\right] .
\end{aligned}
$$

The additional term on the right side is net exports of good 1, valued in terms of good 2 . This is the only change; the dynamical system is made up of (A4.1), (A3.25), (A3.27), and (A3.28) with $\tilde{y}_{1 t}$ and $\tilde{y}_{2 t}$ still given by (A3.23). 


\section{Appendix 5: Aggregating Over Domestic and Foreign Capital}

In this appendix, we show that the production function of sector 2, which is defined over the total capital stock (the sum of domestic and foreign capital) and labor, can be derived. For a particular specification of the rate of return from foreign capital and a Cobb-Douglas production function for domestic output, we will also show that the derived production function is essentially Cobb-Douglas.

To simplify notation, we drop the time subscript throughout this appendix. As in the text, let $K_{2}$ be the total capital stock in sector 2 and $L_{2}$ be labor input in the sector. The representative firm in sector 2 rents $K_{2}$ units of capital from the household and divides them between foreign capital $X$ and domestic capital $K_{2}-X$. The constant-returns-to-scale production function for domestic output is $F_{2}\left(K_{2}-X, L_{2}\right)$. The rate of return from foreign capital depends on the ratio $\xi \equiv \frac{X}{K_{2}}$. Write this schedule as $\rho(\xi)$. It is decreasing and convex function of $\xi$.

The firm's revenue is

$$
\rho\left(\frac{X}{K_{2}}\right) X+F_{2}\left(K_{2}-X, L_{2}\right)
$$

The first term is the return from investing in foreign capital and the second term is domestic production. Clearly, this expression for revenue is a linearly homogeneous function of $\left(K_{2}, L_{2}\right)$ after foreign capital $X$ is maximized out. To see this, define, for the linearly homogeneous production function $F_{2}$,

$$
f\left(\frac{K_{2}-X}{K_{2}}\right) \equiv \frac{1}{L_{2}} F_{2}\left(K_{2}-X, L_{2}\right) .
$$

The expression for revenue can be rewritten as

$$
\left[\rho(\xi) \xi k_{2}+f\left((1-\xi) k_{2}\right)\right] L_{2}
$$

where $k_{2} \equiv \frac{K_{2}}{L_{2}}$. The $\xi$ that maximizes the bracketed expression given $k_{2}$ is a function of $k_{2}$. Write it as $\xi\left(k_{2}\right)$. Letting $h\left(k_{2}\right) \equiv \rho\left(\xi\left(k_{2}\right)\right) \xi\left(k_{2}\right) k_{2}+f\left(\left(1-\xi\left(k_{2}\right)\right) k_{2}\right)$, the firm's revenue can be written as $H\left(K_{2}, L_{2}\right) \equiv h\left(\frac{K_{2}}{L_{2}}\right) L_{2}$. By construction, this function $H$ is linearly homogenous in $\left(K_{2}, L_{2}\right)$. This is the production function defined over total capital $K_{2}$ and $L_{2}$.

To show that this derived production function $H\left(K_{2}, L_{2}\right)$ can be approximately Cobb-Douglas, consider the following functional forms:

$$
F_{2}\left(K_{2}-X, L_{2}\right)=A\left(K_{2}-X\right)^{v} L_{2}^{1-v}, \text { so } f\left((1-\xi) k_{2}\right)=A(1-\xi)^{v} k_{2}^{v}, \quad \text { and } \quad \rho(\xi)=\frac{B}{1+\xi} .
$$

Here, $A, B$, and $v$ are parameters, and $\rho(\xi)$ is decreasing and concave, as required. Also, $\lim _{\xi \downarrow-1} \rho(\xi)=\infty$, meaning that the firm can borrow from abroad only up to its domestic capital stock. If we define $\bar{k}$ so that it satisfies $A=B /\left(v \bar{k}^{v-1}\right)$, then the optimal $\xi$ when $k_{2}=\bar{k}$ is 0 . Appendix Figures 2 and 3 graph $\xi\left(k_{2}\right)$ and $h\left(k_{2}\right)$ for $B=0.15, \bar{k}=2$, and $v=0.338$. Both axis of the graph of $h\left(k_{2}\right)$ are in the log scale, so the near-linearity of the graph of $h\left(k_{2}\right)$ means that the function $h\left(k_{2}\right)$ is very close to the power function $C k_{2}^{\theta}$. The power $\theta$ is the slope of the line, which is about 0.333 . 
Figure 2: Graph of $\xi$

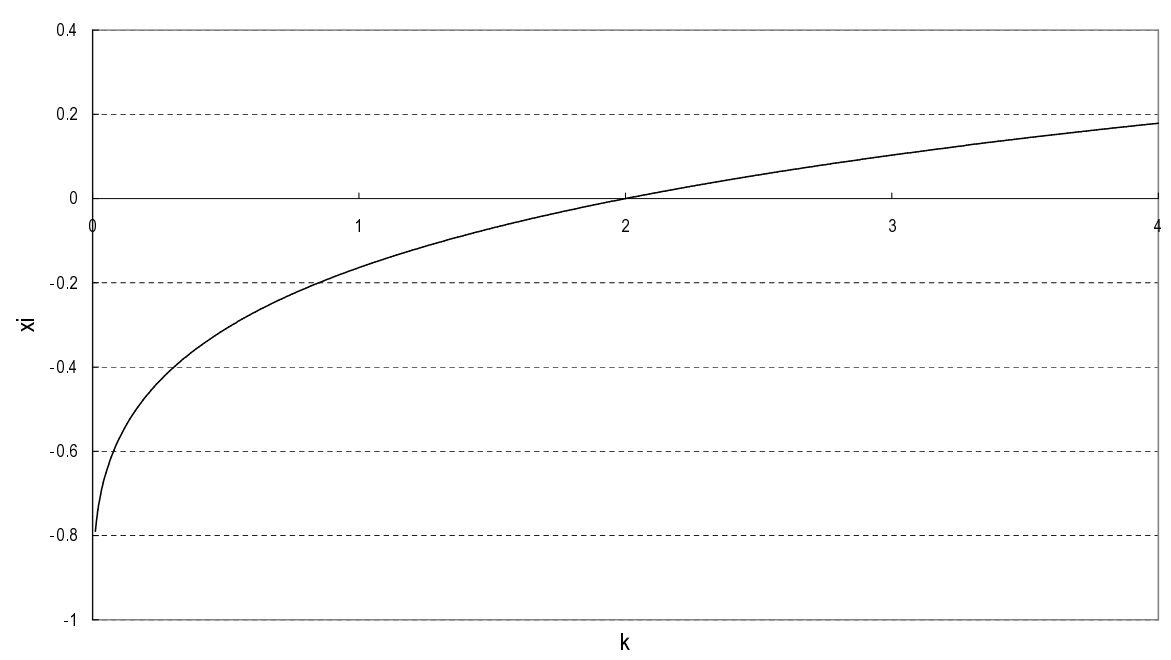

Figure 3: Graph of $h$

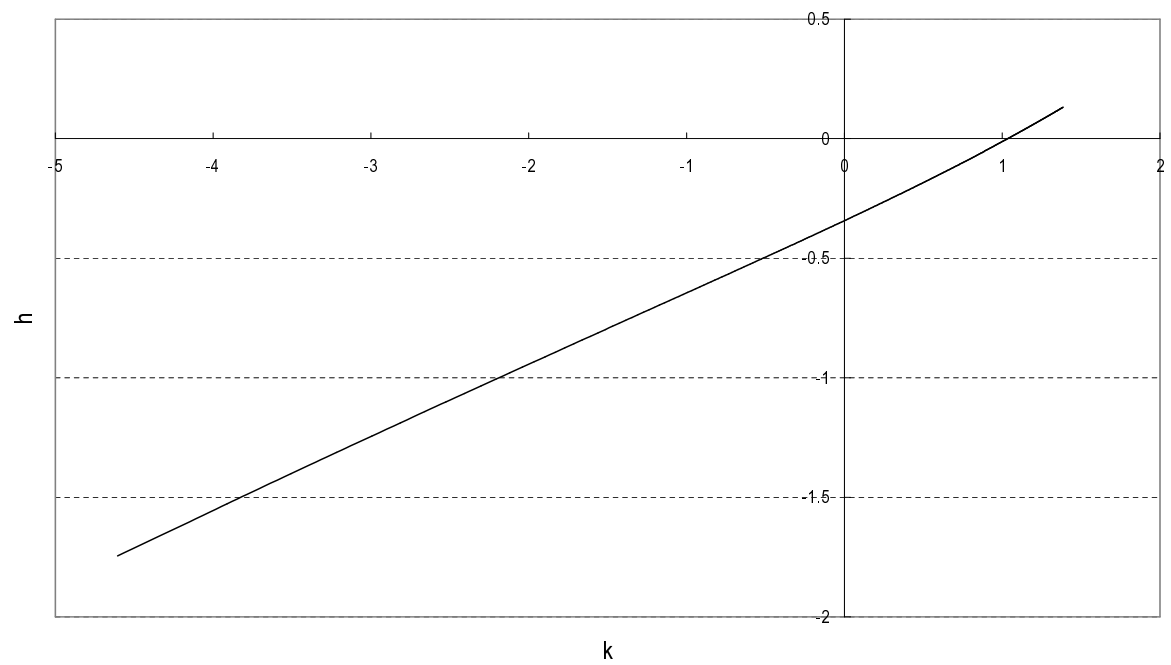




\section{References}

Balke, Nathan, and Robert J. Gordon (1989) “The Estimation of Prewar Gross National Product: Methodology and New Evidence", Journal of Political Economy, Vol. 97, No. 1, pp. 38-92.

Braun, Anton, Toshihiro Okada, and Nao Sudou (2005) “U.S. R\&D and Japanes Medium Cycles", mimeo.

Browning, Martin, Angus Deaton, and Margaret Irish (1985) "A Profitable Approach to Labor Supply and Commodity Demands over the Life-Cycle", Econometrica, Vol. 53, pp. 503-543.

Caselli, Francesco (2004) "Accounting for Cross-Country Income Differences", mimeo, December, London School of Economics, http://personal.1se.ac.uk/casellif/papers/handbook.pdf.

Echeverria, Cristina (1997) "Changes in Sectoral Composition Associated with Economic Growth", International Economic Review, Vol. 38, No. 2, pp. 431-452.

Fujino, S. and R. Akiyama (1977) "Security Prices and the Rates of Interest Rate in Japan: 1874-1975", Report No. 7, Documentation Center for Japanese Economic Statistics, Institute of Economic Research, Hitotsubashi University.

Fujino, S. and J. Teranishi (2000) Quantitative Analysis of Money and Banking in Japan [Nihon Kinyu No Suryo Bunseki], Toyo Keizai, Tokyo.

Godo,Yoshihisa, and Yujiro Hayami (2002) "Catching Up in Education in the Economic Catch-up of Japan with the United States," Economic Development and Cultural Change, Vol. 50, No. 4, pp. 960-978.

Gollin, D., S. Parente, and R. Rogerson (2002) “Structural Transformation and Cross-Country Income Differences", mimeo., University of Illinois,

http://www. business. uiuc. edu/parente/Structural\%20Transformation.pdf

Gordon, Robert J. (2004) "Two Centuries of Economic Growth: Europe Chasing the American Frontier", mimeo., Northwestern University,

http://faculty-web.at. northwestern. edu/economics/gordon/2Cent-CEPR.pdf

Hansen, G. and Edward C. Prescott (2002) "From Malthus to Solow", American Economic Review, Vol. 92, No. 4, pp. 1205-1217.

Hayami, Yujiro (1975) A Century of Agricultural Growth in Japan, U. of Tokyo Press.

Hayami, Yujiro, and Junichi Ogasawara (1999) "Changes in the Sources of Modern Economic Growth: Japan Compared with the United States", Journal of the Japanese and International Economics, Vol. 13, No. 1, pp. 1-21.

Hayashi, F. and Edward C. Prescott (2002) "The 1990s in Japan: A Lost Decade", Review of Economic Dynamics, Vol. 5, No. 1, pp. 206-235.

Honda, Tatsuo (1950) "A Historical Analysis of the Population Problem in Japan" ["Nihon Jinko Mondai No Shiteki Kaiseki"], Kikan Jinko Mondai Kenkyu, Vol. 6, No. 2.

Japan Statistical Association (1986) Historical Statistics of Japan, Japan Statistical Association. 
Jorgenson, Dale W. (1961) “The Development of a Dual Economy", Economic Journal, Vol. 71, No. 282, pp. 309-334.

Kawashima, Takeyoshi (1957) The family as an Ideology [Ideorogi To Shite No Kazokuseido], Iwanami Shoten, Tokyo.

Keizai Shingicho (1954) Japanese Economy and National Income [Nihon Keizai to Kokumin Shotoku], Gakuho Shobo, Tokyo.

King, R. and R. Levine (1994) "Capital Fundamentalism, Economic Development, and Economic Growth", Carnegie-Rochester Conference Series on Public Policy, 40, pp. 259-292.

Klenow, P. and A. Rodriguez-Clare (1997) “The Neoclassical Revival in Growth Economics: Has It Gone Too Far", NBER Macroeconomics Annual, MIT Press, Cambridge, Mass.

Laitner, John (2000) "Structural Change and Economic Growth", Review of Economic Studies, Vol. 67, No. 232, pp. 545-561.

Maddison, Angus (1991) Dynamic Forces of Capitalist Development, Oxford University Press.

Maddison, Angus (2001) The World Economy: A Millennial Perspective, Development Centre Studies, Organization of Economic Co-operation and Development.

Masui, Yukio (1969) Chapter 9 in Agriculture and Economic Growth: Japan's Experience, ed. by Ohkawa, K., B. F. Johnston, and H. Kaneda, University of Tokyo Press, Tokyo (also published by Princeton University Press in 1970).

Matsumura, Katsujiro (1957) A Study of the Inheritance of the Farmland [Nochi Sozoku Ni Kansuru Kenkyu], Noson Seisaku Kenkyusitsu, Tokyo.

Minami, R. and A. Ono (1977) "Surplus Labor in Prewar Japan" [“Senzenki Nihon No Kajo Rodo"], Keizai Kenkyu, Vol. 28, No. 2, pp. 156-166.

Minami, R. and A. Ono (1978) "Trends and Fluctuations in Factor Income Shares" ["Bunpairitsu No Susei to Hendo"], Keizai Kenkyu, Vol. 29, No. 3, pp. 230-242.

Minami, Ryoshin (1973) The Turning Point in Economic Development: Japan's Experience, Kinokuniya Bookstore, Tokyo.

Momose, Takashi (1990) A Dictionary on Japan in Prewar Showa Era [Jiten Showa Senzenki No Nihon], Yoshikawa Kobunkan, Tokyo.

Namiki, Shokichi (1957) "The Problem of Recruiting Farm Population in Postwar Japan" ["Sengo Ni Okeru Nogyo Jinko No Hoju Mondai"], Nogyo Sogo Kenkyu, Vol. 12, No. 1, pp. 89-139.

Nojiri, Shigeo (1942) An Empirical Study of Farm Exodus [Nomin Rison No Jisshoteki Kenkyu], Iwanami Shoten, Tokyo.

Nomura, K. (2004) Measurement of Capital and Productivity in Japan, Keio University Press. 
Oda, Hiroshi (1992) Japanese Law, Butterworth, London.

Ohkawa, Kazushi (various years) Long Term Economic Statistics [Choki Keizai Tokei], Toyo Keizai Shimposha, Tokyo.

Ohkawa, Kazushi (1955) Economic Analysis of Agricuture [Nogyo No Keizai Bunseki], Daimeido, Tokyo.

Ohkawa, Kazushi, and H. Rosovsky (1973) Japanese Economic Growth, Stanford University Press, California.

Ohkawa, Kazushi, and M. Shinohara (1979) Patterns of Japanese Economic Development: A Quantitative Appraisal, Yale University Press, New Haven.

Ramseyer, J. Mark (1996) Odd Markets in Japanese History, Cambridge University Press, New York.

Restuccia, Diego, Dennis Yang, and Xiaodong Zhu (2004) "Agriculture and Aggregate Productivity: A Quantitative Cross-Country Analysis", mimeo., University of Toronto, http://faculty-web.at.northwestern.edu/economics/gordon/2Cent-CEPR.pdf

Robertson, Peter (1999) "Economic Growth and the Return to Capital in Developing Economies", Oxford Economic Papers, Vol. 51, pp. 577-594.

Rodo Undo Shiryo linkai (1959) Documents on Labor Movements in Japan [Nihon Rodo Undo Shiryo], Vol. 10.

Sato, Toshiki (1998) "Social Mobility and Stratification in Modern Japan: 1896-1995" ["Kindai Nihon No Ido To Kaiso: 1896-1995"], in T. Sato ed., Social Mobility and Stratification in Modern Japan: 1896-1995 [Kindai Nihon No Ido To Kaiso: 1896-1995], University of Tokyo.

Shintani, Masahiko (1981) , “A New Estimate of Total Days Worked in Agriculture: 1874-1977” [“Nogyo Bumon Ni Okeru Tokarodonissu No Shinsuikei: 1874-1977”], Keizaigaku Ronshu, pp. 73-95.

Taeuber, Irene (1958) The Population of Japan, Princeton University Press, Princeton, New Jersey.

Takagi, Naofumi (1956) "A Statistical Study of Migration from Rural to Urban Areas in Prewar and Postwar Japan" ["Senzen Sengo Ni Okeru Noson Jinko No Toshi Shuchu Ni Kansuru Toukeiteki Kosatsu"], in S. Tohata ed. Hidden Unemployment in Agriculture [Nogyo Ni Okeru Seizai Sitsugyo], Nihon Hyoronsha, Tokyo.

Takahashi, Kamekichi (1975) "Economic Controls in Japan" [“Nihon Keizai Tosei Ron"], in Ando, Y. ed., Handbook of Modern Japanese Economic History [Kindai Nihon Keizai Shi Yoran], University of Tokyo Press, Tokyo.

Tsuburai, Kaoru (1998) "A Quantitative Analysis of Peasants Leaving the Village" ["Rino To Rison No Keiryo Bunseki"], T. Sato, op. cit.

Umemura, Mataji (1968) , “A New Estimate of Sectoral Employment: 1871-1920" [“Yugyoshasu No Shinsuikei: 1871-1920"], Keizaigaku Kenkyu, Vol. 19, No. 4, pp. 322-329. 
Vogel, Ezra (1967) “Kinship Structure, Migration to the City, and Modernization”, in R. Dore ed. Aspects of Social Change in Modern Japan, Princeton University Press, New Jersey.

Vollrath, Dietrich (2005) "How Important are Dual Economy Effects for Aggregate Productivity?", mimeo., University of Houston, http://www. uh. edu/ 〜evollra/agsector080905.pdf.

Yamada, S. and Y. Hayami (1979) "Agricultural Growth in Japan, 1880-1970", in Hayami, Y. and V. W. Ruttan eds. Agricultural Growth in Japan, Taiwan, Korea, and the Philippines, The University Press of Hawaii, Honolulu.

Zenkoku Nogyo Kaigisho (1979) Report on the Intention and the Practice of Farmland Inheritance [Nochi Sozoku No Iko To Jittai Ni Kansuru Chosakekka], Research Report No. 141, March 1979. 